University of Tennessee Health Science Center UTHSC Digital Commons

\title{
CDC45 Function Alters Cell Sensitivity to DNA Topoisomerase I Poisons
}

Cynthia Sue Lancaster

University of Tennessee Health Science Center

Follow this and additional works at: https://dc.uthsc.edu/dissertations

Part of the Enzymes and Coenzymes Commons

\section{Recommended Citation}

Lancaster, Cynthia Sue , "CDC45 Function Alters Cell Sensitivity to DNA Topoisomerase I Poisons" (2008). Theses and Dissertations (ETD). Paper 151. http://dx.doi.org/10.21007/etd.cghs.2008.0171. 


\title{
CDC45 Function Alters Cell Sensitivity to DNA Topoisomerase I Poisons
}

\begin{abstract}
Eukaryotic DNA topoisomerase I (Top1) is a highly conserved enzyme that functions to manage the torsional strain of DNA during cellular processes such as transcription, replication, chromatid condensation and recombination. The enzyme binds duplex DNA and through a series of strand cleavage and religation reactions removes positive or negative supercoils relieving torsional strain. Top 1 is the sole cellular target of the anticancer agent camptothecin, which stabilizes the covalent complex. CPT cytotoxicity is S-phase dependent. It has been suggested that the mechanism of this S-phase toxicity is due to the advancing replication forks either colliding with the stabilized drug-enzyme-DNA intermediate or colliding with positive supercoils that accumulate in front of the advancing forks leading to S-phase dependent lesions, inhibition of DNA replication and cell death. Despite extensive study, the exact events leading to cell death or repair of these lesions have yet to be defined.
\end{abstract}

Using the genetically tractable budding yeast, $S$. cerevisiae, as a model system, a genetic screen was designed to isolate conditional temperature sensitive mutants that exhibit enhanced sensitivity to the CPT mimetic, Top $1 \mathrm{~T}^{722} \mathrm{~A}$. This genetic screen identified several recessive mutants (tah mutants) involved in a variety of cellular pathways including $C D C 45, D P B 11, T A H 11$, which encode essential products for DNA replication and UBC9, which encodes an E3 SUMO ligase.

The tah mutant $c d c 45-10$ has a single amino acid substitution $\left(\mathrm{G}^{510} \mathrm{R}\right)$. These cells are hypersensitive to Top $1 T^{722} \mathrm{~A}$ and transiently accumulate in early S-phase when shifted $36^{\circ} \mathrm{C}$ due to a defect in Okazaki fragment maturation. These cells also exhibit a slow growth phenotype when a component of the DNA damage checkpoint, $R A D 9$, is deleted and is synthetically lethal with another tah mutant $d p b 11-10$ at $36^{\circ} \mathrm{C}$ suggesting that $c d c 45-10$ exhibits defects in DNA replication. To understand how $\mathrm{Cdc} 45$ functions to protect cells against Top1-induced DNA damage, the defects in cdc45-10 were characterized.

We identified $c d c 45-10$ as a hypomorphic allele and increased gene dosage of this mutant allele restored cell viability in the presence of Top $1 \mathrm{~T}^{722} \mathrm{~A}$ at $36^{\circ} \mathrm{C}$, however, increased gene dosage failed to restore cell viability to the $c d c 45-10, d p b 11-10$ double mutant strain suggesting that the defects in $c d c 45-10$ that specific to Top $1 \mathrm{~T}^{722} \mathrm{~A}$ sensitivity are distinct from the defects in the synthetic interaction of $c d c 45-10$ and $d p b 11-10$. These two distinct functions of Cdc45 were supported by results obtained from further characterizing the defects in cdc45-10 using a dosage suppressor screen to identify extragenic suppressors that complement $c d c 45-10$ cell sensitivity to Top $1 \mathrm{~T}^{722} \mathrm{~A}$ and our attempts to epitope tag Cdc45 and cdc45-10.

The $c d c 45-10$ defects in origin firing and replication fork progression were characterized by isolating replication intermediates and resolving them using 2-D gel electrophoresis.

Several lines of evidence including our report that $c d c 45-10$ is hypersensitive to the antibiotic rapamycin (RAP), suggests a role for TOR signaling in S-phase. To investigate this possibility we isolated replication intermediates that were treated with MMS, RAP, HU or combinations of these drugs and origin firing and replication fork progression was visualized using 2-D gel electrophoresis.

Document Type

Dissertation

Degree Name

Doctor of Philosophy $(\mathrm{PhD})$ 


\section{Program}

Interdisciplinary Program

Research Advisor

Mary-Ann Bjornsti, Ph.D

\section{Keywords}

CDC45, DNA topoisomerase I, Camptothecin, DNA replication

\section{Subject Categories}

Chemicals and Drugs | Enzymes and Coenzymes | Medicine and Health Sciences 


\title{
CDC45 FUNCTION ALTERS CELL SENSITIVITY TO DNA TOPOISOMERASE I POISONS
}

\author{
A Dissertation \\ Presented for \\ The Graduate Studies Council \\ The University of Tennessee \\ Health Science Center
}

In Partial Fulfillment

Of the Requirements for the Degree

Doctor of Philosophy

From The University of Tennessee

By

Cynthia Sue Lancaster

May 2008 
Copyright (C) 2008 by Cynthia Lancaster

All rights reserved 


\section{DEDICATION}

I would like to dedicate this dissertation to my parents, Mark and Brenda

Lancaster for their continuing love and support of my dreams and to my brother Mark who always encourages me to be the best person I can be. Without them I would not be who I am today. 


\section{ACKNOWLEDGMENTS}

I would like to express my sincere thanks to those who contributed to my dissertation research over the past years. First and foremost I would like to thank my research advisor, Mary-Ann Bjornsti, for her patience, guidance and encouragement. Mary-Ann has taught me the valuable skills needed to become a successful scientist. I would like to thank all of the past and present members of the Bjornsti lab for their friendship, continued support and generous knowledge. A special thank you to Robert van Waardenburg for many thoughtful discussions and advice, to Alice Gibson for all of the kindness and moral support you have given me over the years, to Padma Thimmaiah for your friendship and much needed expertise, to Hong Guo for all of the 2-D gel help.

I would also like to thank my graduate committee, Peter Houghton, Katsumi Kitagawa, Peter McKinnon and Larry Pfeffer for taking part in my graduate training, for their guidance of my research and thoughtful discussions.

I would like to extend a very heartfelt thank you my fellow classmates, Ioana

Moisini, Nico West, Bob Borgon and Marie van der Merwe for being my support system over the years.

Last, but certainly not least, I would like to thank my family and friends, who have given me roots to keep me grounded and wings so I can soar. Without their continued support none of this would have been possible. 


\begin{abstract}
Eukaryotic DNA topoisomerase I (Top1) is a highly conserved enzyme that functions to manage the torsional strain of DNA during cellular processes such as transcription, replication, chromatid condensation and recombination. The enzyme binds duplex DNA and through a series of strand cleavage and religation reactions removes positive or negative supercoils relieving torsional strain. Top1 is the sole cellular target of the anticancer agent camptothecin, which stabilizes the covalent complex. CPT cytotoxicity is S-phase dependent. It has been suggested that the mechanism of this Sphase toxicity is due to the advancing replication forks either colliding with the stabilized drug-enzyme-DNA intermediate or colliding with positive supercoils that accumulate in front of the advancing forks leading to S-phase dependent lesions, inhibition of DNA replication and cell death. Despite extensive study, the exact events leading to cell death or repair of these lesions have yet to be defined.

Using the genetically tractable budding yeast, $S$. cerevisiae, as a model system, a genetic screen was designed to isolate conditional temperature sensitive mutants that exhibit enhanced sensitivity to the CPT mimetic, Top $1 \mathrm{~T}^{722} \mathrm{~A}$. This genetic screen identified several recessive mutants (tah mutants) involved in a variety of cellular pathways including $C D C 45, D P B 11, T A H 11$, which encode essential products for DNA replication and UBC9, which encodes an E3 SUMO ligase.
\end{abstract}

The tah mutant $c d c 45-10$ has a single amino acid substitution $\left(\mathrm{G}^{510} \mathrm{R}\right)$. These cells are hypersensitive to Top $1 \mathrm{~T}^{722} \mathrm{~A}$ and transiently accumulate in early S-phase when shifted $36^{\circ} \mathrm{C}$ due to a defect in Okazaki fragment maturation. These cells also exhibit a 
slow growth phenotype when a component of the DNA damage checkpoint, $R A D 9$, is deleted and is synthetically lethal with another tah mutant $d p b 11-10$ at $36^{\circ} \mathrm{C}$ suggesting that $c d c 45-10$ exhibits defects in DNA replication. To understand how Cdc45 functions to protect cells against Top1-induced DNA damage, the defects in $c d c 45-10$ were characterized.

We identified $c d c 45-10$ as a hypomorphic allele and increased gene dosage of this mutant allele restored cell viability in the presence of $\mathrm{Top} 1 \mathrm{~T}^{722} \mathrm{~A}$ at $36^{\circ} \mathrm{C}$, however, increased gene dosage failed to restore cell viability to the $c d c 45-10, d p b 11-10$ double mutant strain suggesting that the defects in $c d c 45-10$ that specific to Top $1 \mathrm{~T}^{722} \mathrm{~A}$ sensitivity are distinct from the defects in the synthetic interaction of $c d c 45-10$ and dpb11-10. These two distinct functions of Cdc45 were supported by results obtained from further characterizing the defects in $c d c 45-10$ using a dosage suppressor screen to identify extragenic suppressors that complement $c d c 45-10$ cell sensitivity to $\operatorname{Top}_{1 \mathrm{~T}} \mathrm{~T}^{722} \mathrm{~A}$ and our attempts to epitope tag Cdc45 and $c d c 45-10$.

The $c d c 45-10$ defects in origin firing and replication fork progression were characterized by isolating replication intermediates and resolveing them using 2-D gel electrophoresis.

Severeal lines of evidence including our report that $c d c 45-10$ is hypersensitive to the antibiotic rapamycin (RAP), suggests a role for TOR signaling in S-phase. To investigate this possibility we isolated replication intermediates that were treated with MMS, RAP, HU or combinations of these drugs and origin firing and replication fork progression was visualized using 2-D gel electrophoresis. 


\section{TABLE OF CONTENTS}

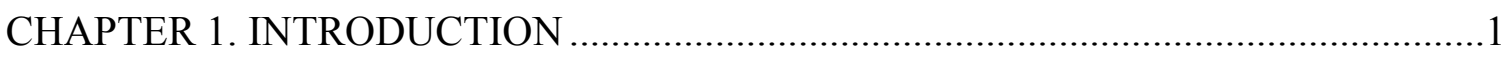

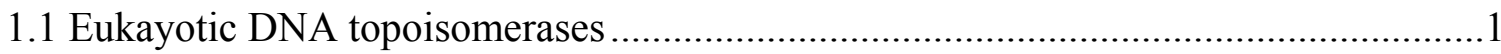

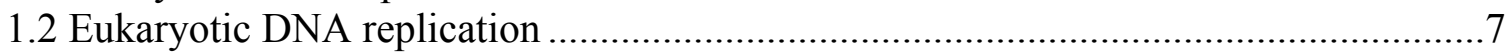

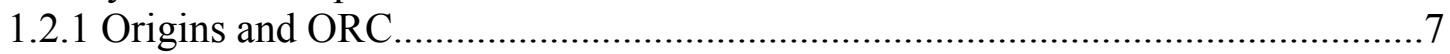

1.2.2 Pre-replicative complex formation ............................................................

1.2.3 Initiation of DNA replication.....................................................................12

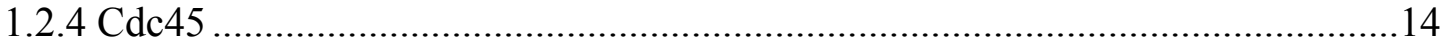

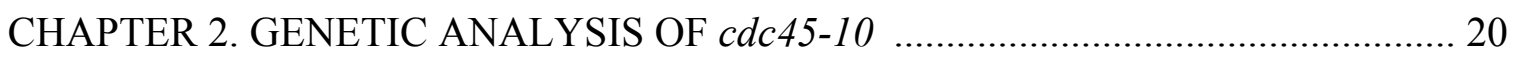

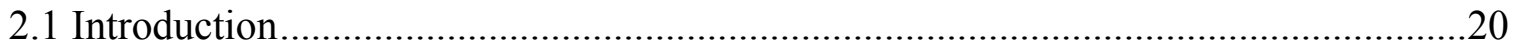

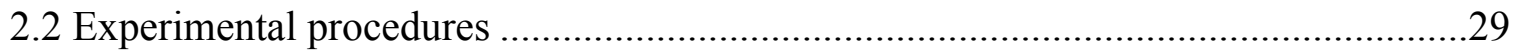

2.2.1 Chemicals, plasmids and yeast strains ..........................................................29

2.2.2 Yeast transformations ...................................................................................33

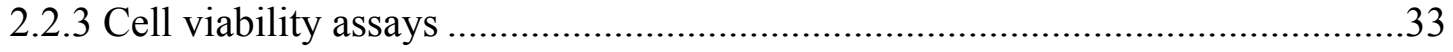

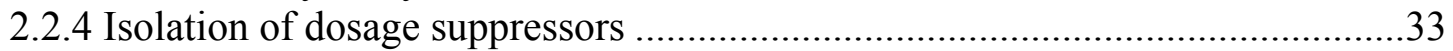

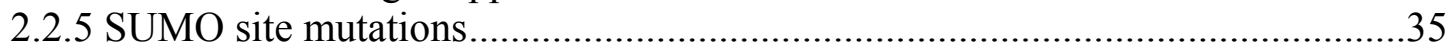

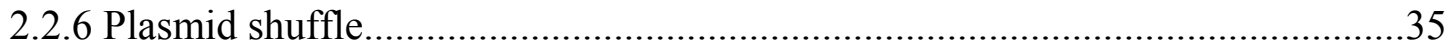

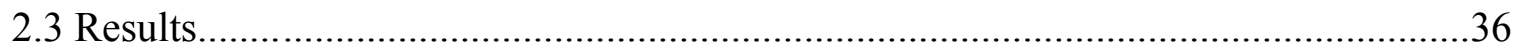

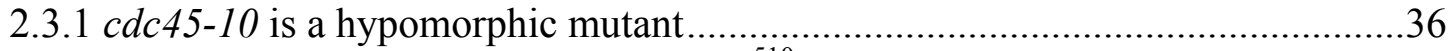

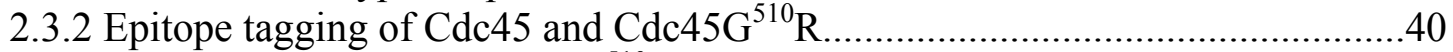

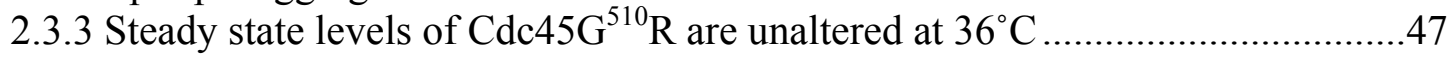

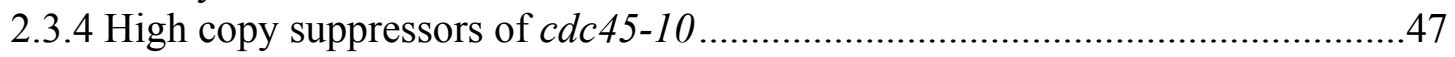

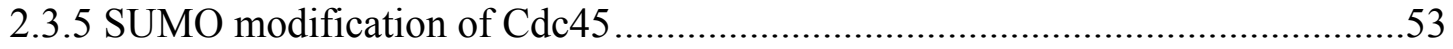

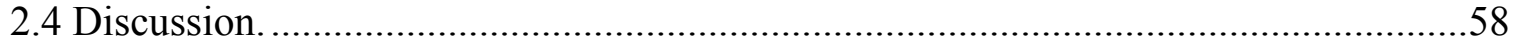

CHAPTER 3. CDC45 ORIGIN FIRING AND REPLICATION FORK

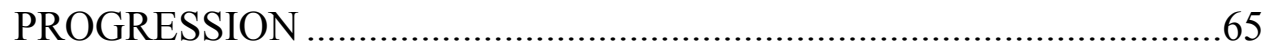

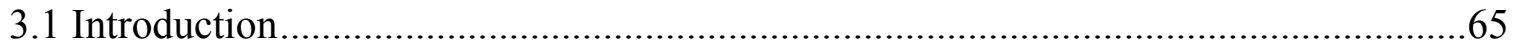

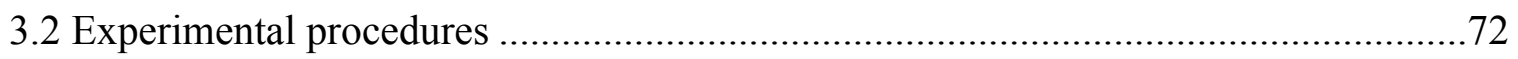

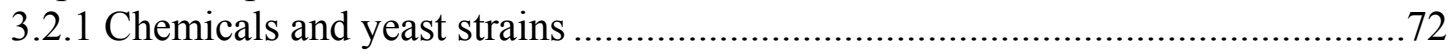

3.2.2 Analysis of cell cycle progression and 2-D gel electrophoresis of replication

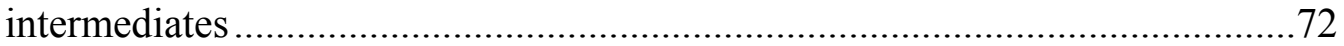

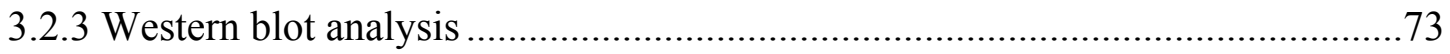

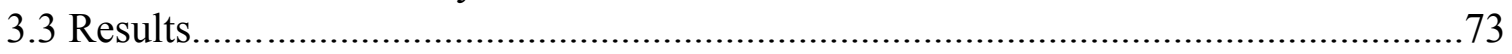

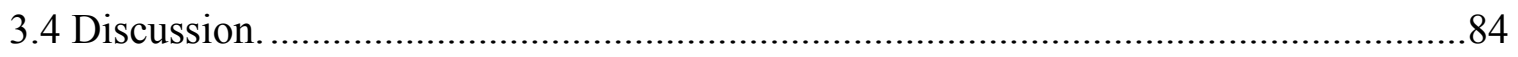




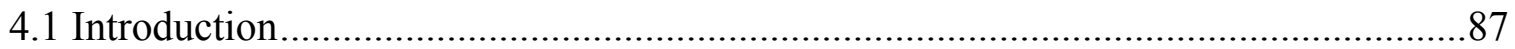

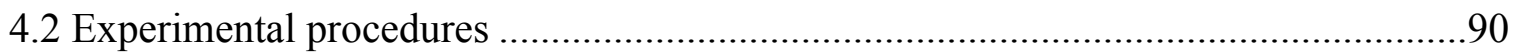

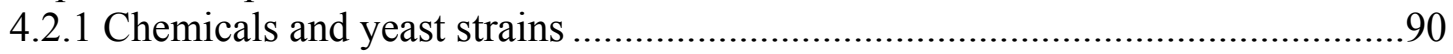

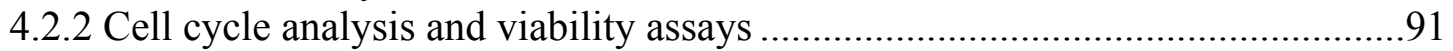

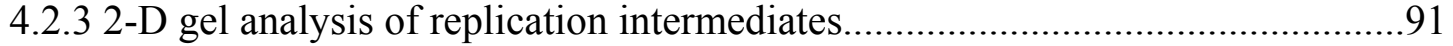

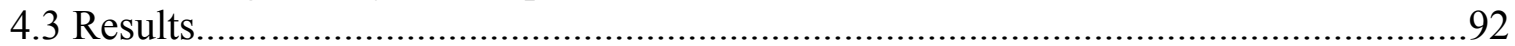

4.3.1 TOR signaling is a determinant of cell suvival in response to DNA damage ...92

4.3.2 Replication fork stability is diminished by MMS + RAP ...............................95

4.3.3 TORC signaling promotes fork progression in response to HU-induced

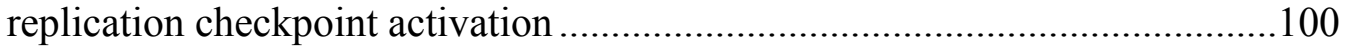

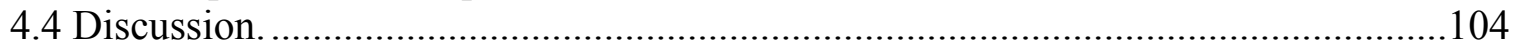

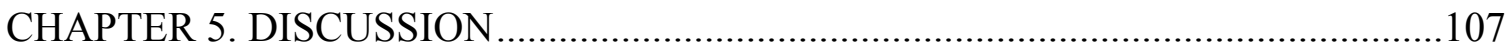

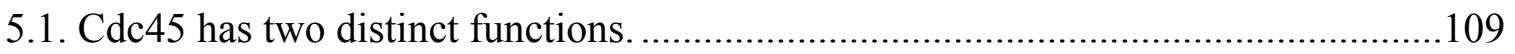

5.2. Dosage suppressors of $c d c 45-10$ suggest distinct defects....................................110

5.3. Cdc45 function is required for timely origin firing and appropriate assembly of

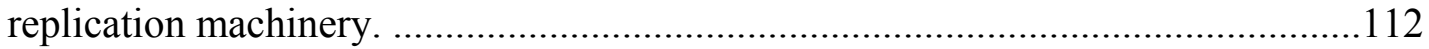

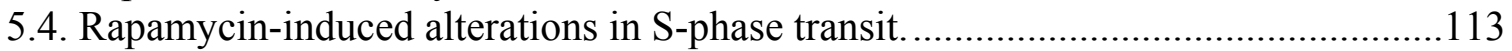

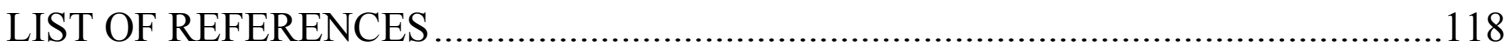

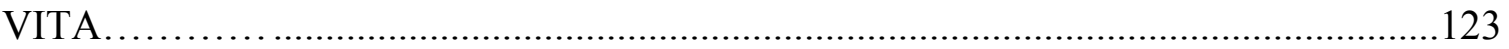




\section{LIST OF FIGURES}

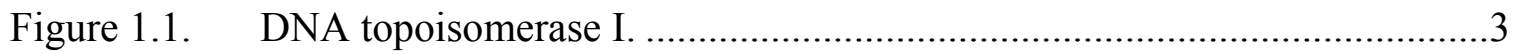

Figure 1.2. Catalytic cycle of eukaryotic DNA topoisomerase I. ..............................4

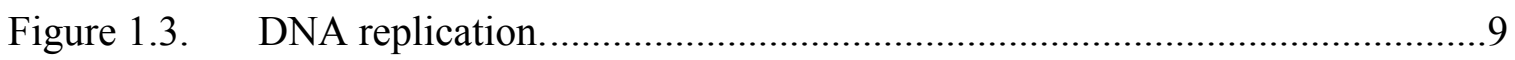

Figure 2.1. Screen for Top $1 \mathrm{~T}^{722} \mathrm{~A}$ hypersensitivity (tah) mutants.............................23

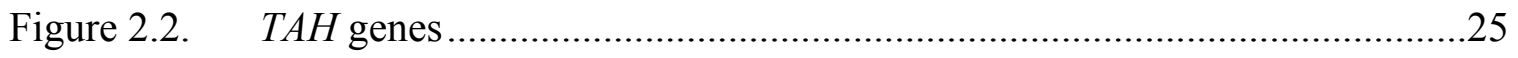

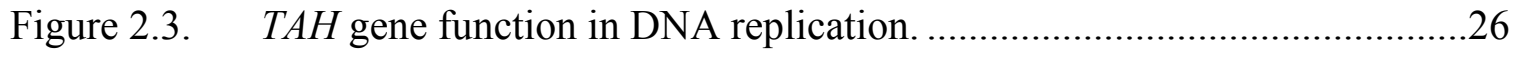

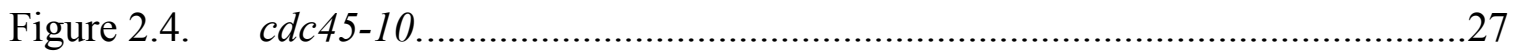

Figure 2.5. Increased gene dosage of $c d c 45-10$ restores cellular resistance to

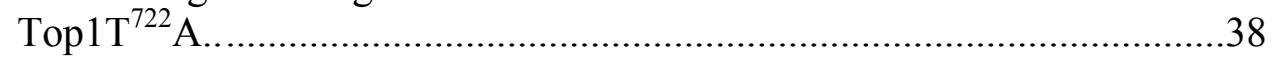

Figure 2.6. Increased expression of $c d c 45-10$ does not restore cell viability to the $c d c 45-10, d p b 11-10$ double mutant strain.........................................39

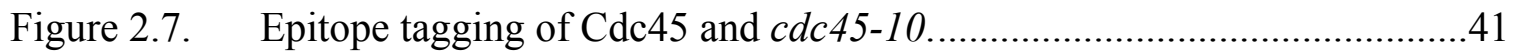

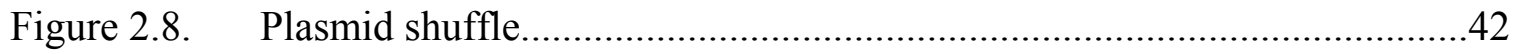

Figure 2.9. Plasmid shuffle of untagged and C-terminally HA tagged CDC45 and $c d c 45-10$.

Figure 2.10. The $c d c 45-10, d p b 11-10$ double mutant strain transformed with untagged and HA tagged Cdc45 vectors.

Figure 2.11. Peptides used to generate S. cerevisiae Cdc45 polyclonal antibodies. ......46

Figure 2.12. Steady state protein levels of $C D C 45$ and $c d c 45-10$ asynchronous cultures..

Figure 2.13. Isolation of dosage suppressor of $c d c 45-10$

Figure 2.14. Dosage suppressor of $c d c 45-10$ complement other tah mutant cell cell sensitivity to Top $1 \mathrm{~T}^{722} \mathrm{~A}$..

Figure 2.15. Dosage suppressor of $c d c 45-10$ are not able to restore cell viability to the $c d c 45-10, d p b 11-10$ double mutant strain at $36^{\circ} \mathrm{C}$ 
Figure 2.16. SUMOylation cycle.

Figure 2.17. Mutating the consensus SUMO site in Cdc45 enhances cdc45-10, but not $C D C 45$ cell sensitivity to Top1 poisons or HU.

Figure 2.18. $\quad \mathrm{Cdc} 45^{\mathrm{SUMO}}$ did not restore cell viability to the $c d c 45-10, d p b 11-10$ double mutant strain. .59

Figure 3.1. DNA replication.

Figure 3.2. Replication intermediate isolation and visualization by 2-D gel electrophoresis.

Figure 3.3. Shapes of replication intermediates. .70

Figure 3.4. Experimental approaches for defining defects in origin licensing in G1-phase and processive DNA replication in S-phase.. .75

Figure 3.5. $C D C 45$ and $c d c 45-10 \mathrm{~S}$-phase transit at $26^{\circ} \mathrm{C}$ and $36^{\circ} \mathrm{C}$. .76

Figure 3.6. Alterations in $\mathrm{Cdc} 45$ function delays and decreases early origin firing but does not affect replication fork progression. .78

Figure 3.7. $c d c 45-10$ cells exhibit increased protein levels when origins are licensed at $26^{\circ} \mathrm{C}$ and S-phase transit occurs at $36^{\circ} \mathrm{C}$.

Figure 3.8. Licensing $A R S 305$ at $36^{\circ} \mathrm{C}$ alters replication fork stability in cdc $45-10$ cells.

Figure 3.9. $\quad c d c 45-10$ cells exhibit elevated protein levels when origin licensing and S-phase transit occurs at $36^{\circ} \mathrm{C}$

Figure 4.1. The TOR pathway.

Figure 4.2. Experimental design for assessing TOR signaling in S-phase.

Figure 4.3. Rapamycin inhibition of TOR signaling decreases cell viability in response to MMS treatment.

Figure 4.4. TORC1 acts as a survival pathway in response to DNA damage by maintaining the dNTP pools .96

Figure 4.5. MMS + RAP treatment diminishes replication fork stability .98

Figure 4.6. Decreased fork stability induced by MMS + RAP treatment is Rad53-independent 
Figure 4.7. TORC1 signaling promotes replication fork progression and maintains the viability of cells exposed to $\mathrm{HU}$

Figure 4.8. TORC1 signaling is required for fork progression during persistent replicative stress 


\section{LIST OF ABBREVIATIONS}

$\begin{array}{ll}\text { 5-FOA } & \text { 5-Fluoroorotic acid } \\ \text { Arg } & \text { Arginine } \\ \text { Asn } & \text { Asparagine } \\ \text { ATP } & \text { Adenosine triphosphate } \\ \text { CPT } & \text { Camptothecin } \\ \text { Dex } & \text { Dextrose } \\ \text { DMSO } & \text { Dimethyl sulfoxide } \\ \text { EMS } & \text { Ethyl Methyl Sulfonate } \\ \text { Gly } & \text { Glycine } \\ \text { His } & \text { Histidine } \\ \text { HU } & \text { Hydroxyurea } \\ \text { kD } & \text { Kilo Dalton } \\ \text { Leu } & \text { Leucine } \\ \text { MMS } & \text { Methyl Methane Sulfonate } \\ \text { RAP } & \text { Rapamycin } \\ \text { rDNA } & \text { Ribosomal DNA } \\ \text { SC } & \text { Synthetic Complete } \\ \text { Thr } & \text { Threonine } \\ \text { Top1 } & \text { DNA topoisomerase I } \\ \text { TOR } & \text { Target of Rapamycin } \\ \text { Tpt } & \text { Topotecan } \\ \text { Trp } & \text { Tryptophan } \\ \text { Tyr } & \text { Tyrosine } \\ \text { Ura } & \text { Uracil }\end{array}$




\section{CHAPTER 1: INRODUCTION}

\subsection{EUKARYOTIC DNA TOPOISOMERASES}

DNA topoisomerases are responsible for managing the topological state of DNA in a cell. Due to the double helical nature of DNA, topoisomerases are needed for processes such as transcription and recombination, in which two strands of the helix must separate temporarily, or replication, in which the two strands separate permanently $(1,2)$.

There are two subfamilies of DNA topoisomerases: type I enzymes cleave a single strand of DNA, while type II enzymes cleave both strands of the DNA duplex to generate a double-strand break $(1,2)$. Type I enzymes are further divided into IA and IB, where IA enzymes link the protein to a 5' phosphate and relax negatively supercoiled DNA, while IB enzymes link the protein to a 3' phosphate and relax both positively and negatively supercoiled DNA $(1,2)$. Type IA enzymes promote passage of the intact strand through the broken strand, while type IB enzymes leave the broken strand free to rotate around the intact strand (3). Type II enzymes are also organized into two families, Top IIA and Top IIB. All type II enzymes require ATP binding and hydrolysis to facilitate catenation or decatenation of duplex DNA. Top II enzymes are essential in all cells for segregation of chromosomal DNA after DNA replication and before cell division (3).

DNA topoisomerase I (Top1), a type IB enzyme, is highly conserved from yeast to human in sequence and domain structure, reaction mechanism and camptothecin sensitivity. In higher eukaryotes, Top1 is essential as TOP1 knockout mice die early during embryogenesis (4). In the budding yeast Saccharomyces cerevisiae TOP1 is 
nonessential, although top 1 null mutants show a slight growth defect at lower temperatures and increased recombination at rDNA loci (5). As diagrammed in Fig. 1.1, Top1 contains four domains: an unstructured, poorly conserved, nonessential N-terminal domain, a highly conserved core domain that binds DNA, a poorly conserved linker domain and a conserved C-terminal domain that contains the active site tyrosine (1). As shown in Fig. 1.2, Top1 is a monomeric enzyme that forms a protein clamp around duplex DNA. The enzyme transiently cleaves a single DNA strand when a phosphodiester bond in the DNA undergoes nucleophilic attack by the active site tyrosine to generate a phosphotyrosyl linkage between the enzyme and the 3 ' phosphate of the nicked DNA. The noncovalently bound end of DNA is free to rotate around the covalently held strand relieving torsional strain and changing the linking number of DNA. In a second transesterification reaction, the nick is religated and the covalent enzyme-DNA complex is resolved (5).

Studies in yeast and mammalian cells have identified Top1 as the sole cellular target of the anticancer drug camptothecin (CPT). Early studies using yeast strains deleted for TOP1 showed cells were resistant to CPT while the introduction of a plasmid expressing human or yeast TOP1 into these cells restored CPT sensitivity (6). Camptothecin was isolated from the bark of the Chinese tree, Camptotheca acuminata (4). Animal studies showed that camptothecin exhibited potent antitumor activity against a broad spectrum of tumors, however, in the early 1970s clinical trials were discontinued due to toxicity $(4,7)$. CPT reversibly stabilizes the covalent Top1-DNA intermediate and inhibits the religation step of the catalytic cycle. Stabilized covalent intermediates can be formed in every stage of the cell cycle. Analysis of replication intermediates using the 
DNA topoisomerase I

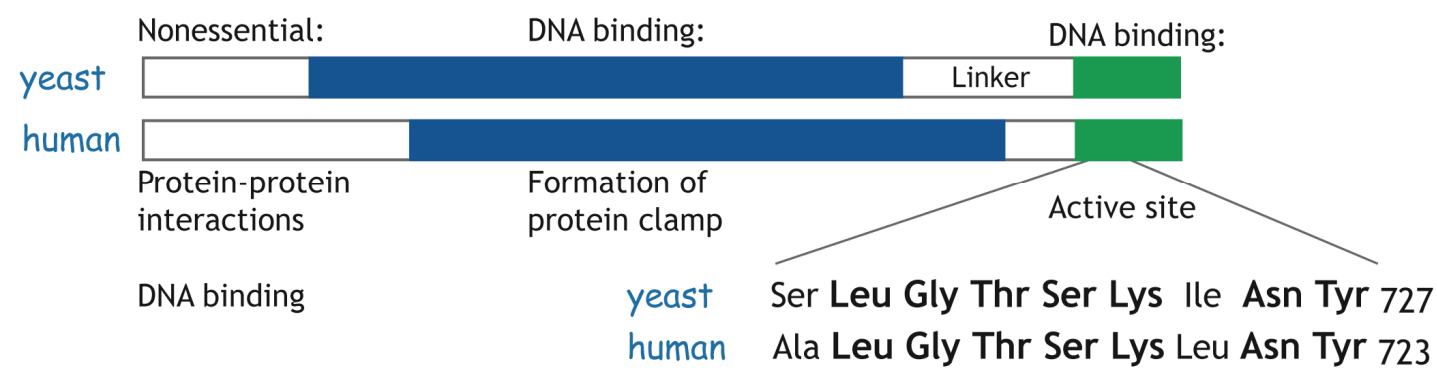

\section{Fig. 1.1 DNA topoisomerase I}

DNA Top1 is highly conserved from yeast to human. It has a nonessential N-terminal domain, a core domain that forms a protein clamp around duplex DNA, a poorly conserved linker domain and a conserved C-terminal domain that contains the active site tyrosine (Tyr727 in yeast and Tyr723 in mammalian cells). 


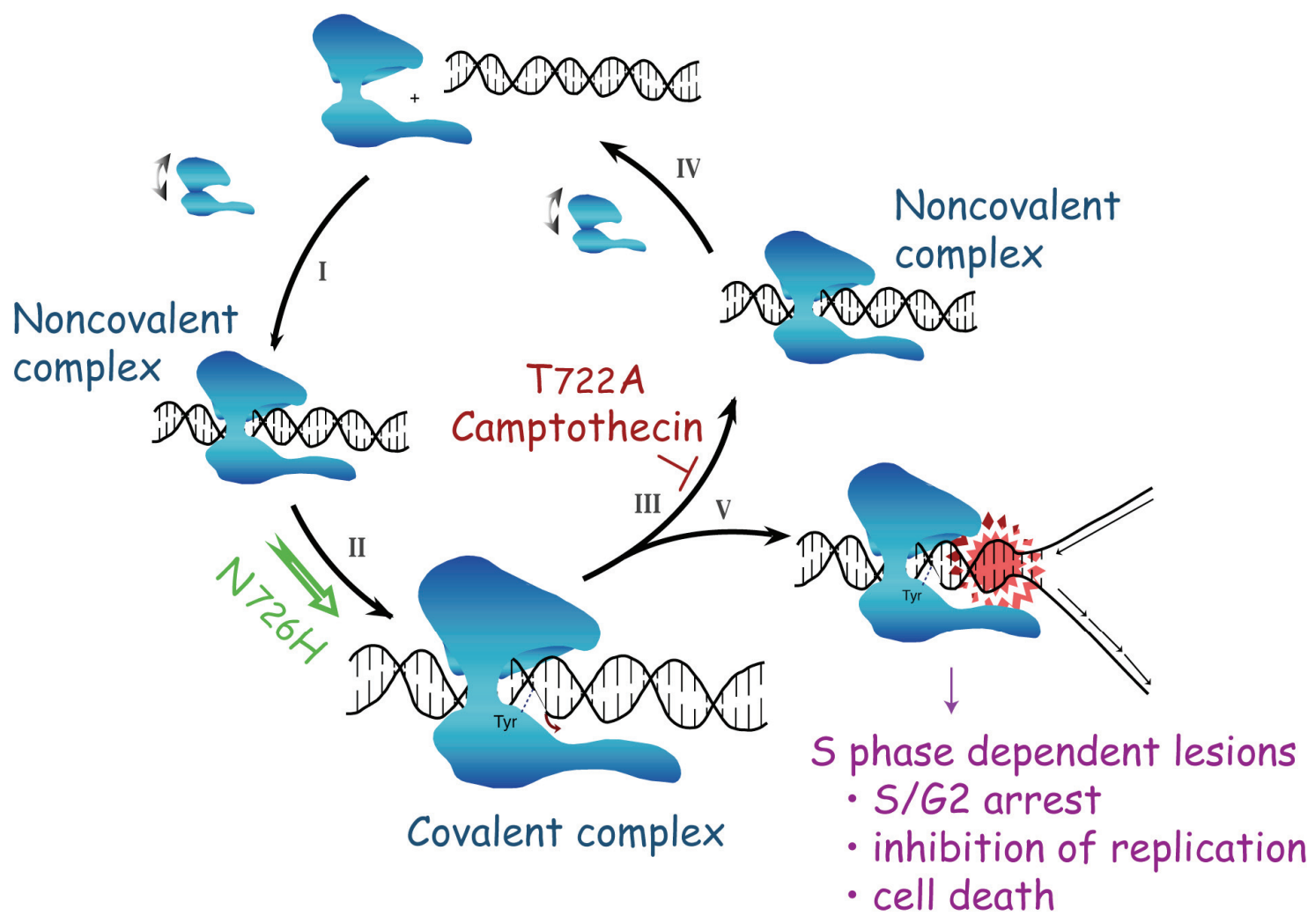

\section{Fig. 1.2 Catalytic cycle of eukaryotic DNA topoisomerase I}

DNA Top1 is a monomeric enzyme that forms a protein clamp around duplex DNA, first noncovalently, then covalently by nicking a single strand of the DNA and forming a phosphotyrosyl linkage with the 5'end leaving the 3' end free to rotate around the covalently held strand unwinding the DNA. After rotation, the nick is religated and the enzyme and DNA dissociate. The anti-tumor drug CPT stabilizes these covalent complexes and advancing replication forks collide with these drug-enzyme-DNA complexes resulting in irreversible DNA lesions that cause S/G2 arrest, inhibition of replication and cell death. Mutations in the Top1 protein change the catalytic activity of the enzyme. Substituting Asn 726 for His results in a Top1 enzyme that exhibits an increase in the rate of DNA cleavage without changing the rate of religation. Mutating Thr 722 to Ala results in an enzyme that is defective in religating the cleaved DNA strand, mimicing the cytotoxic action of CPT. 
SV40 cell-free replication system showed that collision of the replication fork and TOP1 cleavable complexes leads to three distinct events: the formation of a double strand break at the fork, irreversible arrest of replication fork movement and formation of an irreversible TOP1-DNA covalent adduct leading to S-phase specific cell death and arrest in G2 phase of the cell cycle (7).

More recent single molecule studies of human Top1 suggest an alternative mechanism for CPT induced cell death whereby drug binding of the CPT analog topotecan to Top1-DNA complexes induces accumulation of positive supercoils in front of moving replication forks. These local domains of high superhelical density would block fork progression, resulting in fork collapse and lethal DNA lesions that induce cell death (8).

Since Top1 was identified as the cellular target of CPT, several water-soluble derivatives have been developed including topotecan and the prodrug irinotecan. There are several properties that make the camptothecins unique. First, identification of Top1 as the cellular target in yeast and mammalian cells: yeast cells deleted for Top1 are resistant to CPT and in vertebrate cell lines, single point mutations exist that render Top1 resistant to CPT. Second, within minutes of exposure, CPT can penetrate vertebrate cells, target Top1 and reversibly bind to Top1 cleavable complexes. Third, micromolar drug concentrations of CPT and its derivatives are needed to detect trapped Top1 cleavable complexes in biochemical assays suggesting camptothecins have a low affinity for Top 1 cleavable complexes (4).

The amino acids located immediately $\mathrm{N}$-terminal to the active site tyrosine are highly conserved between yeast and human enzymes. Several amino acid substitutions of 
these residues have been reported to affect CPT sensitivity and enzyme catalysis (5). For example, in yeast or human Top1, substituting the two residues preceding the active site Tyr to Arg and Ala rendered the enzymes resistant to CPT. Biochemical studies indicated no difference in enzyme specific activity, however, in DNA cleavage assays the mutant enzymes exhibited diminished levels of CPT stabilized covalent complexes. These results suggest the levels of drug-stabilized enzyme-DNA complexes correspond with the cytotoxic activity of CPT in cells expressing the mutant enzymes (5).

Substituting Ala for Thr 722 in yeast or the corresponding residue in human Top1 creates an enzyme that mimics the action of CPT by increasing the stability of the covalent enzyme-DNA intermediate. The mutant enzyme was catalytically active, yet exhibited a defect in DNA religation, yielding higher concentrations of covalent intermediates (5).

Mutating the Asn immediately preceding the active site Tyr to different amino acids effects various aspects of Top1 function. Substituting Asn with Leu or Asp reduces the specific activity of the enzyme and reduces enzyme sensitivity to CPT. In contrast, mutating Asn to Ser or His had little effect on the specific activity of the enzyme. However, the Ser mutation rendered the enzyme resistant to CPT while the His mutation enhanced enzyme sensitivity to CPT and increased the rate of DNA cleavage (5). 


\subsection{EUKAYROTIC DNA REPLICATION}

\subsubsection{Origins and ORC}

Eukaryotic cell division is a multi-step process where cells must faithfully replicate the entire nuclear content of DNA once and only once per cell cycle to maintain genomic integrity and chromosome ploidy (9). Timely duplication of DNA is accomplished when cells initiate replication from hundreds or even thousands of origins. The genetically tractable yeast system has been central in understanding the temporal order of events that must occur for cells to faithfully replicate DNA. In yeast initiation occurs at Autonomously Replicating Sequences (ARS) sequences that are distributed widely throughout the genome and fire in a temporally regulated pattern (10). Origin structure varies from species to species. S. cerevisiae origins are defined blocks of sequences approximately 100-200 base pairs in length (11). ARS elements are A/T rich regions that contain an $11 \mathrm{bp}$ consensus sequence $\left(5^{\prime}-(\mathrm{A} / \mathrm{T}) \mathrm{TTTAT}(\mathrm{A} / \mathrm{G}) \mathrm{TTT}(\mathrm{A} / \mathrm{T})-3^{\prime}\right)$ (9). This ARS consensus sequence (ACS) and immediate flanking sequences are called domain A. This domain is essential as deletion or mutation completely abolishes ARS function and is a unique identifier of replication origins (11). However, domain A itself is not sufficient for ARS activity. Sequences flanking domain A, domain B and C,

contribute to ARS function. Domain B consists of sequences 3' to the T-rich strand of the ACS and enhances the efficiency of origin utilization while domain $\mathrm{C}$ consists of sequences $5^{\prime}$ to the T-rich strand (9).

Variations in efficiency and timing exist among origins. The temporal pattern of origin firing is such that origins are licensed to fire in late G1-phase. However DNA 
synthesis is not initiated until S-phase when additional proteins are recruited to the origins as a consequence of Dbf4-dependent kinase and the cyclin-dependent kinase activity (discussed in detail below). These two kinases act on converging pathways to allow fail-safe activation of origins in S-phase and simultaneously prevent re-licensing of an origin (10). Strong or efficient origins fire in most S-phases while weak or inefficient origins fire only if replication is delayed. Early origins fire at the onset of S-phase while late firing origins are activated by $\mathrm{Clb} 5 / \mathrm{Cdk}$ in late S-phase to complete DNA synthesis (10). Cryptic origins are those that only fire in S-phase when replication has been interrupted. For example, the cryptic origin, ARS301, fires in Rad53 defective strains exposed to DNA damaging agents (12)

The six-subunit origin recognition complex (Orc), consisting of Orc1-6, was one of the first origin binding protein complexes identified and remains bound to the origin throughout the cell cycle. Orc is highly conserved in eukaryotes and archaea and is a sequence specific binding protein complex that recognizes the core sequence of the origin. Orc binds to active replication origins as well as transcriptional silencers, telomeric DNA and cryptic origins, suggesting that it may act as a landing platform for other chromosomal proteins (10).

\subsubsection{Pre-replicative complex formation}

To ensure that each origin fires once and only once during each S-phase, origin function is regulated in two discreet steps: pre-replicative complex (pre-RC) formation in G1-phase of the cell cycle and initiation of DNA replication in S-phase, as shown in Fig. 1.3. In G1-phase, pre-RC formation involves the sequential binding of Cdc6, Tah11 


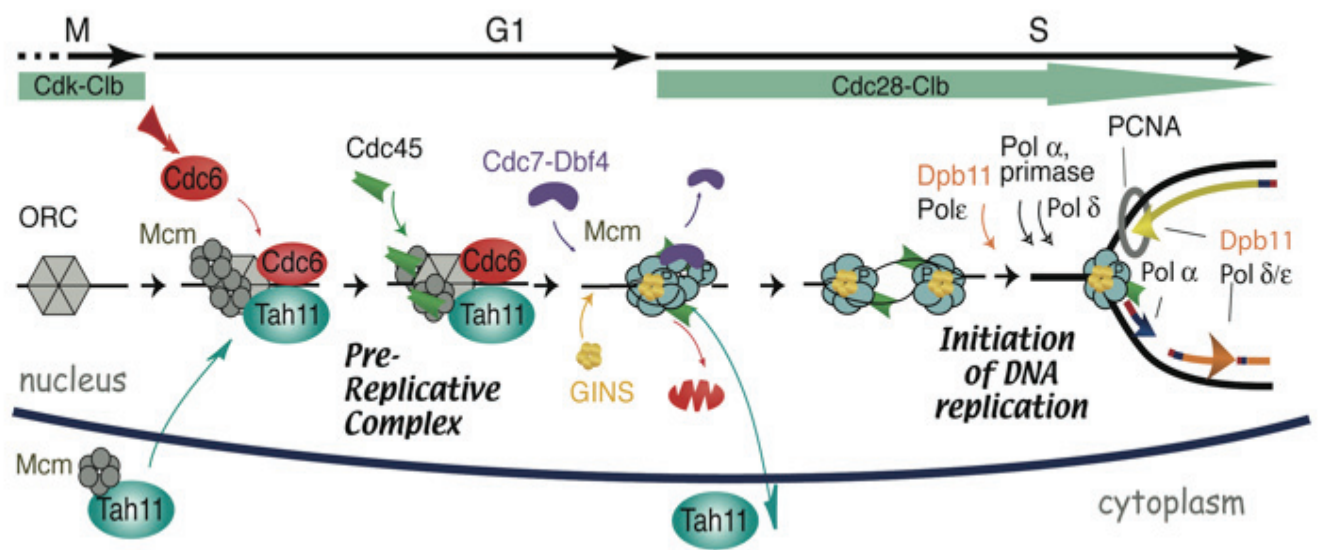

\section{Fig. 1.3 DNA replication}

At the end of mitosis a decrease in Cdk-Clb kinase activity allows pre-replicative complex formation consisting of Orc, Mcm2-7, Tah11 and Cdc6. Cells pass through "START" in G1-phase committing them to DNA replication. As cells begin to transit from late G1 to S-phase, Dbf4-Cdc7 and Clb5/6-Cdc28 protein kinases become active and phosphorylate components of the pre-RC promoting the recruitment of $\mathrm{Cdc} 45$ and GINS. Once DNA replication is initiated, Dpb11 recruits Pol $\varepsilon$ and facilitates the switch between Pol $\alpha$ and Pol $\varepsilon$. Mcm2-7, GINS and Cdc45 move with replication forks as elongation occurs. 
(Cdt1), and the Mcm2-7 complex to the Orc bound origin (13). Cdc6 and Tah11 first bind to Orc, Orc and Cdc6 then hydrolyze ATP to promote loading of Mcm2-7 on the DNA. The contribution of Tah11 in this process remains unclear. Cdc6 is phosphorylated upon origin activation by the cyclin dependent kinases (CDK), Dbf4-Cdc7 and Clb5/6-Cdc28, leading to protein degradation or nuclear export restricting its activity to the G1/S-phase of the cell cycle. Cdt1 (Tah11) is regulated in metazoans when geminin binds Cdt1 and prevents its activity in G2-phase or mitosis (10). The Mcm2-7 complex has a hexameric ring structure that is highly suggestive of a replicative DNA helicase. In S. cerevisiae, Mcms cycle in and out of the nucleus during the cell cycle. In other organisms they are located in the nucleus throughout the cell cycle, but binding to chromatin only occurs during G1/S-phase. In all eukaryotes, the Mcm2-7 complex is dislodged from the chromatin to move with replication forks. Assembly of Orc, Cdc6, Tah11, and Mcm2-7 at the origin completes the pre-RC, effectively licensing the origin for DNA replication in the subsequent S-phase (10).

For licensed origins to initiate DNA replication, however, they must pass through the G1 decision point, called START, which irreversibly commits the cells to a new round of cell division. START is properly executed when Cdc28, a cyclin dependent kinase, becomes active by forming a complex with $\mathrm{C} \ln 1 / 2$. Nine cyclins modulate $\mathrm{Cdc} 28$ activity: three G1 cyclins, Cln1-3, which are required for the passage through START and six B-type cyclins, Clb1-6, which are involved in S-phase and mitotic progression. The G1 cyclins are those that act on the pre-RC and lead directly to the initiation of DNA replication (9). Early studies showed that any of the three Cln proteins could compensate for the loss of another without affecting START. However, there are different functions 
of $\mathrm{Cln} 1-3$. Cln1 and $\mathrm{Cln} 2$ are highly similar proteins, whose expression is cell cycle regulated with levels peaking in late G1. $\mathrm{Cln} 3$ is less similar to $\mathrm{Cln} 1$ and $\mathrm{Cln} 2$ and is constitutively expressed throughout the cell cycle. Cln3 is responsible for activating the transcription of select genes in late G1 phase, including CLN1 and CLN2. Induction of these transcripts leads to an increase in $\operatorname{Cln} 1 / 2-C d c 28$ kinase activity, which catalyzes most or all of the events associated with START (9).

Cln1/2-Cdc28 kinase activation is required for DNA replication to occur, however it is the B-type cyclins, $\mathrm{Clb5}$ and $\mathrm{Clb6}$, which directly activate origin firing. $\mathrm{Clb5} / \mathrm{Clb} 6-$ Cdc28 complexes are formed in late G1-phase, but are kept inactive by the CDK inhibitor Sic1. Sic1 has two functions in the cell cycle. First, it contributes to the shut off of the mitotic form of the $\mathrm{Clb}-\mathrm{Cdc} 28$ kinase promoting the exit of a cell from mitosis. Second, Sic 1 regulates the activity of $\mathrm{Clb} 5 / 6-\mathrm{Cdc} 28$ kinase, thereby controlling the timing of Sphase. A primary function of $\mathrm{Cln} 1 / 2-\mathrm{Cdc} 28$ is to target Sic 1 for degradation to promote entry into S-phase. It was shown in wild-type cells that Sic1 accumulates in late mitosis, is phosphorylated at START in a Cln-dependent manner and is degraded shortly before S-phase. Sic1 degradation is dependent both on Cdc34, an ubiquitin-conjugating enzyme, and on the Cln-Cdc28 kinase. Following the down regulation of Sic1, the Clb5/6-Cdc28 kinase is activated (9).

A second protein kinase, Dbf4-dependent kinase (DDK), is also required for Sphase entry. DDK consists of a catalytic subunit $\mathrm{Cdc} 7$ and a regulatory subunit Dbf4 that confers substrate specificity (10). Cdc7 protein levels are constant throughout the cell cycle. However, kinase activity is periodic, peaking at the G1/S boundary. Activation of the Cdc7 kinase requires interaction with the regulatory subunit Dbf4, which is expressed 
in late G1-phase and turned over rapidly allowing for a short burst of Cdc7 activity at the beginning of S-phase. Thus, Cdc7 kinase activity appears to be the last regulatory step before the initiation of DNA replication (9).

\subsubsection{Initiation of DNA replication}

The initiation of replication, or origin firing, occurs as cells enter S-phase (13). Activation of the pre-RC by protein kinases results in Cdc45 binding to the Mcm2-7 complex (14), which appears to be the most critical event in origin firing. Both Cdc45 and the Mcms are required for initiation and elongation steps of DNA replication. Cdc45 is less abundant than the Mcm proteins and is therefore rate limiting for replication. The ratio of the Mcm2-7 complex to ORC is 40:1 while the ratio of Cdc45 to Orc is 2:1 (10). Both Cdc7/Dbf4 and Clb-Cdc28 activity is required for Cdc45 loading. In addition, this step may be mediated by Dpb11, which is part of a CDK-regulated complex and is required for Cdc45 loading. One model suggests that DDK phosphorylation of Mcms causes a change in the complex to allow a limited amount of $\mathrm{Cdc} 45$ to bind to the Mcms at the origin (10). Once Cdc45 is bound, the replication origins unwind to allow binding of the single strand DNA binding protein Rpa, then DNA polymerase alpha $(\alpha)$ and epsilon $(\varepsilon)$ are recruited $(10,14)$. Origin unwinding depends on Cdc45 forming a complex with Sld3. SLD3 was isolated in S. cerevisiae as a gene interacting with DPB11. Dpb11, when bound by Sld2/Drc1 associates with DNA polymerase $\varepsilon$ at the replication origin (14). There are at least two independent functions of Dpb11. It is required for the initiation of DNA replication and is important for checkpoint responses to unreplicated or damaged DNA. 
There is some evidence that the Mcm2-7 complex has helicase activity and all six Mcms are required for DNA unwinding. Moreover, Cdc45 may be the essential cofactor that converts the Mcm complex to an active DNA helicase. The GINS complex also appears to be essential for DNA unwinding. GINS is a ring-shaped, four protein complex that is highly conserved from archaea to eukaryotes (10), which is required for the loading of both Cdc45 and Dpb11 onto origin DNA and then becomes associated with moving replication forks (15).

Another protein, Mcm10, also participates in recruiting Cdc45 to origin DNA and regulates DNA polymerase $\alpha$ stability $(10,16)$. After the replication origins have been activated, the Mcm2-7 complex and Cdc45 move with the assembled replication enzymes at the forks to complete DNA replication. After initiation, the movement of the Mcm2-7 complex away from the origin converts the origin to an unlicensed state thus preventing re-initiation (14).

After DNA unwinding is initiated, the DNA synthesis machinery, the replisome, is assembled and DNA replication begins. DNA synthesis begins with DNA polymerase $\alpha$ associating with primase to initiate a short RNA primer, which is then extended by DNA polymerases. Next, DNA polymerase $\alpha$ is replaced with the more processive polymerases, delta $(\Delta)$ or epsilon $(\varepsilon)$. At the same time, PCNA, the "sliding clamp" processivity factor is loaded. PCNA loading is dependent on a clamp-loading complex replication factor $\mathrm{C}(\mathrm{Rfc})$, which promotes the polymerase switch. One strand of DNA is synthesized as the leading strand the other as the lagging strand. Leading strand synthesis is very efficient, highly processive and follows closely behind the helicase. Lagging strand synthesis requires multiple cycles of priming and extension as the underlying DNA 
is exposed and synthesis occurs in the direction away from the helicase. Lagging strand synthesis results in Okazaki fragments that must be processed by nucleases and DNA ligase to create a single DNA chain. To protect the underlying DNA and ensure completion of DNA synthesis, leading and lagging strand synthesis remains coupled throughout S-phase (10).

\subsubsection{Cde45}

To better understand the process of cell division, a cold sensitive $(c s)$ genetic screen in S. cerevisiae was used to identify more than 40 essential genes whose products were needed to carry out cell division. One mutant, $c d c 45-1$ (for cell division cycle 45), was shown to arrest at medial nuclear division, with a single large bud and the nucleus in the neck between the mother and daughter (17).

Several groups simultaneously reported the isolation of a gene encoding the Cdc45 protein. Zou and colleagues reported the predicted protein sequence of $S$. cerevisiae $\mathrm{Cdc} 45$ as a 74.2 kilo Dalton $(\mathrm{kDa})$ acidic protein with a bipartite nuclear localization sequence. The cold sensitive mutant, $c d c 45-1$, is defective in initiating DNA replication and has inefficient origin firing at the non-permissive temperature suggesting Cdc45 functions at replication origins and affects the frequency of origin firing. $c d c 45-1$ is synthetically lethal with orc2-1, $m c m 2-1$ and $m c m 3-1$ confirming the interaction of Cdc45 with Mcm and ORC and further suggesting that all three act together in the initiation of DNA replication (18).

At the same time, Hopwood and Dalton reported the isolation of Cdc 45 as a 650 amino acid polypeptide that is essential for the initiation of chromosomal DNA 
replication in S. cerevisiae, yet shows no obvious homology with the Mcm family of proteins. They used a conditional $c d c 45$ null mutant strain where the $\mathrm{Cdc} 45$ protein can be rapidly degraded at $37^{\circ}$ due to a signal peptide that was fused to the $\mathrm{N}$-terminus creating a temperature-sensitive degron signal. At $37^{\circ} \mathrm{C}$ this strain is not viable. The cells arrest uniformly at the G1/S boundary with a 1N DNA content suggesting Cdc45 is required for an early step in DNA replication. This phenotype is similar to the cold sensitive $c d c 45-1$ mutant that was previously characterized and the same as the phenotype associated with many Mcm mutants. In immunoprecipitation studies, Hopwood and Dalton showed that Cdc45 forms a complex with Mcm5 in the Mcm2-7 multi-protein complex and is localized in the nucleus throughout the cell cycle. In contrast, the Mcm proteins shuttle in and out of the nucleus in a cell cycle dependent manner. Hopwood and Dalton mapped the canonical bipartite nuclear localization signal (NLS) to residues 209-228 as mutations of these residues abolish Cdc45 nuclear import (19). A bipartite NLS consists of two essential interdependent domains of basic amino acids separated by a 10 amino acid spacer (20).

By complementation of the cold sensitive $c d c 45-1$ mutant, Hardy mapped $C D C 45$ to an open reading frame on Chromosome XII. FASTA/BLAST analysis suggested Cdc45 was similar toTsd2 from Ustilago maydis, which also has a role in DNA replication $(19,21)$. The amino acid sequences of Cdc45 and Tsd2 are $30 \%$ identical and $50 \%$ similar. Hardy also reported that $C D C 45$ is $\mathrm{G} 1 / \mathrm{S}$ cell cycle regulated at the mRNA level. The MluI cell cycle box (MCB) is the upstream regulatory sequence that drives G1/S specific gene expression and enzymes involved in DNA synthesis are transcriptionally regulated by MCB elements in their upstream non-translated sequences. 
CDC45 contains two MluI sites 145 base pairs and 175 base pairs upstream of the start codon. An analysis of $C D C 45$ RNA levels showed transcription peaks in early G1 and is diminished as cells enter S-phase suggesting regulation is in a G1/S specific manner. This is consistent with the pattern of other MCB regulated genes such as PCNA (21). However, the Cdc45 protein appears to be long-lived and is constant throughout the cell cycle.

Another mutant allele of $\mathrm{Cdc} 45$ is $c d c 45-10$. This temperature sensitive allele was isolated in the Bjornsti lab using a $S$. cerevisiae genetic screen to identify conditional mutants with enhanced sensitivity to DNA Top1-mediated DNA damage. Since yeast sensitivity to CPT is modulated by the pleiotropic drug resistance network, the selfpoisoning Top1 $\mathrm{T}^{722} \mathrm{~A}$ mutant was used as a source of DNA damage (5). Substituting Ala for $\mathrm{Thr}^{722}$ increases the stability of the covalent Top1-DNA intermediate, mimicing the cytotoxic action of CPT. The $c d c 45-10$ mutant encodes a Gly to Arg substitution at amino acid 510 near the C-terminus of the protein (22). The mutant cells exhibit enhanced sensitivity to CPT, UV and a replication inhibitor hydroxyurea (HU), at the non-permissive temperature, $36^{\circ} \mathrm{C}(5) . c d c 45-10$ cells also transiently accumulate in early S-phase when shifted to $36^{\circ} \mathrm{C}$ due to defective Okazaki fragment maturation. These cells exhibit a slow growth phenotype at $36^{\circ}$ when a component of the DNA damage checkpoint, Rad9, is deleted suggesting that the damage occurring in these cells is recognized by this pathway (22).

As described above, Cdc45 is a member of a growing number of gene products that are required for cells to initiate DNA replication. Cdc45 associates with chromatin at the G1/S transition after "START" as cells move to S-phase and this is crucial for 
committing the cells to initiation of DNA replication $(23,24)$. Cdc45 is also required for Pol $\alpha$ loading onto chromatin and associates with Mcm2, Rpa and Pole a part of the elongation machinery. It is suggested that $\mathrm{Cdc} 45$ and Rpa may continually stimulate Mcm helicase activity during replication elongation (25). Sld3 is another protein that is required for Cdc 45 binding at origins. Sld3 and Cdc45 must form a complex in order for either protein to associate with origin DNA. Studies have shown that the Sld3-Cdc45 complex associates with origins through the interaction of $\mathrm{Cdc} 45$ and the Mcm2-7 complex. Once Sld3-Cde45 is bound, origin DNA unwinds and is bound by replication factor A (RF-A), the single-strand DNA binding protein (15). The function of Sld3 is limited to events prior to initiation; it is not required for the completion of replication once early origins have fired and does not move with replication forks. In contrast, the GINS complex is not needed for the initial recruitment of Cdc45 but is required for the stable engagement of $\mathrm{Cdc} 45$ with the previously bound replication machinery, and then becomes stably associated with the Mcm2-7 complex during replication elongation (26). Due to its ring-like shape, GINS may act as a clamp for replication proteins such as Pol $\varepsilon$ that function during the elongation steps of replication (15). In vitro GINS forms a 1:1 complex with Pole and greatly stimulates its catalytic activity. Pole is also more processive and dissociates from replicated DNA more easily when GINS is present. The GINS complex has also been show to promote the interaction between Sld2-Dpb11-and Pole (27). Dpb11 is required for DNA polymerases to associate with origins. Sld2 and Dpb11 form a complex when Sld2 is phosphorylated by S phase Cdk activity and this complex is essential for DNA replication. Dpb11 is required for GINS association with origin DNA. The interaction between GINS and Dpb11 must be limited to assembly at 
origin DNA because Dpb11 dissociates from replication forks after its function is complete and therefore does not move with replication forks during elongation (15). dpb11-10 is a temperature sensitive allele that was isolated from the same genetic screen as $c d c 45-10 . d p b 11-10$ cells exhibit a similar phenotype to $c d c 45-10$ cells: they are hypersensitive to $\mathrm{CPT}$, UV and $\mathrm{HU}$ at $36^{\circ} \mathrm{C}$ and they transiently accumulate in early Sphase at $36^{\circ} \mathrm{C}$ due to a defect in Okazaki fragment maturation (22). A double mutant strain, containing both the $c d c 45-10$ and $d p b 11-10$ mutations, is temperature sensitive for growth at $36^{\circ} \mathrm{C}$ in the absence of DNA damage, indicating a synthetic interaction between Cdc45 and Dpb11 (22).

$C D C 45 L$ is the human homolog of $S$. cerevisiae CDC45. It is 30 kilobases long with 15 introns and 16 exons that encode a protein of 566 amino acids with a molecular mass of $64 \mathrm{kDa}$. Cdc45L is $27.6 \%$ identical and $52 \%$ similar to $S$. cerevisiae Cdc45 and $26.8 \%$ identical and $49.5 \%$ similar to Ustilago maydis Tsd2p. Like the fungal proteins, Cdc45L also contains a bipartite nuclear localization signal. Cdc45L mRNA levels increase during the G1/S transition, but protein levels remain constant throughout the cell cycle, which is typical of proteins involved in the initiation of DNA replication. The Cdc45L gene is located on chromosome 22q11.2 and one copy of the gene is frequently deleted in DiGeorge syndrome (DGS) patients. DGS is marked by parathyroid hypoplasia, thymic aplasia, or hypoplasia and cardiac abnormalities. Since DGS is a developmental anomaly of the derivatives of the third and fourth pharyngeal pouches in the embryo and Cdc45L is the first gene identified in the DGS critical region that is required for cell division, deleting one copy may impair cell division during embryo development leading to the abnormalities seen in DGS patients (28). 
The goals of this dissertation project were to understand how alterations in Cdc45 function affects cell sensitivity to DNA topoisomerase I poisons and to better understand the function of $\mathrm{Cdc} 45$ as a component of replication complexes. Both of these goals were achieved by characterizing the defects in the $c d c 45-10$ mutant cells. First, a genetic screen was developed to isolate dosage suppressors of $c d c 45-10$ that allow $c d c 45-10$ cells to survive in the presence of DNA Top1 poisons. The essential function of Cdc45 in initiation and elongation steps of DNA replication was also assayed by isolating replication intermediates, then using two-dimensional gel electrophoresis to compare the initiation of replication and the progression of replication forks in the mutant and wildtype cells. An antibody was also raised against $S$. cerevisiae $\mathrm{Cdc} 45$, to assess alterations in protein levels and modifications that dictate differences between the Cdc45 mutant and wild-type protein function. 


\section{CHAPTER 2: GENETIC ANALYSIS OF $c d c 45-10$}

\subsection{INTRODUCTION}

Eukaryotic DNA topoisomerase I (Top1) plays a critical role in DNA replication, recombination and transcription by catalyzing the relaxation of supercoiled DNA through a mechanism of transient DNA strand cleavage and religation $(1,2)$. Top1 is a monomeric enzyme that forms a protein clamp around duplex DNA. The active site tyrosine (Tyr727 in yeast Top1) acts as a nucleophile to cleave the phosphodiester backbone of a single DNA strand, forming a covalent 3' phospho-tyrosyl linkage with the DNA. Within this covalent Top1-DNA complex, the rotation of the 5' DNA end about the nonscissile strand relaxes the overwinding or underwinding of the DNA strands (positive or negative supercoils, respectively). The $5^{\prime} \mathrm{OH}$ of the cleaved DNA strand acts as a nucleophile in a second transesterification reaction to resolve the Top1-DNA intermediate and religate the DNA $(1,2)$.

Top1 is the sole cellular target of the anticancer agent camptothecin (CPT). CPT targets Top 1 by reversibly binding the covalent enzyme-DNA intermediate, which prevents religation of the cleaved DNA. The stabilized drug-enzyme-DNA intermediates are formed in all stages of the cell cycle; however, the cytotoxic activity of CPT is Sphase dependent. Two mechanisms have been advanced to explain the replicationdependent toxicity of camptothecins. First, biochemical and genetic data suggest advancing replication forks collide with the stabilized CPT-Top1-DNA complexes to induce irreversible DNA lesions that trigger checkpoint activation and cell death (6). However, a recent study of camptothecin analog poisoning of human Top1 in a single 
molecule setting and in yeast cells suggests a distinct mechanism (8), whereby drug binding of Top1-DNA complexes induces the accumulation of positive supercoils in front of the moving replication fork. Such local domains of high superhelical density would block fork progression, resulting in fork collapse and lethal DNA lesions that induce cell death (8). However, despite extensive study, little is known of the molecular interactions that convert the ternary Top1-DNA-CPT complexes into the DNA lesions that trigger checkpoint activation or the downstream pathways required for the resolution and repair of these lesions.

The budding yeast $S$. cerevisiae has proved an invaluable model for studies of processes such as DNA replication and the mechanism of action of cancer therapeutics (29). This genetically tractable microorganism has a genome of relatively low complexity, exhibits high rates of homologous recombination and can be readily transformed with mitotically stable plasmids. Mating of haploid strains of opposite mating type to generate diploid cells, coupled with a sporulation program that allows the recovery of all four meiotic products in a single ascus, underlies the facile genetics necessary to elucidate complex cellular processes (29). Indeed, most basic cellular processes and the cell cycle machinery are highly conserved from yeast to human, as are the mechanisms of cell sensitivity and resistance to CPT. Yeast cells deleted for TOPI $($ top 1 $\Delta)$ are viable due to the presence of other activities, such as that of DNA topoisomerase II, which maintain cell viability. However, top $1 \Delta$ strains are resistant to CPT. Drug sensitivity can be restored by the expression of plasmid encoded yeast or human Top1 (6). These studies establish Top1 as the cellular target of CPT, which converts Top1 into a cellular poison. 
Alterations in the DNA cleavage-religation equilibrium of Top1, induced either by drug binding or mutation of residues within the catalytic pocket of the enzyme, poison Top1 by enhancing covalent complex stability. For example, mutation of Thr722 to Ala

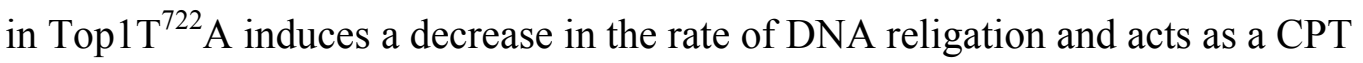
mimetic. DNA repair and checkpoint proficient yeast cells can tolerate low-level expression of this self-poisoning $\operatorname{top}_{1} T^{722} A$ mutant (5). Thus, this mutant allele provides a valuable tool for identifying gene products and pathways that mediate cellular responses to CPT, while avoiding the complications of drug uptake and efflux. As diagrammed in Fig. 2.1, a genetic screen was designed to isolate conditional (temperature sensitive or ts) mutants with enhanced sensitivity to Top $1 \mathrm{~T}^{722} \mathrm{~A}$, thereby identifying gene products that act normally to protect cells against Top1-mediated damage.

In this screen, top $1 \Delta$ cells, transformed with a plasmid that constitutively expresses low levels of Top $1 \mathrm{~T}^{722} \mathrm{~A}$, were mutagenized with ethyl methanesulfonate (EMS) and grown at $26^{\circ} \mathrm{C}$. Following replica plating, colonies that were viable at $26^{\circ} \mathrm{C}$,

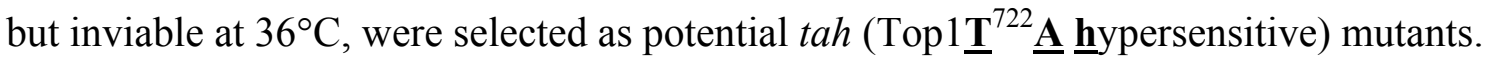
At $36^{\circ} \mathrm{C}$, tah mutants were unable to survive damage induced by Top $1 \mathrm{~T}^{722} \mathrm{~A}$ due to the loss or decrease of $T A H$ gene product function. To ensure that the phenotype of the $t a h$ mutants was linked to top $1 T^{722} A$ expression, the cells were first cured of the URA3 marked vector by successive replica plating on media containing 5-fluoroorotic acid (5FOA), then re-screened for growth at $36^{\circ} \mathrm{C}$. In the absence of Top $1 \mathrm{~T}^{722} \mathrm{~A}$, the top $1 \Delta$, tah mutants were viable at $36^{\circ} \mathrm{C}$ and cell growth was unaffected by the expression of Top1. Extensive backcrossing of individual tah mutants with an isogenic wild-type strain identified ten recessive mutants that defined nine complementation groups. The 


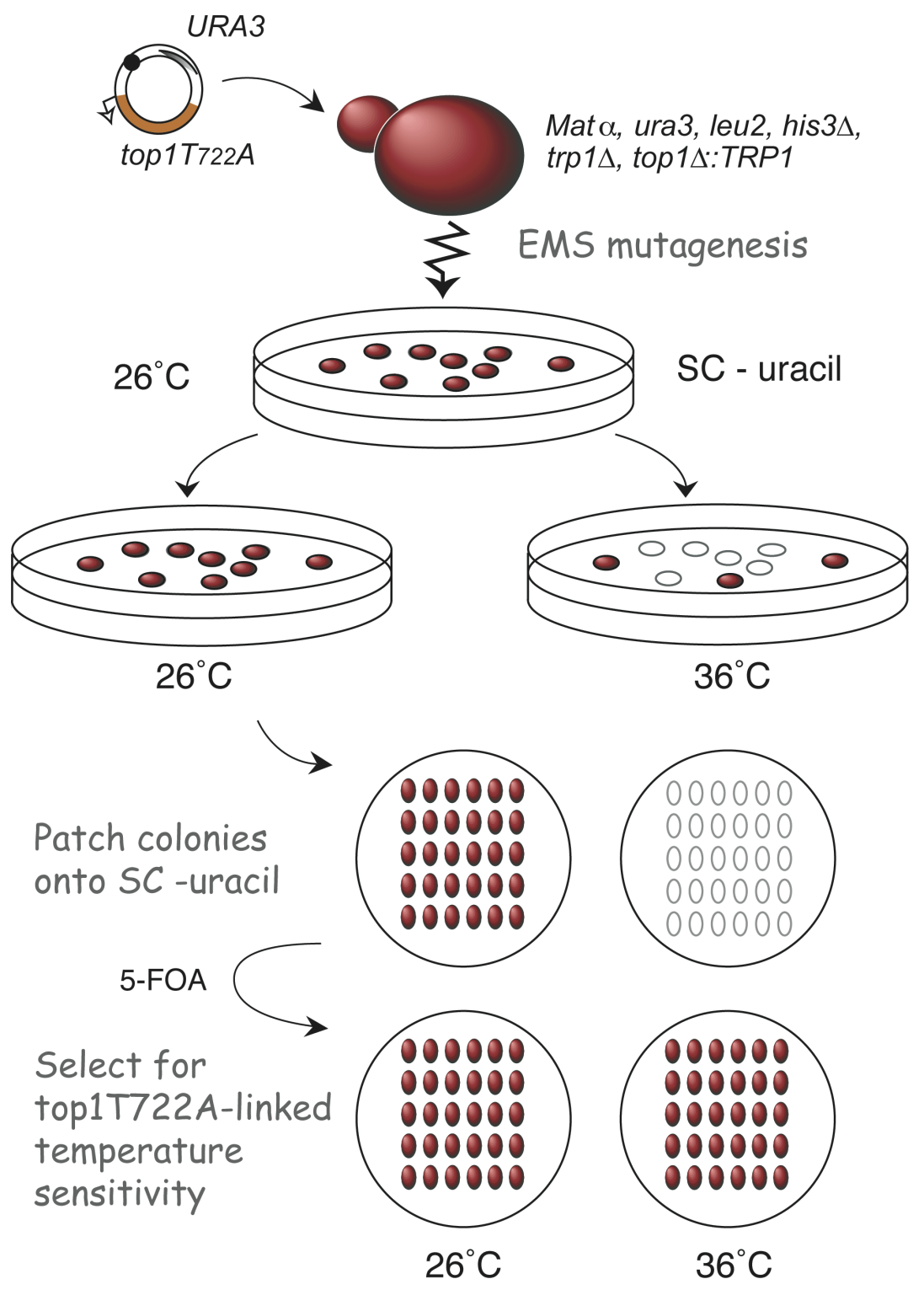

Fig. 2.1 Screen for Top1 ${ }^{722}$ A hypersensitive (tah) mutants

Yeast cells deleted for $T O P 1$ were transformed with a vector expressing low levels of Top $1 \mathrm{~T}_{722} \mathrm{~A}$. The transformants were EMS mutagenized and plated at $26^{\circ} \mathrm{C}$. Those transformants that grew at $26^{\circ}$ but failed to grow when plated at $36^{\circ} \mathrm{C}$ were isolated as tah mutants. To ensure the temperature sensitivity was linked to Top $1 \mathrm{~T}^{722} \mathrm{~A}$, cells were cured of the URA3 based plasmid using 5-FOA and re-screened for temperature sensitive growth. 
corresponding wild-type $T A H$ alleles were cloned by complementation using a low copy vector-based yeast genomic DNA library. As summarized in Fig. 2.2, at the nonpermissive temperature, the tah mutants were also hypersensitive to CPT, when the cells expressed wild-type Top1. The mutants also exhibited enhanced sensitivity to the ribonucleotide reductase inhibitor hydroxyurea (HU), which further suggested defects in DNA replication. The tah mutants exhibited varying levels of sensitivity to other DNA damaging agents, such as the alkylating agent methyl methanesulfonate (MMS) and UV light. The majority of $T A H$ genes encode essential gene products, suggesting that the tah mutants were hypomorphic. They also function in a surprising variety of cellular processes. $U B C 9$ encodes the sole SUMO E2 conjugating enzyme in yeast. DOA4 encodes a C-terminal ubiquitin hydrolase that functions to maintain ubiquitin homeostasis. TAF47 (re-named TAF3) encodes a TATA binding protein that regulates global transcription from the RNA polymerase II promoter. SLA1 encodes a cytoskeletal binding protein required for the assembly of the cortical actin cytoskeleton. SLA2 encodes a transmembrane actin-binding protein involved in membrane cytoskeleton assembly and cell polarization.

As diagrammed in Fig. 2.3, three of the $T A H$ genes are essential for DNA replication. $C D C 45$ encodes a DNA replication initiation factor that is essential for the initiation and elongation steps of DNA replication. DPB11 encodes a subunit of the DNA polymerase II epsilon $(\varepsilon)$ complex that is essential for the loading of DNA polymerases to initiate DNA synthesis and is required for the S-phase checkpoint. TAH11 encodes a DNA replication licensing factor required for pre-replicative complex formation (5). As shown in Fig. 2.4, the tah mutant, $c d c 45-10$, harbors a single mutation where Arg 


\begin{tabular}{|c|c|c|c|c|c|c|}
\hline \multirow[b]{2}{*}{ Mutant } & \multirow[b]{2}{*}{ Gene } & \multirow[b]{2}{*}{ Function } & \multicolumn{4}{|c|}{ Sensitivity to: } \\
\hline & & & CPT & $\mathrm{HU}$ & UV & MMS \\
\hline $\operatorname{tah} 1$ & DPB11 & DNA replication & +++ & +++ & ++ & + \\
\hline tah2 & $C D C 45$ & DNA replication & +++ & +++ & ++ & - \\
\hline $\operatorname{tah} 3$ & TAF47 & TFIID component & +++ & +++ & ++ & ++ \\
\hline $\operatorname{tah} 6$ & $S L A 1$ & cortical actin & +++ & ++ & ++ & ++ \\
\hline $\operatorname{tah} 11$ & TAH11 & $c d+1-D N A$ replication & +++ & +++ & $+/-$ & - \\
\hline $\operatorname{tah} 12$ & UBC9 & Sm+3-conjugation & +++ & +++ & ++ & ++ \\
\hline $\operatorname{tah} 14$ & SLA2 & cortical actin & +++ & +++ & - & - \\
\hline $\operatorname{tah} 18$ & TAH18 & unknown & +++ & +++ & + & - \\
\hline $\operatorname{tah} 20$ & SLA1 & cortical actin & +++ & +++ & + & ++ \\
\hline $\operatorname{tah} 22$ & $D O A 4$ & ubiqutin hydrolase & +++ & +++ & - & - \\
\hline
\end{tabular}

Fig. 2.2 TAH genes

$T A H$ genes encoding essential gene products are depicted in bold print. TAH gene products function in different cellular processes: DPB11, CDC45 and TAH11 encode proteins that function in DNA replication, $U B C 9$ encodes the sole E2 SUMO conjugating enzyme, SLA1 and SLA2 encode gene products involved in cortical actin organization, TAF47 (re-named TAF3) encodes a transcription factor component and DOA4 encodes a ubiquitin hydrolase. The tah mutants are all hypersensitive to $\mathrm{CPT}$ and $\mathrm{HU}$ at $36^{\circ} \mathrm{C}$ and some are also hypersensitive to MMA and UV light. 

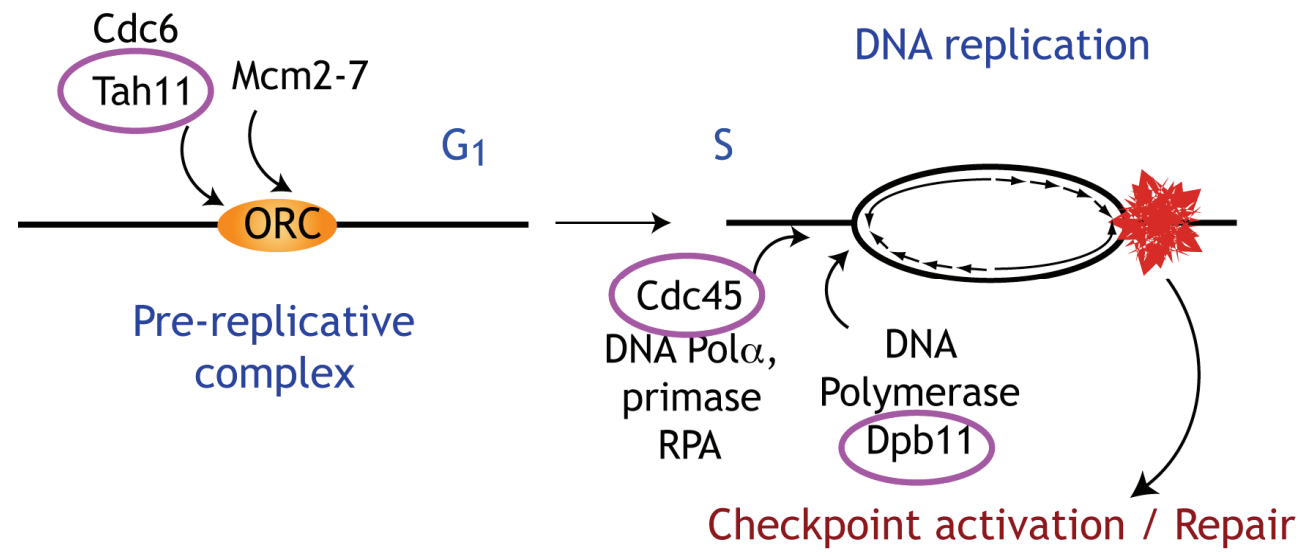

Fig. 2.3 $T A H$ gene function in DNA replication

Three of the $T A H$ genes encode gene products that are essential for DNA replication. Tah11 functions in pre-replicative complex formation, $\mathrm{Cdc} 45$ is required for the initiation and elongation steps of replication and Dpb11 functions in polymerase switching and checkpoint activation. 


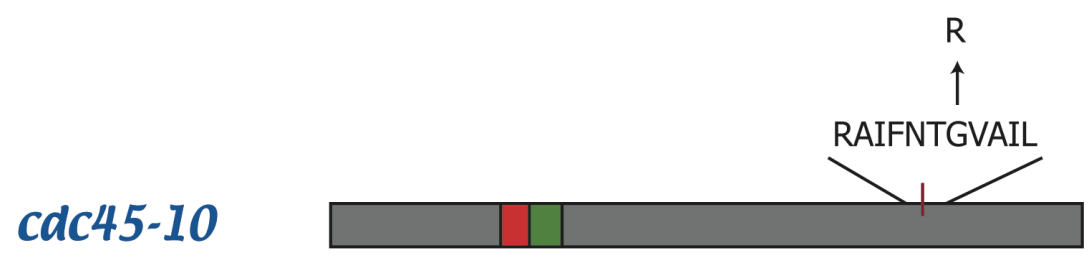

\begin{tabular}{|c|c|c|}
\hline O of 4 & top $1 \Delta$ & $0 \% \%$ \\
\hline 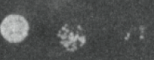 & top 1 T722A & \\
\hline $0 \Rightarrow \ddot{m}$ & TOP1 & 0 한 \\
\hline $26^{\circ} \mathrm{C}$ & & $36^{\circ} \mathrm{C}$ \\
\hline
\end{tabular}

Fig. 2.4 cdc45-10

The tah mutant $c d c 45-10$ encodes a single missense mutation $\left(\mathrm{G}^{510} \mathrm{R}\right)$. The cells are viable when TOP1 is present or deleted (top $1 \triangle)$, however, cell viability is lost at $36^{\circ} \mathrm{C}$ when the cells express low constitutive levels of the CPT mimetic, Top $1 \mathrm{~T}^{722} \mathrm{~A}$. 
substituted for Gly510. With the exception of a bipartite nuclear localization signal, the amino acid sequence of Cdc45 does not predict similarities with any known domains. cdc45-10 cells are viable when either TOP1 is deleted or is expressed, however, the cells are hypersensitive to Top $1 \mathrm{~T}^{722} \mathrm{~A}$ expression at $36^{\circ} \mathrm{C} . c d c 45-10$ cells transiently accumulate in early S-phase when shifted to $36^{\circ} \mathrm{C}$ due to a defect in Okazaki fragment maturation. They also exhibit a slow growth phenotype when $R A D 9$ is deleted suggesting that damage accumulates and is sensed by the Rad9 DNA damage checkpoint. Double mutant strains were constructed by combining the different $t a h$ alleles. The combination of $c d c 45-10$ with $d p b 11-10$ resulted in a double mutant strain that was inviable at $36^{\circ} \mathrm{C}$ in the absence of exogenous DNA damage. This synthetic lethal interaction suggests that Cdc45 and Dpb11 share a common essential function. Because Cdc45 is required for polymerase $\alpha$ loading and Dpb11 is a subunit of the DNA pol II $\varepsilon$ complex, which is required for DNA polymerase loading, the shared function of Cdc45 and Dpb11 could be switching between the pol $\alpha$ primase to the more processive polymerases $\varepsilon$ and $\delta$.

Despite extensive study, the exact function of $\mathrm{Cdc} 45$ during the initiation and elongation steps of DNA replication has yet to be defined. Our findings suggest that Cdc45 functions normally to protect cells against Top1 induced DNA damage. However, further characterization of the replication defects in $c d c 45-10$ cells would provide insights into the molecular interactions required for cellular resistance to Top1-induced DNA damage. In this study, we report that $c d c 45-10\left(c d c 45 G^{510} R\right)$ is hypomorphic for resistance to Top $1 \mathrm{~T}^{722} \mathrm{~A}$-induced DNA damage; however, this was not due to alterations in $\mathrm{Cdc} 45 \mathrm{G}^{510} \mathrm{R}$ protein levels. In contrast, increased expression of this mutant allele failed 
to suppress the synthetic lethality of $c d c 45-10, d p b 11-10$ cells, suggesting distinct effects of the $\mathrm{G}^{510} \mathrm{R}$ substitution on $\mathrm{Cdc} 45$ function in response to Top1 poisons and it's interactions with Dpb11. These findings were further supported by the results of a yeast genetic screen for dosage suppressors, which identified the SUMO E3 ligase, Siz1, as a partial dosage suppressor of $c d c 45-10$ cell sensitivity to Top $1 \mathrm{~T}^{722} \mathrm{~A}$, but not $c d c 45$ 10,dpb11-10 synthetic lethality. Indeed, a $c d c 45$ SUMO consensus site mutant also exhibited a synthetic lethal interaction with $d p b 11-10$, suggesting the functional interaction of these replication proteins is facilitated by SUMO modification.

\subsection{EXPERIMENTAL PROCEDURES}

\subsubsection{Chemicals, plasmids and yeast strains}

Camptothecin, purchased from Sigma, was dissolved in dimethyl sulfoxide (DMSO) and $4 \mathrm{mg} / \mathrm{ml}$ stock solutions were stored at $-20^{\circ} \mathrm{C}$. Hydroxyurea (HU) and 5fluoroorotic acid (5-FOA) were obtained from U.S. Biological. 20T Zymolyase was purchased from Seikagaku Corp.

Plasmids and yeast strains used in these studies are listed in Table 2.1 and 2.2, respectively. Plasmids were amplified in Escherichia coli TOP10F' cells (Invitrogen) and purified using a kit from Qiagen. All mutations were confirmed by DNA sequencing. The isogenic yeast strains were derived from FY250 (30). Where indicated, gene disruptions were accomplished by PCR-based homologous recombination (31) and confirmed by PCR of genomic DNA using primers that flanked the site of integration within the genomic DNA. Primer sequences are available upon request. 
Table 2.1 Plasmids

\begin{tabular}{|c|c|c|}
\hline Plasmids & Characteristics & Reference \\
\hline YCpSctop $1 \mathrm{~T}_{722} \mathrm{~A} \cdot \mathrm{U}$ & $\begin{array}{l}\text { A 2.9-kb BamH1-XbaI fragment excised from } \\
\text { YCpGAL1top1T722A was ligated into YCpSc } \cdot \mathrm{U}\end{array}$ & $(32)$ \\
\hline YCpSctop $1 \mathrm{~T}_{722} \mathrm{~A} \cdot \mathrm{H}$ & $\begin{array}{l}\text { CEN6/ARSH4; a } 3.5-\mathrm{kb} \text { XhoI-NotI fragment of } \\
\text { top } 1 T_{722} A \text { was excised from YCpSctop } 1 \mathrm{~T}_{722} \mathrm{~A} \cdot \mathrm{U} \text {, } \\
\text { and ligated into the same site in pRS } 413\end{array}$ & $(32)$ \\
\hline YEp24pL & $\begin{array}{l}\text { Modified YEp24 vector with multiple cloning site } \\
\text { of pBluescript }\end{array}$ & $(33)$ \\
\hline $\begin{array}{l}\text { YEp } \cdot \text { FY250 genomic } \\
\text { DNA library }\end{array}$ & $\begin{array}{l}\text { 6-10kb genomic fragments were ligated into } \\
\text { partially Sau3A-digested DNA into } \\
\text { dephosphorylated BamHI ends of YEp24pl }\end{array}$ & $(34)$ \\
\hline YEp•HCS81 & $\begin{array}{l}\text { Genomic fragment from YEp } \cdot F Y 250 \text { genomic } \\
\text { DNA library inserted into the BamHI site of } \\
\text { YEp24pL }\end{array}$ & This work \\
\hline YEp•HCS86 & $\begin{array}{l}\text { Genomic fragment from YEp } \cdot F Y 250 \text { genomic } \\
\text { DNA library inserted into the BamHI site of } \\
\text { YEp24pL }\end{array}$ & This work \\
\hline YCpCDC45 & $\begin{array}{l}\text { CEN6/ARSH4;URA3; genomic fragment of } \\
\text { CDC45 cloned into pRS416. }\end{array}$ & $(22)$ \\
\hline YEpCDC45 & $\begin{array}{l}2 \mu \mathrm{m} ; U R A 3 ; \text { Not1-Sal1 fragment of YCpCDC45 } \\
\text { cloned into YEp24pL. }\end{array}$ & $(22)$ \\
\hline YCpcdc45-10 & $\begin{array}{l}C E N 6 / A R S H 4 ; \text { URA3; HindIII-SpeI fragment of } \\
\text { the } c d c 45 G^{510} R \text { mutant from chromosome XII } \\
\text { ligated into pRS } 416 .\end{array}$ & $(22)$ \\
\hline YEpcdc45-10 & $\begin{array}{l}2 \mu \mathrm{m} ; U R A 3 ; \text { HindIII-SpeI fragment of } \\
\text { YCpcdc } 45-10 \text { ligated into YEp24pL }\end{array}$ & This work \\
\hline pAG60 & $\begin{array}{l}\text { TEF-promoter/terminator; C. albicans URA3 } \\
\text { cassette }\end{array}$ & $(31)$ \\
\hline pCLcdc45-10 & $\begin{array}{l}\text { PvuII-HindIII fragment from YEpcdc45-10 } \\
\text { cloned into pAG60. }\end{array}$ & This work \\
\hline pRS415 & CEN6/ARSH4; LEU2 & $(35)$ \\
\hline $\mathrm{YCpCDC} 45 \cdot \mathrm{L}$ & $\begin{array}{l}\text { EagI-SalI fragment of } C D C 45 \text { was excised from } \\
\text { YCpCDC45 and ligated into pRS } 415\end{array}$ & This work \\
\hline YCpcdc $45-10 \cdot \mathrm{L}$ & $\begin{array}{l}\text { NotI-HindIII fragment of pCLcdc45-10 was } \\
\text { excised and cloned into pRS415 }\end{array}$ & This work \\
\hline pRS413 & CEN6/ARSH4; HIS3 & This work \\
\hline pRS416 & CEN6/ARSH4; URA3 & $(34)$ \\
\hline
\end{tabular}


Table 2.1 (continued)

\begin{tabular}{|c|c|c|}
\hline Plasmids & Characteristics & Reference \\
\hline pCLcde $45^{\text {sUMO }}, \mathrm{G}^{510} \mathrm{R}$ & $\begin{array}{l}\text { Lys }^{385} \text { of pCLcdc } 45-10 \text { was mutated to Arg using } \\
\text { oligonucleotide-directed mutagenesis }\end{array}$ & This work \\
\hline $\mathrm{YCpCDC} 45-\mathrm{HA} \cdot \mathrm{L}$ & $\begin{array}{l}\text { CEN6/ARSH4; LEU2; CDC45-HA amplified } \\
\text { from CLY6 and cloned into pRS415 using EagI } \\
\text { and SalI }\end{array}$ & This work \\
\hline YCpcdc45-10-HA $\cdot \mathrm{L}$ & $\begin{array}{l}C E N 6 / A R S H 4 ; \text { LEU2; EagI-PstI fragment of } \\
\text { YCpCDC } 45 \cdot \mathrm{L} \text { excised and ligated into } \\
\text { YCpCDC } 45-\mathrm{HA} \text { to create } \mathrm{G}^{510} \mathrm{R} \text { mutation }\end{array}$ & This work \\
\hline pFA6a-3HA-His3MX6 & $\begin{array}{l}\text { Sequence encoding } 3 \mathrm{HA} \text { with } S \text {. cerevisiae } \\
\text { ADH1 terminator and the His } 3 \mathrm{MX} 6 \text { module } \\
\text { including the } S \text {. pombe his } 5+\text { gene }\end{array}$ & $(36)$ \\
\hline $\mathrm{YCpCDC} 45^{\mathrm{SUMO}} \cdot \mathrm{L}$ & $\begin{array}{l}\text { BstZ71I-NcoI fragment of pCLcdc } 45^{\mathrm{SUMO}}, \mathrm{G}^{510} \mathrm{R} \\
\text { was cloned into YCpCDC45.L }\end{array}$ & This work \\
\hline $\mathrm{YCpcdc} 45^{\mathrm{SUMO}}, \mathrm{G}^{510} \mathrm{R} \cdot \mathrm{L}$ & $\begin{array}{l}\text { BstZ71I-NcoI fragment of pCLcdc } 45^{\mathrm{SUMO}}, \mathrm{G}^{510} \mathrm{R} \\
\text { was cloned into YCpcdc } 45 \mathrm{G}^{510} \mathrm{R} \cdot \mathrm{L}\end{array}$ & This work \\
\hline
\end{tabular}


Table 2.2 Yeast strains

\begin{tabular}{|c|c|c|}
\hline Strain & Genotype & Reference \\
\hline EKY2 & MATa, ura3-52, his3 4200, leu2 $\Delta 1$, trp1 163, top $1 \Delta:: H I S 3$ & $(22)$ \\
\hline EKY3 & MAT $\alpha$, ura3-52, his $3 \Delta 200$, leu $2 \Delta 1$, trp $1 \Delta 63$, top $1 \Delta:: T R P 1$ & $(22)$ \\
\hline RRY72-7 & $\mathrm{EKY} 3, c d c 45-10$ & This work \\
\hline RRY72-2 & $\mathrm{EKY} 2, c d c 45-10$ & This work \\
\hline RRY71-7 & $\mathrm{EKY} 3, d p b 11-10$ & $(22)$ \\
\hline RRY81-1 & EKY3, $\operatorname{tah} 11-10$ & This work \\
\hline RRY82 & EKY3, $u b c 9-10$ & $(32)$ \\
\hline MSY18-6 & $\mathrm{EKY} 3, c d c 45-10, d p b 11-10$ & This work \\
\hline PTY35 & 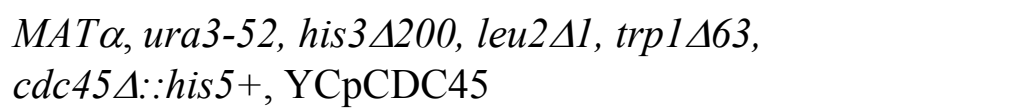 & This work \\
\hline CLY6 & $\begin{array}{l}\text { MAT } \alpha, \text { ura3-52, his } 3 \Delta 200 \text {, leu } 2 \Delta 1, \operatorname{trp} 1 \Delta 63, C D C 45 \mathrm{C}- \\
\text { terminally tagged with HA using pFA6a-3HA-His3MX6 }\end{array}$ & This work \\
\hline
\end{tabular}




\subsubsection{Yeast transformations}

Lithium acetate treated yeast cells, transformed with $U R A 3, L E U 2, T R P 1$ or HIS3-marked plasmids were selected on synthetic complete media lacking uracil (SCura), leucine (SC-leu), histidine (SC-his) or tryptophan (SC-trp), and supplemented with $2 \%(\mathrm{w} / \mathrm{v})$ dextrose.

\subsubsection{Cell viability assays}

To assay cell sensitivity to Top $1 \mathrm{~T}^{722} \mathrm{~A}$, exponential cultures of cells transformed with the indicated YCptop $1 \mathrm{~T}^{722} \mathrm{~A}$ vector, were grown in selective media at $26^{\circ} \mathrm{C}$, adjusted to an O.D. $=0.3$. Serial ten fold dilutions were then spotted in $5 \mu$ aliquots onto selective plates supplemented with dextrose. To assay cell sensitivity to HU, plates were supplemented with $5 \mathrm{mg} / \mathrm{ml} \mathrm{HU}$. For CPT sensitivity, the agar plates were supplemented with $25 \mathrm{mM}$ HEPES (pH 7.2) and 0 or $5 \mu \mathrm{g} / \mathrm{ml} \mathrm{CPT}$ in a final $0.125 \%$ DMSO. In all cases, cell viability was assessed following incubation at $26^{\circ} \mathrm{C}$ or $36^{\circ} \mathrm{C}$.

\subsubsection{Isolation of dosage suppressors}

cdc45-10 (RRY72) cells were co-transformed with YCpSctop $1 \mathrm{~T}^{722} \mathrm{~A} \cdot \mathrm{H}$ and the YEp-FY250 yeast genomic DNA library and selected on SC-ura,-his plates at $36^{\circ} \mathrm{C}$. To ensure that cell viability at $36^{\circ} \mathrm{C}$ was due to the presence of the genomic DNA fragment contained in the YEp plasmid, the cells were cured of the URA3-marked YEp plasmid by successive replica plating of the transformants on SC-his plates supplemented with 5FOA. The resulting colonies were then replica plated onto SC-his plates and incubated at $36^{\circ} \mathrm{C}$. For those colonies that were inviable at $36^{\circ} \mathrm{C}$, the YEp vector was then recovered 
from the original transformants for further characterization. Individual transformants, grown in SC-ura at $26^{\circ} \mathrm{C}$, were collected by centrifugation, washed with $\mathrm{dH}_{2} \mathrm{O}$, resuspended in 1M sorbitol, 20mMEDTA and treated with a freshly prepared solution of $20 \mathrm{~T}$ zymolyase in $1 \mathrm{M}$ sorbitol at $37^{\circ} \mathrm{C}$ for 30 minutes. The spheroplasts were then pelleted, resuspended in buffer P1 from the Qiagen miniprep kit and the plasmid DNA was purified as per the manufacturer's instructions. The purified plasmids were subsequently amplified in E. coli TOP10F' cells, and the DNA from individual transformants were digested with XbaI and EcoRI to determine the size of the yeast genomic DNA inserts. The restriction enzymes were chosen based on the restriction maps of YCpCDC45, YCpSctop1T ${ }_{722} \mathrm{~A}$ and YEp24pL. Digesting YCpCDC45 with XbaI and EcoR1 yields a 1.4 kilobase $(\mathrm{kb})$ fragment of $C D C 45$ that was used as a control to determine if any inserts in the plasmids were $C D C 45$, whereas digests of YCpSctop $1 \mathrm{~T}_{722} \mathrm{~A}$ or YEp24pL served to distinguish Top $1 \mathrm{~T}^{722} \mathrm{~A}$ and vector fragments from vectors containing genomic DNA inserts. The restriction digests were resolved in agarose gels and visualized by ethidium bromide staining using a BioRad Gel Doc System. The high copy suppressor digests were compared to that of the vector controls to determine the insert size. The recovered plasmids were verified by transformation with YCpScTop $1 \mathrm{~T}^{722} \mathrm{~A}$ into $c d c 45-10$ cells. Individual colonies were picked and grown in selective media at $26^{\circ} \mathrm{C}$. Cell viability assays were used to access cell viability at $26^{\circ} \mathrm{C}$ and $36^{\circ} \mathrm{C}$. The high copy suppressor inserts were sequenced using $\mathrm{T}_{3}$ and $\mathrm{T}_{7}$ primers. The DNA sequences obtained were used to query the Saccharomyces genome database (SGD) and to identify the genomic DNA inserts. 
As each insert contained multiple reading frames, further subcloning determined which open reading frame was responsible for the dosage suppression. YEp24-HCS86 was digested with EagI to excise $1.2 \mathrm{~kb}$ of the $5.5 \mathrm{~kb}$ insert, leaving the entire SIZ1 ORF and 179 base pairs of the 644 base pair $A D E 8$ gene. YEp24-HCS81 was digested with SalI to excise the complete NDI1 gene including 140 base pairs upstream of the start codon. This fragment was ligated into YEp24pl and the remainder of the digested plasmid was religated. Each plasmid was co-transformed with YCpTop1T ${ }_{722} \mathrm{~A}$ into cdc45-10 cells and viability was accessed at $26^{\circ} \mathrm{C}$ and $36^{\circ} \mathrm{C}$.

\subsubsection{SUMO site mutations}

Substitution of Arg for $\mathrm{Lys}^{385}$, in the consensus sumoylation site $\mathrm{IK}^{385} \mathrm{RE}$ of

$\mathrm{Cdc} 45 \mathrm{G}^{510} \mathrm{R}$, was accomplished by oligonucleotide-directed mutagenesis of pCLcdc4510 with the Quick Change Site-Directed Mutagenesis Kit (Stratagene) to generate pCLcdc $45^{\mathrm{SUMO}}, \mathrm{G}^{510} \mathrm{R}$, using the primer pairs 5'CATGGATCATTCTATTAGGAGAGAACTTGGG 3' and 5' CCCAAGTTCTCTCCTAATAGAATGATCCATG 3'. The DNA fragment spanning the SUMO site mutant was then excised with BSTZ71I and Nco1 and ligated into the corresponding sites in $\mathrm{YCpCDC} 45 \cdot \mathrm{L}$ and $\mathrm{YCpcdc} 45-10 \cdot \mathrm{L}$, to generate $\mathrm{YCpCDC} 45^{\mathrm{SUMO}} \cdot \mathrm{L}$ and $\mathrm{YCpcdc} 45^{\mathrm{SUMO}}, \mathrm{G}^{510} \mathrm{R} \cdot \mathrm{L}$, respectively.

\subsubsection{Plasmid shuffle}

To create the $c d c 45 \Delta$ plasmid shuffle strain (PTY35), wild-type FY250 cells were transformed with YCpCDC45 and the genomic copy of $C D C 45$ was replaced with the 
his5+ gene via PCR based homologous recombination (36). The primers used 5' TAGAGAGAAGGCACATAATAACAAGAATATACTCTCGCACCGGATCCCCGGGTTA ATTAA 3' and 5'AATTTTGATTATAACAATCCACTCAAGGTCAGCTTCTCCAGGAATTCGAGCTCGT TTAAAC 3' contained 40 bases that were complementary to sequences flanking the 5' and 3' ends of CDC45 (in italics), respectively, while the remaining sequences are complementary to plasmid sequences flanking the his $5+$ gene. YCpCdc $45 \cdot \mathrm{L}$,

$\mathrm{YCpCdc}^{\mathrm{SUMO}} \cdot \mathrm{L}, \mathrm{YCpcdc} 45-10 \cdot \mathrm{L}$ and $\mathrm{YCpcdc}{ }^{\mathrm{SUMO}}, \mathrm{G}^{510} \mathrm{R} \cdot \mathrm{L}$ vectors were transformed into the $c d c 45 \Delta$ strain and individual transformants were cured of the URA3-based vector by successive replica plating on 5-FOA. Viable cells, containing only the $L E U 2$ vectors, were selected for further characterization.

\subsection{RESULTS}

\subsection{1 $c d c 45-10$ is a hypomorphic mutant}

The tah screen for conditional mutants exhibiting enhanced cell sensitivity to Top1 poisons (described in Fig. 2.1) generated temperature sensitive mutations in several essential genes including $C D C 45, D P B 11, T A H 11$ and $U B C 9$. In the case of the $u b c 9-10$ mutant, we reported that the mutant protein was thermolabile at $36^{\circ} \mathrm{C}$, as steady state protein levels were reduced upon shift to the non-permissive temperature. The resultant decrease in global SUMO conjugation sufficed to maintain cell viability at $36^{\circ} \mathrm{C}$ yet reduced cellular resistance to low levels of genotoxic stresses. These data indicated that 
the $u b c 9-10$ mutant was hypomorphic, such that the mutant phenotypes resulted from a decrease in Ubc9 function.

To assess whether the phenotypes ascribed to the $c d c 45-10$ mutant were also a consequence of a global decrease in Cdc45 function, we asked if increased copy number of the $c d c 45-10$ mutant allele would restore cellular resistance to low levels of Top $1 \mathrm{~T}^{722} \mathrm{~A}$-induced DNA damage. To address this question, the entire coding region of the $c d c 45-10$ allele and the 5'flanking sequences necessary for gene expression were cloned into a high copy $2 \mu \mathrm{m}$-based vector. This vector was then co-transformed into cdc45-10 mutant cells with YCpSctop $1 \mathrm{~T}^{722} \mathrm{~A} \cdot \mathrm{H}$ or vector control. As shown in Fig. 2.5, increased gene dosage of wild-type $C D C 45$ or mutant $c d c 45-10$ complemented the slow growth phenotype exhibited by $c d c 45-10$ cells in the absence of DNA damage as well as the Top $1 \mathrm{~T}^{722} \mathrm{~A}$-induced cell lethality at $36^{\circ} \mathrm{C}$. These data suggest that $c d c 45-10$ is hypomorphic for the defects necessary to protect cells from low levels of Top1-induced DNA damage.

These data contrasted with the inability of YEpcdc45-10 to dosage suppress the synthetic lethal interactions of $c d c 45-10$ with $d p b 11-10$. As shown in Fig. 2.6, while increased dosage of wild-type CDC45 complemented the lethal phenotype of the $c d c 45$ $10, d p b 11-10$ strain at $36^{\circ} \mathrm{C}$, YEpcdc45-10 failed to restore viability. These results raise two possibilities. First, there are distinct functions for $\mathrm{Cdc} 45$, one required to protect cells from low levels of S-phase DNA damage and another for the functional interaction with Dpb11. Alternatively, a lower threshold of Cdc45 function may be necessary for cellular resistance to Top $1 \mathrm{~T}^{722} \mathrm{~A}$ in wild-type DPB11 cells, while higher levels of Cdc45 activity is needed to maintain cell viability when both Cdc45 and Dpb11 function is altered. 
high copy vector

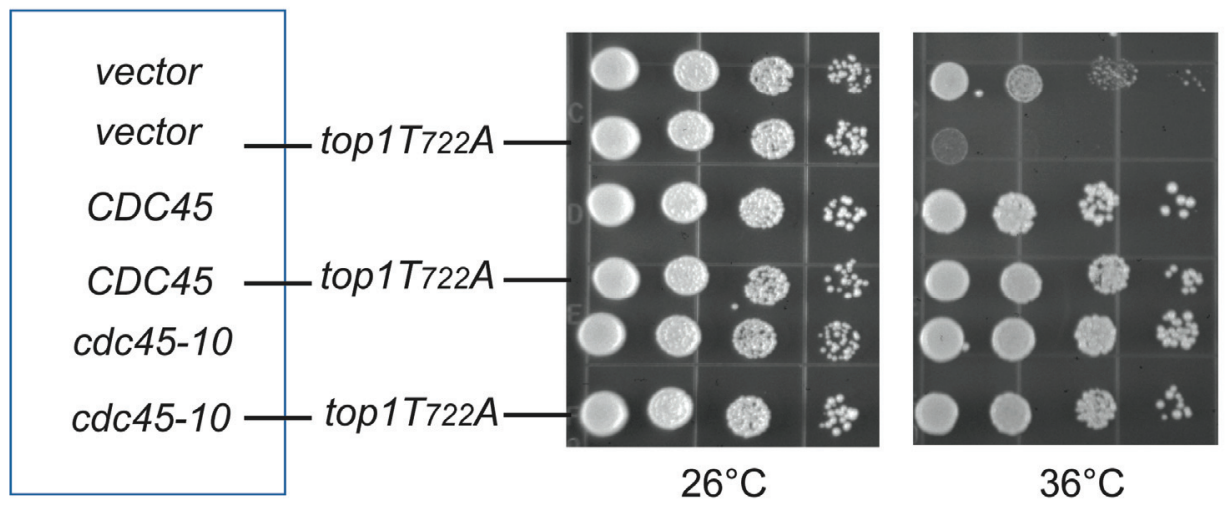

Fig. 2.5 Increased gene dosage of $c d c 45-10$ restores cellular resistance to Top1T $\mathrm{T}^{722} \mathrm{~A}$ $c d c 45-10$ cells were co-transformed with $\mathrm{CDC} 45$ or $c d c 45-10$ vectors and Top $1 \mathrm{~T}^{722} \mathrm{~A}$. Expression of CDC45 (low copy or high copy) and high copy expression of $c d c 45-10$ restores cell viability to $c d c 45-10$ cells in the presence of Top $1 \mathrm{~T}^{722} \mathrm{~A}$ at $36^{\circ} \mathrm{C}$. 


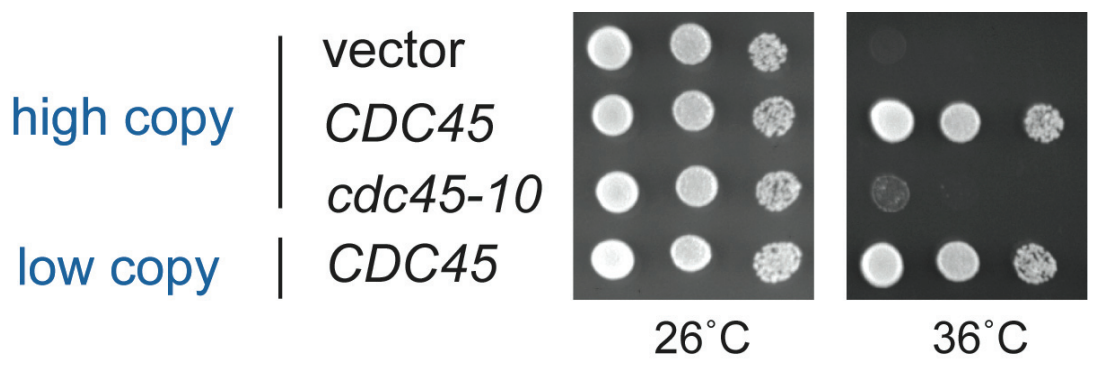

Fig. 2.6 Increased expression of $c d c 45-10$ does not restore cell viability to the $c d c 45$ 10, $d p b 11-10$ double mutant strain

The $c d c 45-10, d p b 11-10$ double mutant strain was transformed with vectors expressing low or high levels of CDC45 or a vector expressing high levels of $c d c 45-10$. Low or high level expression of CDC45 (YCpCDC45 or YEpCDC45) was able to restore cell viability to the double mutant strain at $36^{\circ} \mathrm{C}$, however, increased expression of $c d c 45-10$ (YEpcdc45-10) was not able to restore cell viability at $36^{\circ} \mathrm{C}$. 


\subsubsection{Epitope tagging of $\mathrm{Cdc} 45$ and $\mathrm{Cdc} 45 \mathrm{G}^{510} \mathrm{R}$}

To address these questions, and the basis for the hypomorphic phenotype of $c d c 45-10$ itself, we attempted to incorporate an epitope tag into the genomic copy of CDC45 and $c d c 45-10$. This approach, of introducing a C-terminal HA tag into wild-type Cdc45, has been extensively used to characterize Cdc45 protein levels, interactions with other proteins and chromatin association $(16,23-26,37,38)$. Thus, we anticipated this approach would be a relatively straightforward means of incorporating an epitope tag into Cdc $45 \mathrm{G}^{510} \mathrm{R}$. However, this was not the case. As summarized in Fig. 2.7, several approaches were taken. First, we attempted to introduce a hemagglutinin (HA) or Myc epitope tag at the $\mathrm{C}$ - terminus of $\mathrm{Cdc} 45$ and $c d c 45 G^{510} R$ by integrating sequences encoding these tags into the genome of haploid yeast strains using PCR-based homologous recombination. While this method was successful for CDC45 it was unsuccessful for $c d c 45 G^{510} R$. In both cases, viable HIS $+c d c 45-10$ colonies were not recovered. Related attempts to recover an N-terminal HA-cdc45-10 strain also failed. As diagrammed in Fig. 2.7, these findings suggest that incorporating an epitope tag at either the $\mathrm{N}$ - or $\mathrm{C}$-terminus of $\mathrm{Cdc} 45 \mathrm{G}^{510} \mathrm{R}$ further impairs protein function such that the cells are no longer viable.

To further investigate this possibility, $C D C 45-H A$ was amplified from genomic DNA and cloned into YCpCDC45-HA. A DNA fragment of $c d c 45 G^{510} R$ that contained the nucleotide sequence coding the $\mathrm{G}^{510} \mathrm{R}$ mutation was then ligated into YCpCDC45-HA to create YCpcdc45-10-HA. The tagged and untagged versions of these vectors were then shuffled into the $c d c 45 \Delta$ (TOP1 and top $1 \Delta$ ) strains (as depicted in Fig. 2.8) and the ability of each $c d c 45$ allele to maintain cell viability was assayed. As shown in Fig. 2.9, 


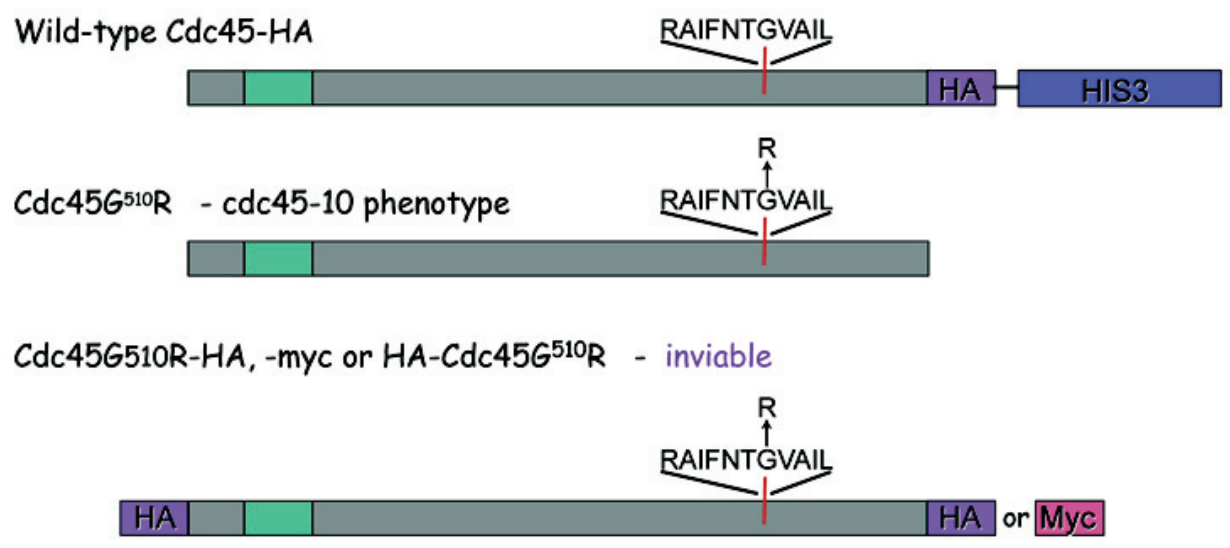

Fig. 2.7 Epitope tagging of Cdc45 and $c d c 45-10$

A HA tag was incorporated at the C-terminus of CDC45 using PCR based homologous recombination. However, incorporating a $\mathrm{HA}$ or $\mathrm{Myc}$ tag at the $\mathrm{C}$ or $\mathrm{N}$-terminus of $c d c 45-10$ resulted in a protein that was not able to maintain cell viability. 

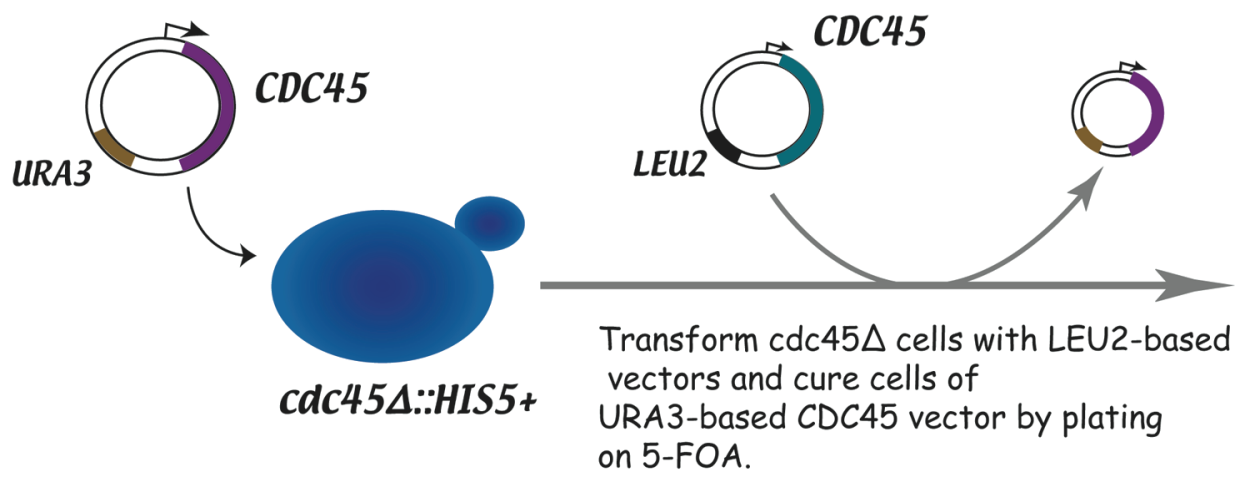

Assay cell viability

\section{Fig. 2.8 Plasmid shuffle}

Cells were transformed with a $U R A 3$ vector carrying wild-type $C D C 45$. The genomic copy of $C D C 45$ was deleted and replaced with HIS5+. The deleted strain was transformed with LEU2 vectors carrying the Cdc 45 mutations to be assayed and cured of the $U R A 3$ vectors using 5-FOA. The cells carrying the $L E U 2$ vectors were assayed for cell viability. 


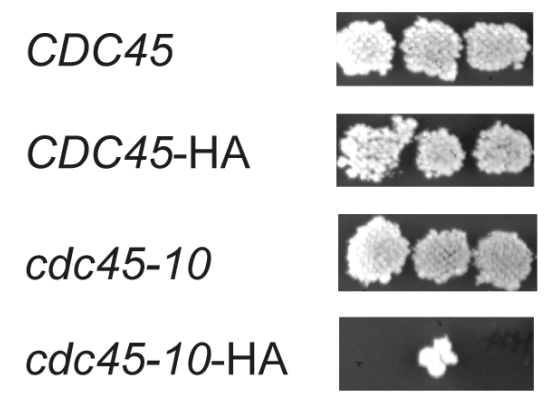

Fig. 2.9 Plasmid shuffle of untagged or C-terminally HA tagged CDC45 and cdc4510

Vectors expressing C-terminally tagged or untagged CDC45 or $c d c 45-10$ were shuffled into a $c d c 45 \Delta$ strain. CDC45, CDC45-HA and $c d c 45-10$ were able to maintain cell viability while $c d c 45-10$-HA was not able to maintain cell viability. 
each of the untagged constructs and YCpCDC45-HA maintained cell viability, whereas cells containing YCpcdc45-10-HA as the sole source of Cdc45 were inviable. These results were independent of Top1. Moreover, they could not be ascribed to a decrease in protein function, as increased dosage of the $c d c 45-10-H A$ allele on a high copy YEp vector also failed to maintain cell viability (data not shown). In parallel, attempts to recover haploid $c d c 45-10-H A$ cells from heterozygous diploids following sporulation and tetrad dissection were also unsuccessful (data not shown). Taken together, these data demonstrate that the introduction of a C-terminal epitope tag into $C d c 45 \mathrm{G}^{510} \mathrm{R}$ induces a null phenotype, consistent with a more severe defect in Cdc45 function.

These results also questioned the effects of the C-terminal HA tag on wild-type Cdc45 function. The $c d c 45-10, d p b 11-10$ double mutant strain is inviable at $36^{\circ} \mathrm{C}$ in the absence of exogenous DNA damage. Thus, to determine if incorporating a C-terminal epitope alters wild-type Cdc45 protein function, YCpCDC45-HA and YCpcdc45-10-HA vectors were transformed into the $c d c 45-10, d p b 11-10$ double mutant strain and cell viability was assessed at $26^{\circ} \mathrm{C}, 30^{\circ} \mathrm{C}$ and $36^{\circ} \mathrm{C}$. As shown in Fig. $2.10, \mathrm{YCpCDC} 45-\mathrm{HA}$ and YCpcdc45-10-HA transformants exhibited a slow growth phenotype at $30^{\circ} \mathrm{C}$, while neither vector restored $c d c 45-10, d p b 11-10$ cell viability at $36^{\circ} \mathrm{C}$. These findings suggest that incorporating an $\mathrm{HA}$ tag at the $\mathrm{C}$-terminus of $\mathrm{Cdc} 45$ alters normal protein function, including that required to suppress the synthetic lethal interaction with $d p b 11-10$. Although modifying the $\mathrm{C}$-terminus of the protein induced interesting alterations in Cdc45 function, this strategy failed to provide a means of assessing Cdc45 protein levels in vivo. Therefore, we next attempted to generate peptide-based polyclonal antibodies. As shown in Fig. 2.11, several peptides were generated and used as antigens in rabbits. The 


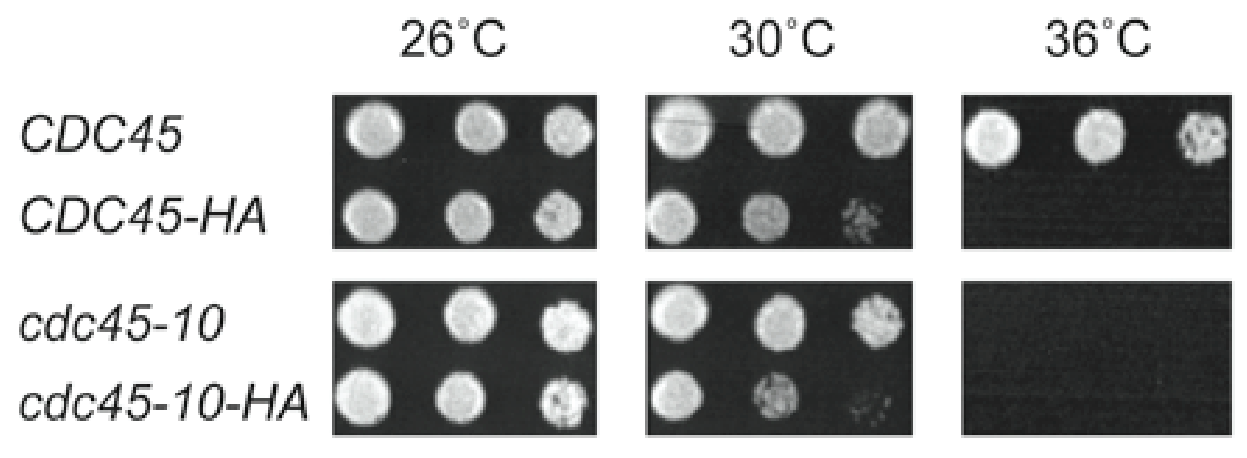

Fig. 2.10 The $c d c 45-10, d p b 11-10$ double mutant strain transformed with untagged and $\mathrm{HA}$ tagged $\mathrm{Cdc45}$ vectors

The $c d c 45-10, d p b 11-10$ strain was transformed with vectors expressing CDC45, CDC45$\mathrm{HA}, c d c 45-10$ and $c d c 45-10$ - $\mathrm{HA}$ and cell viability was assessed at $26^{\circ} \mathrm{C}, 30^{\circ} \mathrm{C}$ and $36^{\circ} \mathrm{C}$. $\mathrm{YCpCDC45-HA}$ and $\mathrm{YCp} c d c 45-10-\mathrm{HA}$ exhibit a slow growth phenotype at $30^{\circ} \mathrm{C}$, while neither vector can restore cell viability to $c d c 45-10, d p b 11-10$ at $36^{\circ} \mathrm{C}$. 
Peptide-based antibodies:

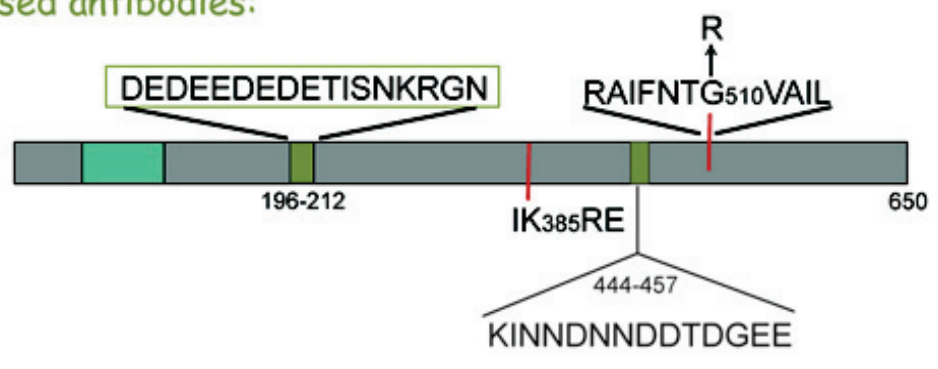

Fig. 2.11 Peptides used to generate $S$. cerevisiae $\mathrm{Cdc45}$ polyclonal antibodies

Two antigens were used to immunize rabbits to produce a $S$. cerevisiae polyclonal Cdc45 antibody. The peptide spanning amino acid region 444-457 failed to recognize Cdc45 while the peptide spanning amino acid region 196-212 recognize the $74 \mathrm{kDa}$ band corresponding to $\mathrm{Cdc} 45$. 
resulting antibodies were purified on peptide-coupled resins as described (39). The antibody generated against the peptide spanning amino acids 444-457 failed to recognize Cdc45 in western blots of whole cell extracts. A second peptide, spanning amino acids 196-212, was also used based on discussions with Bruce Stillman's lab. This antibody recognized the 74 kilo dalton $(\mathrm{kDa})$ band corresponding to $\mathrm{Cdc} 45$, which was confirmed in western blots of Cdc45-HA and in immunoprecipitations of Cdc45-HA proteins immunoblotted with our Cdc45 polyclonal antibody.

\subsubsection{Steady state levels of $C d c 45 G^{510} \mathrm{R}$ are unaltered at $36^{\circ} \mathrm{C}$}

As shown in Fig. 2.12, the steady state levels of $\mathrm{Cdc} 45 \mathrm{G}^{510} \mathrm{R}$ protein obtained from crude extracts of asynchronous cells grown at the permissive $\left(26^{\circ} \mathrm{C}\right)$ or nonpermissive temperature $\left(36^{\circ} \mathrm{C}\right)$ mirrored those of wild-type Cdc45. Thus, unlike the

dramatic decrease in $\mathrm{Ubc}_{9} \mathrm{P}^{123} \mathrm{~L}$ protein levels induced upon shifting the tah mutant $u b c 9$ 10 to the non-permissive temperature, the hypomorphic phenotype of $c d c 45-10$ cells could not be attributed to the down regulation of a thermolabile protein. Although CDC45 gene expression is cell cycle regulated, $\mathrm{Cdc} 45$ protein levels have been reported to be constant throughout the cell cycle. Thus, the $\mathrm{G}^{510} \mathrm{R}$ mutation did not appear to alter mutant protein levels in exponentially growing cells, either in the presence or absence of Top1.

\subsubsection{High copy suppressors of $c d c 45-10$}

As the increased gene dosage of $c d c 45-10$ suppressed the hypersensitivity of these cells to Top $1 \mathrm{~T}^{722} \mathrm{~A}$, but not the synthetic lethality of $c d c 45-10, d p b 11-10$ cells, we posited 

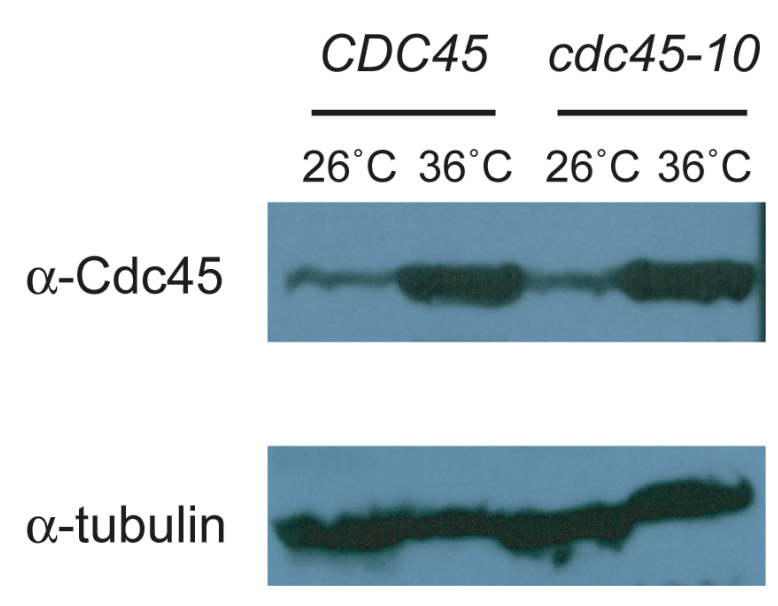

Fig. 2.12 Steady state protein levels of $C D C 45$ and $c d c 45-10$ asynchronous cultures Steady state protein levels of Cdc45 and $c d c 45-10$ at $26^{\circ} \mathrm{C}$ and $36^{\circ} \mathrm{C}$ were visualized by western blots using the Cdc45 polyclonal antibody. In both, CDC45 and cdc45-10, there is an increase in protein levels at $36^{\circ} \mathrm{C}$ compared to $26^{\circ} \mathrm{C}$. 
that a yeast genetic screen for extragenic dosage suppressors of $c d c 45-10$ would further define pathways specific for cellular resistance to Top1 poisons. As shown in Fig. 2.13, $c d c 45-10$ cells were co-transformed with two vectors: a low copy ARS/CEN vector expressing Top $1 \mathrm{~T}^{722} \mathrm{~A}$ from a weak constitutive promoter and a high copy $(\sim 50-200$ copies/cell) URA3-marked YEp vector containing random fragment of yeast genomic DNA. The transformants were selected for viability at the non-permissive temperature, $36^{\circ} \mathrm{C}$. To ensure that cell viability at $36^{\circ} \mathrm{C}$ was due to the presence of increased copies of a gene(s) in the YEp vector, the transformants were first patched onto SC-leu plates at $26^{\circ} \mathrm{C}$, then successively replica plated onto SC-leu media supplemented with 5-FOA. Only cells that have lost the YEp-genomic DNA vector, yet retained the Top $1 \mathrm{~T}^{722} \mathrm{~A}$ expressing vector would be viable under these conditions. These cells were then examined for Top $1 \mathrm{~T}^{722} \mathrm{~A}$-induced lethality at $36^{\circ} \mathrm{C}$. The YEp library plasmid was isolated from the original $26^{\circ} \mathrm{C}$ transformants that met these criteria and rescreened for gene dosage suppression of $c d c 45-10$. Two high copy suppressors (HCS81 and HCS86) were isolated and identified by querying the Saccharomyces Genome Database (SGD) with DNA sequences obtained from the 5' and 3' ends of the inserts. As shown in Fig. 2.14, HCS81 contains a fragment of chromosome XIII, with two complete open reading frames (ORFs), two partial ORFs and an origin of replication, ARS 1303. Of the complete ORFs: NDI1 encodes a NADH-ubiquinone oxidoreductase and YML119W encodes a protein with unknown function. The two partial ORFs are GTR1 and NGL3. Based on annotated sequences obtained from the SGD, subsequent restriction digestion and subcloning of the individual ORFs in HCS81 failed to define any of the ORFs as a dosage suppressor of $\operatorname{top} 1 T^{722} A$-induced $c d c 45-10$ cell lethality at $36^{\circ} \mathrm{C}$ (data not shown). Rather, 

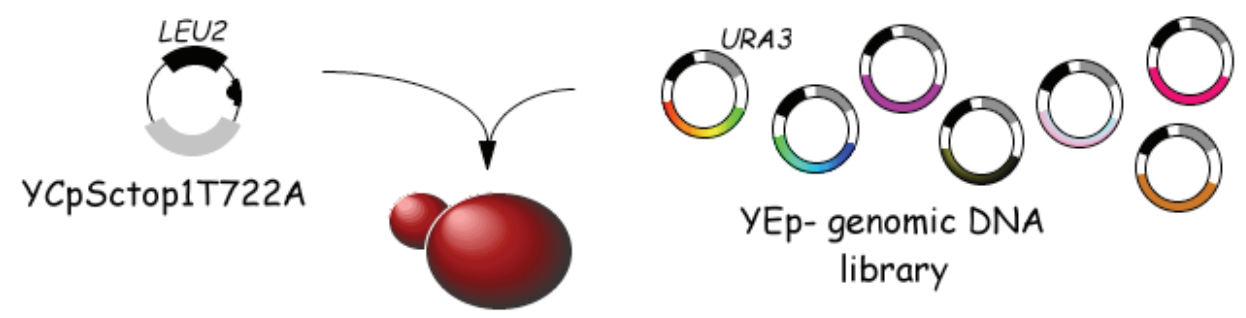

Mat a, cdc45-10, ura3, leu2, top1 $:$ :TRP1

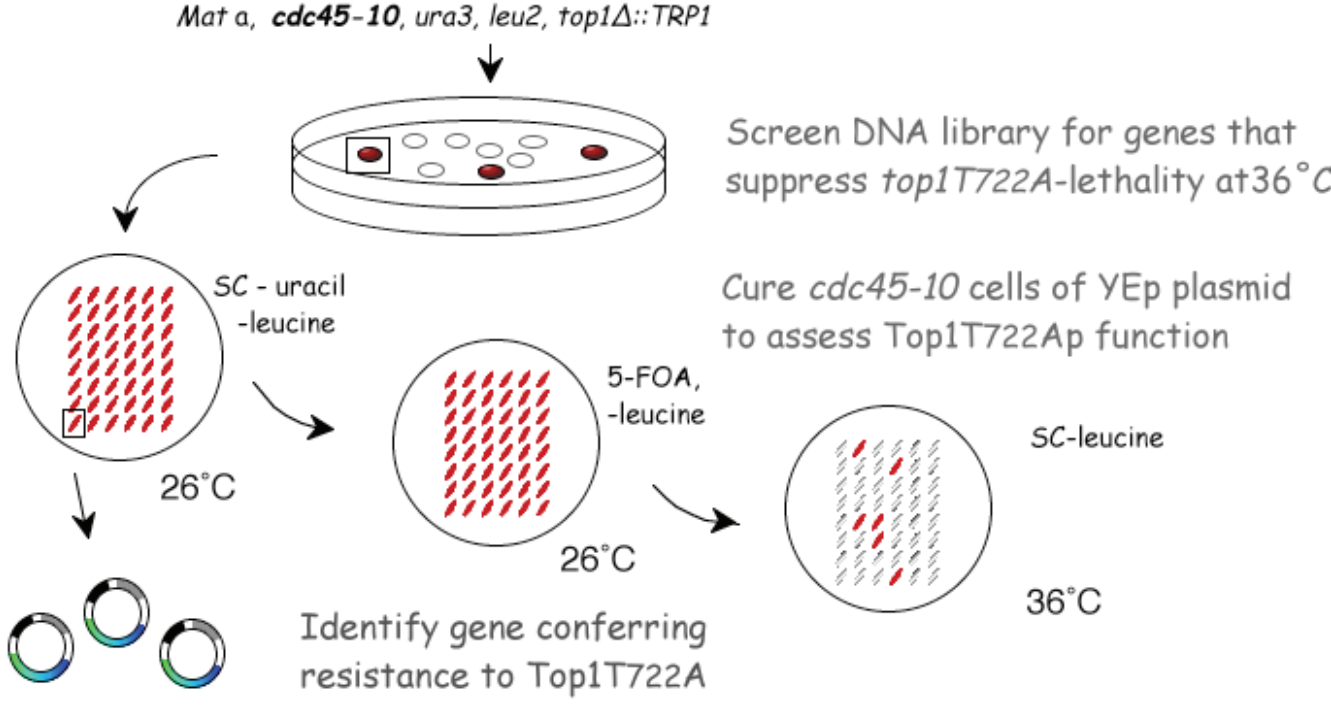

Fig. 2.13 Isolation of dosage suppressors of $c d c 45-10$

$c d c 45-10$ cells were co-transformed with Top $1 \mathrm{~T}^{722} \mathrm{~A}$ and a high copy yeast genomic library, plated and grown at $36^{\circ} \mathrm{C}$. The transformants that were viable at $36^{\circ} \mathrm{C}$ were cured of the library plasmid using 5-FOA to ensure the viability $36^{\circ} \mathrm{C}$ was due to the presence of the library plasmid. The plasmids were isolated, sequenced to identify the high copy suppressor fragment and re-screened for resistance to Top $1 \mathrm{~T}^{722} \mathrm{~A}$. 
cdc45-10

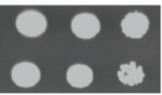

vector

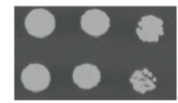

cdc45-10

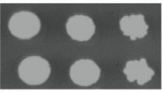

top1T722A

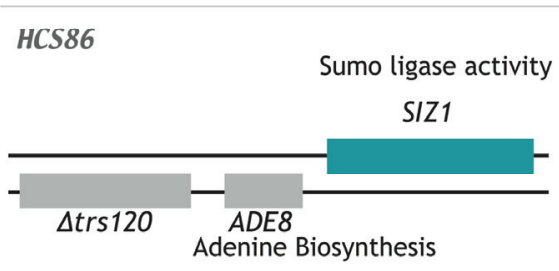

cdc45-10

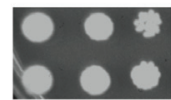

HCS $86+$ top1T722A

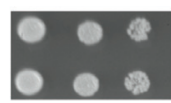

HCS $86+$ top1T722A

ubc9-10

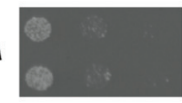

HCS 81

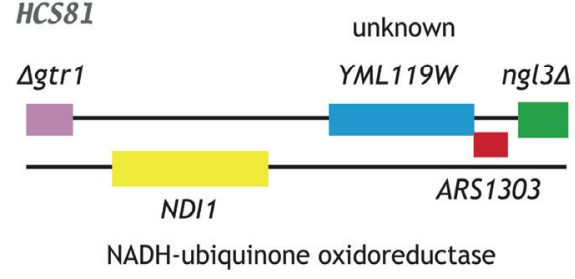

cdc45-10

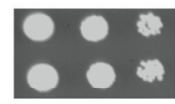

HCS $81+$ top 1T722A

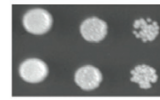

HCS $81+$ top1T722A

dpb11-10

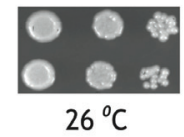

HCS $81+$ top1T722A

$\operatorname{tah} 11-10$

$26{ }^{\circ} \mathrm{C}$

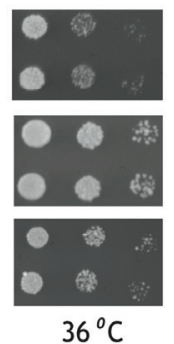

Fig. 2.14 Dosage suppressors of $c d c 45-10$ complement other tah mutant cell sensitivity to Top1 $\mathrm{T}^{722} \mathrm{~A}$

HCS86 contains two complete ORFs and one partial ORF. When digested the fragment containing SIZ1 was responsible for the suppression of $c d c 45-10$ and $u b c 9-10$ in the presence of Top $1 \mathrm{~T}_{722} \mathrm{~A}$ at $36^{\circ} \mathrm{C}$. HCS81 contains two complete ORFs, two partial ORFs and the origin ARS1303. HCS81 restores cell viability to $c d c 45-10, d p b 11-10$ and tah1110 in the presence of Top $1 \mathrm{~T}_{722} \mathrm{~A}$ at $36^{\circ} \mathrm{C}$. 
the presence of an additional origin of replication, ARS1303, in the YEp vector appeared to partially suppress the inability of $c d c 45-10$ cells to grow on SC-leu,-ura (data not shown).

Previous studies of conditional tahl1 mutants suggested that a defect in origin licensing by Tah11 results in the preferential loss of $A R S / C E N$ vectors, due to diminished plasmid replication resulting in plasmid instability. However, this defect in plasmid mitotic stability could be suppressed by the presence of multiple ARS elements on a single vector, thereby increasing the likelihood that at least one origin would fire per cell cycle. The identification of $A R S 1303$ as a dosage suppressor of $c d c 45-10$ led us to consider that a defect in origin firing in these cells might render the YEp vectors unstable, thereby contributing to the inability of these cells to grow on SC-ura media. If so, then this vector should also act as a partial HCS of tah11-10 cells. Indeed, of all the tah strains surveyed, HCS81 only suppressed the Top $1 \mathrm{~T}^{722} \mathrm{~A}$-hypersenitivity of $c d c 45-10$, dpb11-10 and tah1 1-10 strains (Fig. 2.14), consistent with a defect in the licensing and/or firing of origins for replication.

The second dosage suppressor, HCS86 contains two complete ORFs and one partial ORF (Fig. 2.14). The complete ORFs are $A D E 8$, which encodes a protein involved in adenine biosynthesis and SIZ1, which encodes a SUMO E3 ligase. The partial ORF is TRS120. Subcloning of HCS86 determined that a DNA fragment containing SIZI and a portion of $A D E 8$ sufficed to partially restore $c d c 45-10$ cellular resistance to $T o p 1 \mathrm{~T}^{722} \mathrm{~A}$ induced DNA damage (data not shown). As with HCS81, the ability of HCS86 to dosage suppress the Top $1 \mathrm{~T}^{722} \mathrm{~A}$-dependent lethality of the other tah mutants was also assessed. However, in this case, only $u b c 9-10$ cell viability was enhanced by HCS86 (Fig. 2.14). 
Because HCS81 and HCS86 restored cell viability to different tah strains, they were independently transformed into the $c d c 45-10, d p b 11-10$ strain to determine if they could complement the temperature-sensitive phenotype of the double mutant at $36^{\circ} \mathrm{C}$. As shown in Fig. 2.15, neither restored cell viability at $36^{\circ} \mathrm{C}$. These findings further support the notion that the $c d c 45-10$ defect responsible enhanced cell sensitivity to $T_{0 p} 1 \mathrm{~T}_{722} \mathrm{~A}$ is distinct from the synthetic lethal interactions of $c d c 45-10$ with $d p b 11-10$.

\subsubsection{SUMO modification of Cdc45}

The isolation of SIZ1 as a high copy suppressor of $c d c 45-10$ suggested that increased SUMO modification of a protein or proteins could alter cell sensitivity to Top1 poisons. As diagrammed in Fig. 2.16, SUMO (small ubiquitin-like modifier) in mammalian cells or Smt3 in yeast is activated when a peptide tail is removed by the Ulp1 protease to yield a mature di-Gly C terminus. A highly conserved SUMO E1 enzyme (Aos1/Uba2) initiates conjugation by first adenylating SUMO and then forming a covalent thioester bond between the C-terminus of SUMO and the active site Cys of the E1. The E1 then transfers SUMO to the catalytic Cys of the sole SUMO E2 conjugating enzyme, Ubc9. Next, either Ubc9 alone or in association with an E3 ligase (such as Siz1, Siz2, or Mms21) catalyzes the formation of an isopeptide linkage between the C-terminal carboxyl group of SUMO and the $\varepsilon$-amino group of the lysine in the target protein. Substrates can be de-SUMOylated by the action of the proteases Ulp1 or Ulp2. Modification of a target protein by SUMO can alter the protein's subcellular localization, activity, stability or interactions with other proteins, to affect cellular processes such as gene transcription, apoptosis, cell cycle progression, chromatin organization and DNA 

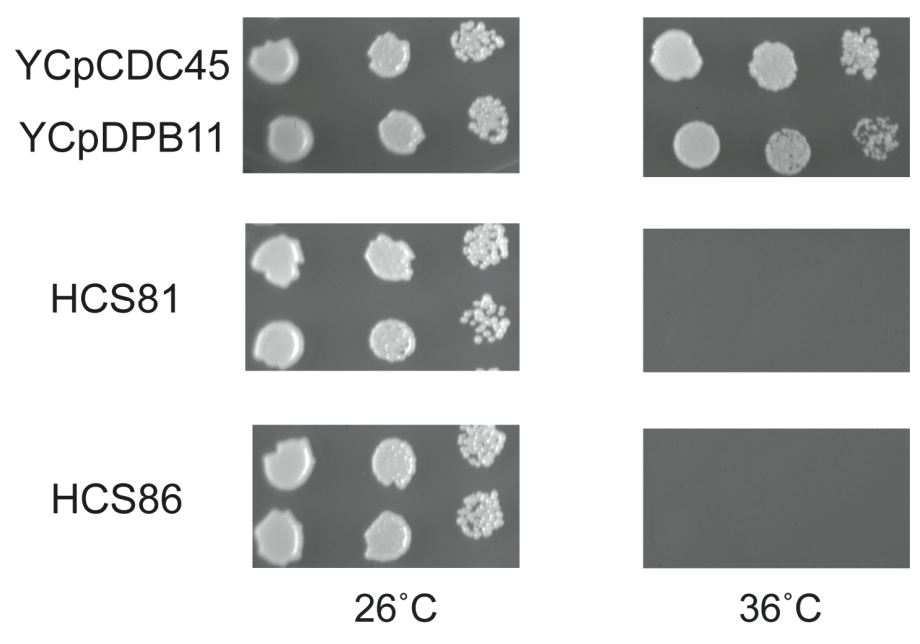

$36^{\circ} \mathrm{C}$

Fig. 2.15 Dosage suppressors of $c d c 45-10$ are not able to restore cell viability to the cdc45-10, dpb11-10 double mutant strain at $36^{\circ} \mathrm{C}$

HCS81 and HCS86 were transformed into the $c d c 45-10$, dpb11-10 double mutant strain and cell viability was assayed. Neither high copy suppressor could restore cell viability to the double mutant strain at $36^{\circ} \mathrm{C}$. 


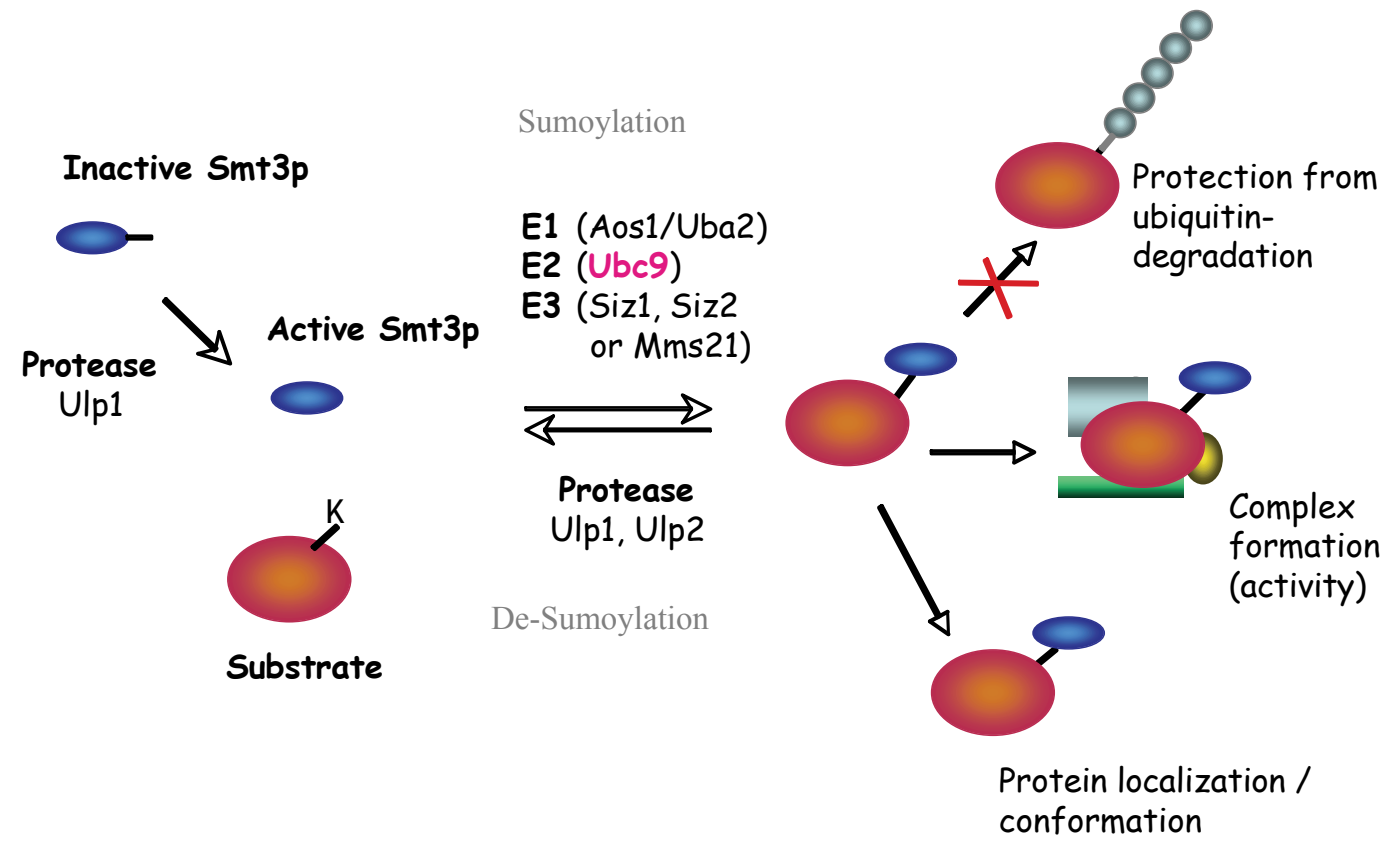

Fig. 2.16 SUMOylation cycle

SUMO is expressed as an inactive protein that becomes active when the protein tail is removed by the protease Ulp1. Active SUMO binds to the E1which transfers it to the E2, Ubc9. Ubc9 alone or with the help of an E3 conjugates SUMO to the lysine of the target protein. Target proteins can be de-sumoylated by the proteases Ulp1 or Ulp2.

SUMOylation of a protein can affect protein localization or conformation, complex formation or protect from ubiquitin degradation. 
repair. Ubc9 itself contains determinants of SUMO target recognition and binds directly to a consensus $\Psi \mathrm{KX}(\mathrm{D} / \mathrm{E})$ motif, where $\Psi$ is a hydrophobic residue, $\mathrm{X}$ is any amino acid and $\mathrm{K}$ is the lysine modified with SUMO. However, this specificity of Ubc9 is insufficient to account for the increasing number of SUMOylated proteins that are being reported and modification of nonconsensus SUMO sites has also been reported (32). An added complication of the analysis of protein SUMOylation is the transient nature of the SUMO linkage. For most targets, considerably less than $10 \%$ of the protein is modified at any given time, which makes SUMO target identification extremely difficult.

The ability of SIZ1 to dosage suppress $u b c 9-10$ sensitivity to Top1-induced DNA damage (32) was not surprising, as we had previously reported a decrease in global SUMO conjugation in $u b c 9-10$ cells shifted to the non-permissive temperature (30). However, the results obtained with $c d c 45-10$ cells prompted us to consider $\mathrm{Cdc} 45$ as a potential target of SUMOylation. Indeed, inspection of the primary amino acid sequence of S. cerevisiae Cdc45 revealed a consensus SUMO site located at Lys ${ }^{385}$. To assess if this site was an important determinant of temperature or drug sensitivity, $C D C 45$ and cdc45-10 sequences were mutated, such that Arg was substituted for Lys 385. Vectors bearing wild-type $C D C 45, c d c 45-10$ and the corresponding SUMO mutants, $c d c 45^{\text {SUMO }}$ and $c d c 45^{S U M O}, G^{510} R$, respectively, were used in a plasmid shuffle in a $c d c 45 \Delta$ strain, as previously depicted in Fig. 2.8 and the effects of mutating K385 on cell sensitivity to high temperature, HU or CPT was assayed. As shown in Fig. 2.17, the viability of cells expressing $\operatorname{cdc} 45^{\mathrm{SUMO}}$ versus $\mathrm{Cdc} 45$ was unaffected by high temperature $\left(36^{\circ} \mathrm{C}\right)$ or exposure to $\mathrm{HU}$ or $\mathrm{CPT}$ at $36^{\circ} \mathrm{C}$. In contrast, expression of cdc $45^{\mathrm{SUMO}}, \mathrm{G}^{510} \mathrm{R}$ further enhanced the slow growth phenotype and hypersensitivity to HU and CPT induced by 


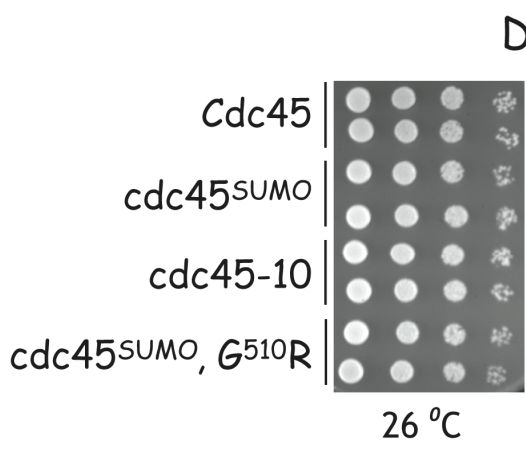

DMSO
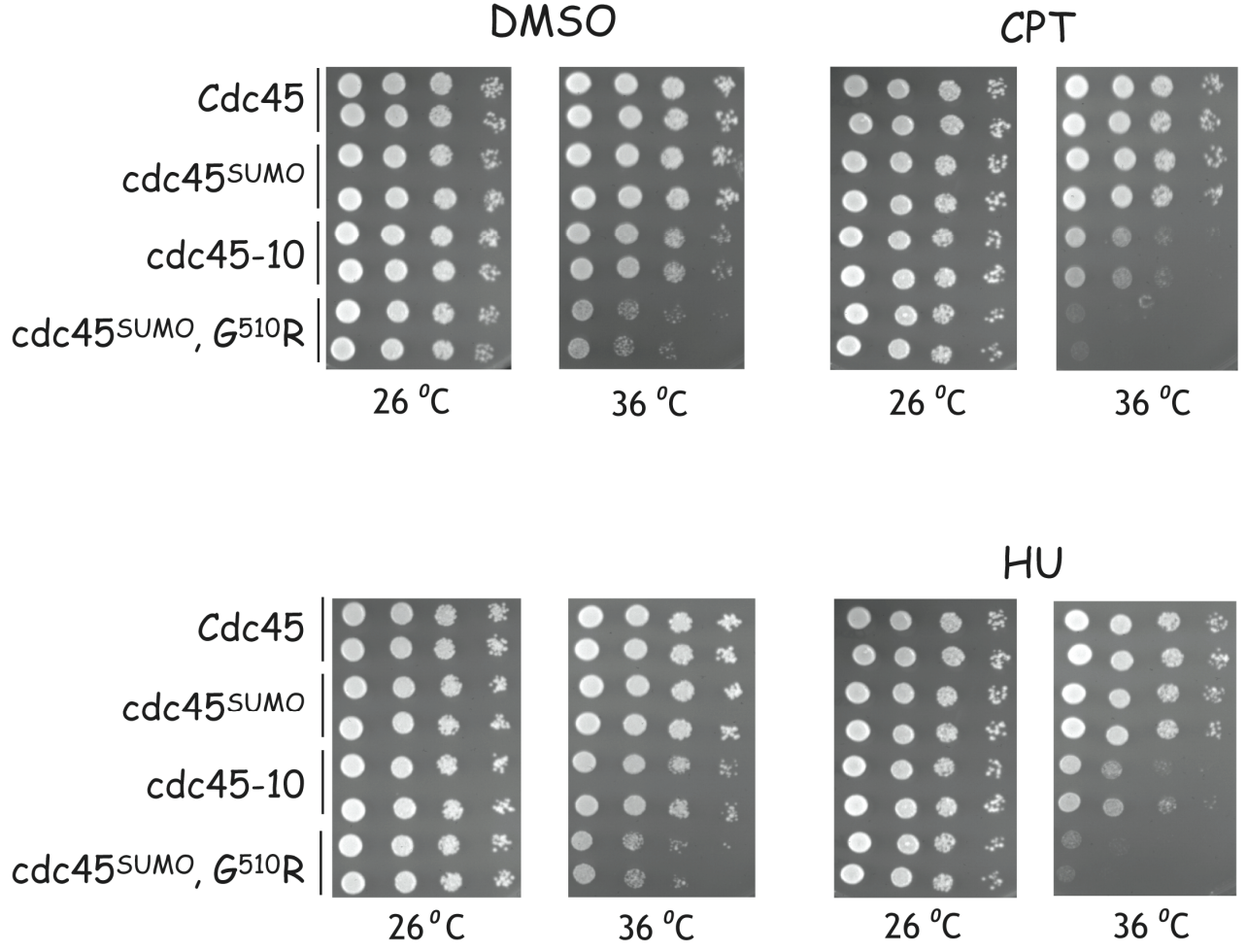

HU
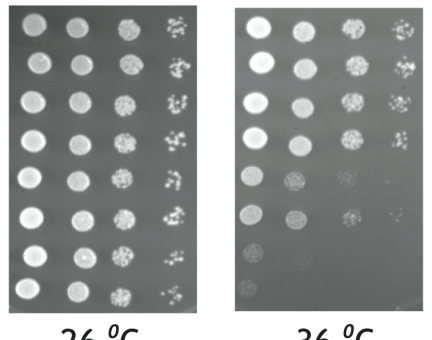

$36{ }^{\circ} \mathrm{C}$

Fig. 2.17 Mutating the consensus SUMO site in Cdc45 enhances cdc45-10, but not CDC45, cell sensitivity to CPT or $\mathrm{HU}$

$\mathrm{Cdc} 45, \operatorname{cdc} 45^{\mathrm{SUMO}}, c d c 45-10$ and $c d c 45^{S U M O} G^{510} R$ were shuffled in to the cdc $45 \Delta$ plasmid shuffle strain and cell viability was assayed. Mutating the consensus SUMO site in $\mathrm{Cdc} 45$ did not alter cell sensitivity to CPT or HU. However, mutating the consensus SUMO site in $c d c 45-10$ enhanced temperature sensitivity and sensitivity to CPT and HU. 
$c d c 45-10$ at $36^{\circ} \mathrm{C}$. These results suggest that mutation of the consensus SUMO site in Cdc45 does not alter cell sensitivity to CPT or HU; however, substitution of this Lys residue potentiates the defects in $\mathrm{Cdc} 45 \mathrm{G}^{510} \mathrm{R}$ function responsible for the tah phenotype of $c d c 45-10$ cells at $36^{\circ} \mathrm{C}$.

We next asked if the SUMO site mutation had any impact on the synthetic lethality of the double $c d c 45-10, d p b 11-10$ mutant. The vectors were transformed into $c d c 45-10, d p b 11-10$ cells and the viability of individual transformants was assayed at $26^{\circ} \mathrm{C}$ and $36^{\circ} \mathrm{C}$. As shown in Fig. 2.18 , cdc $45^{\mathrm{SUMO}}$ was not able to complement the synthetic lethal interactions of $c d c 45-10$ and $d p b 11-10$, suggesting that SUMO modification is required for the functional association of Cdc45 with Dpb11.

\subsection{DISCUSSION}

Cdc45 plays essential roles in DNA replication, both in the initiation of DNA replication and in processive DNA polymerization. In addition to recruiting replication factors necessary for origin firing, $\mathrm{Cdc} 45$ also acts as a processivity factor for the replicative Mcm2-7 helicase. Indeed, chromatin immunoprecipitation of crosslinked Cdc45-DNA complexes, followed by queries of high density tiling arrays of yeast chromosome VI, demonstrate that Cdc45 is associated with ARS sequences in G1 phase of the cell cycle, yet tracks with the replication fork following origin firing. We previously reported that $\mathrm{Cdc} 45$ also plays a role in protecting cells from low levels of DNA damage induced by the CPT mimetic, Top $1 \mathrm{~T}^{722} \mathrm{~A}$. The conditional $c d c 45-10$ mutant harbors a single amino acid substitution, $\mathrm{G}^{510} \mathrm{R}$, and is hypersensitive to CPT, HU and $\mathrm{UV}$ at $36^{\circ} \mathrm{C}$. Upon shift to $36^{\circ} \mathrm{C}$ in the absence of DNA damage, these cells exhibit a 

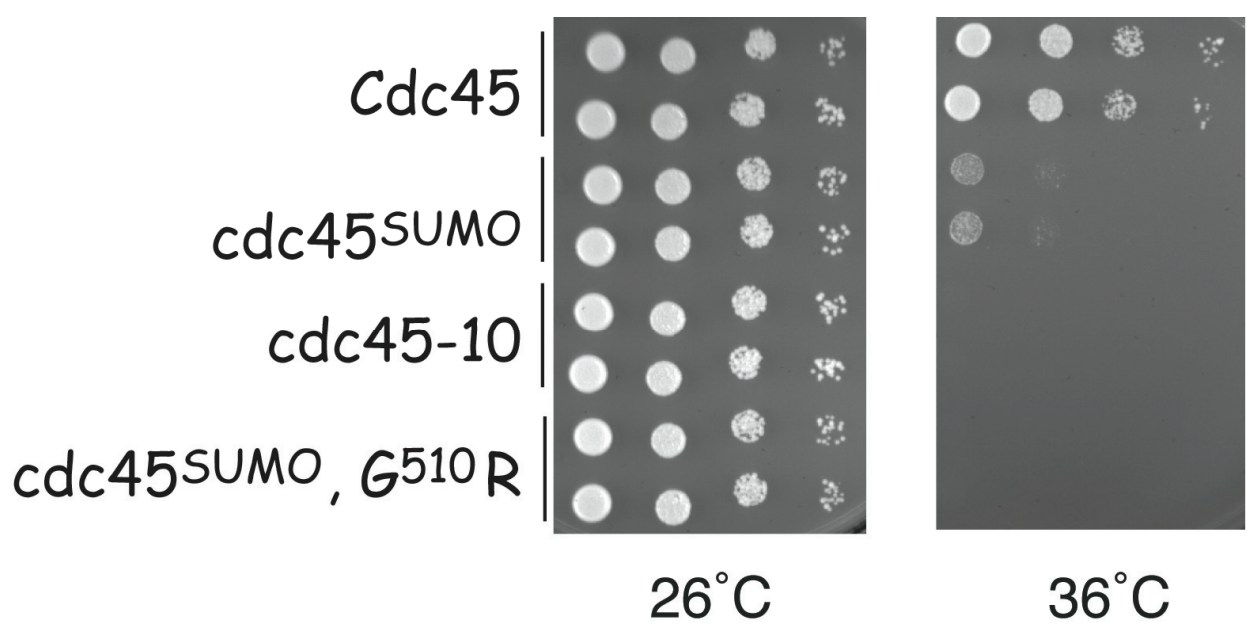

Fig. $2.18 \mathrm{Cdc}^{\mathrm{SUMO}}$ did not restore cell viability to the $c d c 45-10, \mathrm{dpb} 11-10$ double mutant strain

$\mathrm{Cdc} 45, \mathrm{cdc} 45^{\mathrm{SUMO}}, c d c 45-10, c d c 45^{\mathrm{SUMO}} G^{510} R$ plasmids were transformed into the $c d c 45-10, d p b 11-10$ double mutant strain and cell viability was assayed at $26^{\circ} \mathrm{C}$ and $36^{\circ} \mathrm{C}$. $\operatorname{cdc} 45^{\mathrm{SUMO}}$, cdc $45-10$ or cdc $45^{\mathrm{SUMO}}, \mathrm{G}^{510} \mathrm{R}$ was not able to restore cell viability to the double mutant strain at $36^{\circ} \mathrm{C}$. 
transient defect in Okazaki fragment maturation. We previously reported that this mutant also exhibits a synthetic lethal interaction with another tah mutant, $d p b 11-10$, which coincides with a persistent accumulation of Okazaki sized DNA fragments. The $c d c 45-10$ mutant also exhibits a slow growth phenotype when $R A D 9$ is deleted suggesting that the damage accumulating in $c d c 45-10$ cells is sensed by the Rad9 DNA damage checkpoint. Indeed, this mutant also exhibits synthetic lethal interactions with $\operatorname{mrc} 1 \Delta$ and $\operatorname{rad} 52 \Delta$ (data not shown), which is consistent with defects in processive DNA polymerization that require the Mrc1 checkpoint and homologous recombination for effective resolution of the Okazaki fragments.

In these studies, we provide direct evidence that $c d c 45-10$ is hypomorphic for cellular resistance to Top1-induced DNA damage, as increased gene dosage of the mutant allele restored cell resistance to low levels of Top1-DNA damage as well as the slow growth of this mutant at $36^{\circ} \mathrm{C}$. However, as $c d c 45-10$ failed to dosage suppress the synthetic lethality of $c d c 45-10, d p b 11-10$ cells, these findings support a model whereby the functional interactions that are essential to maintain cell viability and Okazaki fragment maturation are distinct from the activity of $\mathrm{Cdc} 45$ needed to protect cells from Top1 poisons. Indeed, the results of the genetic screen for HCS of $c d c 45-10$ cell sensitivity to Top $1 \mathrm{~T}^{722} \mathrm{~A}$ also demonstrated that HCS81 and HCS86 failed to complement the temperature sensitive lethality of $c d c 45-10, d p b 11-10$ cells. An alternative explanation is that the shared defect in $c d c 45-10, d p b 11-10$ cells is more severe than that of $c d c 45-10$ in the presence of wild-type $D P B 11$, ergo the synthetic lethal phenotype. However we favor the former interpretation since mutation of Lys385 within the 
consensus SUMO site in Cdc45 abolished $c d c 45-10, d p b 11-10$ cell viability, yet had no effect on cell sensitivity to Top $1 \mathrm{~T}^{722} \mathrm{~A}$ or cell growth.

Our attempts to develop epitope tagged versions of the $\mathrm{Cdc} 45 \mathrm{G}^{510} \mathrm{R}$ mutant protein with which to assess alterations in Cdc45 levels, chromatin association, proteinprotein interactions, and subcellular distribution were unsuccessful. Nevertheless, these experiments clearly demonstrated that the C-terminal modifications of Cdc $45 \mathrm{G}^{510} \mathrm{R}$ completely abrogated the essential function of this protein. These findings indicate a functional interaction between the C-terminus of $\mathrm{Cdc} 45$ and residues spanning $\mathrm{Gly}^{510}$. Since Gly is a very flexible amino acid, it is tempting to speculate that a change in protein architecture induced by the loss of Gly at this position is responsible for the tah phenotype of $c d c 45-10$ cells. However, such considerations of mutant protein function will have to await the X-ray structure of Cdc45.

The analysis of wild-type Cdc45 bearing a C-terminal HA tag also revealed some surprises. Although such constructs have been used extensively to assess Cdc 45 association with chromatin and it's association with other cellular components, we found that $\mathrm{Cdc} 45-\mathrm{HA}$ was unable to suppress the synthetic lethality of $c d c 45-10, d p b 11-10$, while untagged Cdc45 did. These data demonstrate that the C-terminal HA residues altered the activity of Cdc45 in vivo. Moreover, these data raise the distinct possibility that additional functions for $\mathrm{Cdc} 45$ may yet be defined that are abolished or diminished in strains expressing Cdc45-HA. While the peptide-based antibodies generated in these studies were useful in assessing Cdc 45 proteins in westerns blots, they proved ineffective in immunoprecipitation experiments. Thus, questions concerning alterations in mutant 
Cdc45 interactions with Dpb11, Mcm5 or other components of the replication machinery will require the generation of additional antibodies.

The isolation of HCS81 and HCS86 as dosage suppressors of $c d c 45-10$ cell sensitivity to Top $1 \mathrm{~T}^{722} \mathrm{~A}$ suggested specific defects in $\mathrm{Cdc} 45 \mathrm{G}^{510} \mathrm{R}$ function. First, our determination that ARS1303 was responsible for the dosage suppression induced by HCS81 suggests a defect in origin licensing or firing in $c d c 45-10$ cells. Indeed, the presence of two origins of replication ( $2 \mu \mathrm{m}$ and ARS1303) in the URA3 marked YEp vector also partially suppressed the tah phenotype of $d p b 11-10$ and tah11-10. Since $C D C 45, D P B 11$ and $T A H 11$ each provide essential functions in the initiation of replication, these findings suggest the mutants are defective in the replication and, therefore, the maintenance of plasmid DNA. The presence of an additional ARS may increase the likelihood of at least one origin firing per cell cycle. The temporal pattern and efficiency of ARS firing on yeast chromosome III have been well characterized. However, considerably less is known about ARS1303. Other ARS sequences were not isolated in our yeast HCS screen. Although the screen was not saturated, the sole isolation of ARS1303 raises the possibility that a unique feature of ARS1303 may be critical for this dosage suppression. Some origins, such as ARS305 fire early and efficiently in S-phase, while ARS309 fires late. ARS301 is a cryptic origin that only fires in Rad53 checkpoint defective strains exposed to DNA damaging agents. Whether any or all of these ARS sequences would also act as dosage suppressors of cdc45-10 or if ARS1303 function is uniquely enhanced by the defects in $c d c 45-10$, tah11-10 or $d p b 11$ 10 cells have yet to be defined. 
In the case of HCS86, the ability of the SIZ1 to restore $c d c 45-10$ or $u b c 9-10$ cell viability in the presence of Top $1 \mathrm{~T}_{722} \mathrm{~A}$ at $36^{\circ} \mathrm{C}$ suggests that SUMOylation of specific target proteins is required to protect cells from Top1 poisons. While mutation of the Cdc45 SUMO consensus site ( $\left(\mathrm{Cys}^{385}\right.$ ) did not alter cell sensitivity to $\mathrm{CPT}$ or $\mathrm{HU}$ at $36^{\circ} \mathrm{C}$, this mutation in the context of $c d c 45-10$ enhanced the temperature sensitivity and CPT and $\mathrm{HU}$ sensitivity of these cells at $36^{\circ} \mathrm{C}$. Moreover, $\mathrm{Cdc} 45^{\mathrm{SUMO}}$ was not able to restore cdc45-10,dpb11-10 cell viability, suggesting that SUMO modification of Cdc45 is a critical determinant of the functional interaction of Cdc45 and Dpb11.

Mutations in genes that encode proteins involved in the SUMO pathway have also been shown to induce cell cycle defects (40). For instance, yeast Smt3 (SUMO) was first identified in a screen for high copy suppressors of mutants of MIF2, which encodes a centromere binding protein. SUMO E1 (uba2-ts) and ubc9-ts mutants exhibit cell cycle defects and arrest at the G2/M boundary. On the other hand, SUMO modification of target proteins is typically very transient, such that only a small percentage of a given protein is SUMOylated at any one time. Thus, sensitive detection methods are often employed to ascertain whether a specific protein is actually SUMOylated, under a limited set of experimental conditions. Several large-scale proteomic analyses have identified SUMO substrates that are involved in many cellular processes including cell cycle, DNA replication, repair and recombination. For example, PCNA, the DNA polymerase sliding clamp, is SUMOylated in a cell cycle regulated manner, suggesting this modification is important for events occurring S-phase (41). SUMOylation of PCNA in response to DNA damage also promotes error-prone synthesis through recruitment of a translesion polymerase (42). DNA topoisomerase I itself has been shown to be modified by SUMO, 
however, the consequence of this modification is debatable (30). Although our data implicate SUMOylation as a determinant of Cdc45 function, we have yet to ascertain whether Cdc45 itself is modified, or if SUMO conjugation of other replication proteins indirectly impacts the function of $\mathrm{Cdc} 45$ is protecting cells from Top1 poisons. 


\section{CHAPTER 3: CDC45 ORIGIN FIRING AND REPLICATION FORK PROGRESSION}

\subsection{INTRODUCTION}

DNA replication is fundamental for the maintenance and growth of eukaryotic organisms (43). Chromosomal DNA must be replicated once and only once during S-phase to ensure the faithful transmission of genetic information to daughter cells (12). DNA replication is a complex process involving stringent regulatory mechanisms that couple replication to cell cycle progression (11). Failure to coordinate replication with cellular pathways such as cell cycle progression, checkpoints, recombination, repair and sister chromatid cohesion could result in chromosomal lesions or mutations leading to genomic instability, cell death or cancer (12).

The budding yeast, Saccharomyces cerevisiae, has been proven to be a particularly tractable model system for identifying components of the DNA replication machinery due to the distinctive growth patterns that allow cell division cycle $(c d c)$ phenotypes to be easily distinguished from defects in other cellular processes (44). In $S$. cerevisiae, DNA replication is initiated at restricted regions called autonomously replicating sequences (ARS). As diagrammed in Fig. 3.1, the six-subunit origin recognition complex (ORC) binds ARS throughout the cell cycle. At the end of mitosis the pre-replicative complex (pre-RC) consisting of the Mcm2-7 complex, Cdc6 and Tah11binds to ARS, licensing cells for DNA replication. As cells transition through late G1 phase, Cdc45 binds to the Mcm2-7 complex. As the pre-RC and initiation complexes are assembled, the cyclin dependent kinases, $\mathrm{Cdc} 28 / \mathrm{Clb5} / \mathrm{Clb} 6$ and $\mathrm{Cdc} 7 / \mathrm{Dbf} 4$, become 


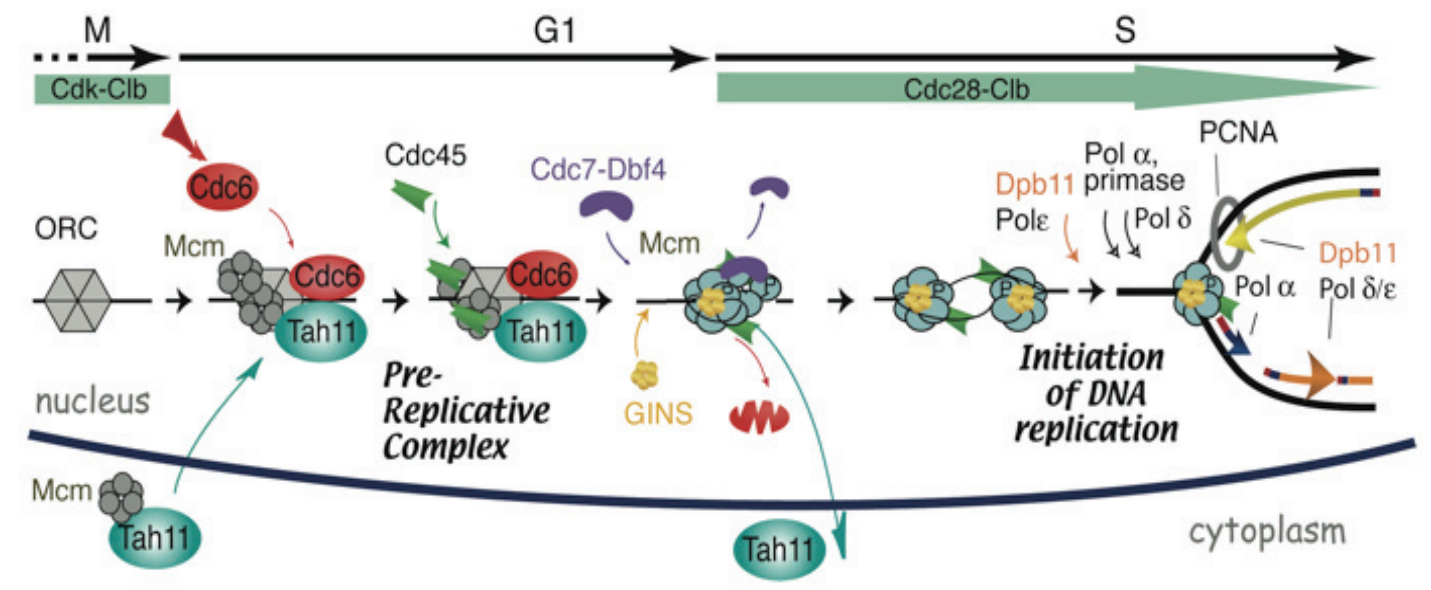

\section{Fig. 3.1 DNA replication}

At the end of mitosis a decrease in Cdk-Clb kinase activity allows pre-replicative complex formation consisting of Orc, Mcm2-7, Tah11 and Cdc6. Cells pass through "START" in G1-phase committing them to DNA replication. As cell begin to transit from late G1 to S-phase Dbf4-Cdc7 and Clb5/6-Cdc28 protein kinases become active and phosphorylate components of the pre-RC promoting the recruitment of Cdc 45 and GINS. Once DNA replication is initiated, Dpb11 recruits Pol $\varepsilon$ and facilitates the switch between Pol $\alpha$ and Pol $\varepsilon$. Mcm2-7, GINS and Cdc45 move with replication forks as elongation occurs. 
active and phosphorylate components of the pre- $\mathrm{RC}$ and $\mathrm{Cdc} 45$ resulting in stable protein-protein interactions (45). In particular, the binding of the GINS complex stabilizes the association of $\mathrm{Cdc} 45$ with $\mathrm{Mcm} 2-7$ to facilitate the processive activity of the replicative helicase during the elongation phase of DNA replication.

Cdc45 is an essential protein that is required for the initiation and elongation steps of DNA replication. The binding of $\mathrm{Cdc} 45$ to the $\mathrm{Mcm} 2-7$ complex at the origin is a critical event for origin firing. Following Cdc45 binding and initiation of replication, the origin DNA unwinds allowing the replicative machinery to bind and synthesis to progress. The initial step in elongation is the synthesis of a short RNA primer laid down by Pol $\alpha$ primase. Pol $\alpha$ is then replaced with the more processive polymerases delta $(\Delta)$ and epsilon $(\varepsilon)$ through the action of PCNA, the "sliding clamp" processivity factor and replication factor $\mathrm{C}(\mathrm{Rfc})$, the clamp-loading complex. DNA is synthesized as leading and lagging strands. Leading strand synthesis is very efficient and highly processive, while lagging strand synthesis requires multiple cycles of priming and extension. Lagging strand synthesis results in Okazaki fragments that must be processed by nucleases and DNA ligase to create a single DNA chain. To protect the underlying DNA and ensure completion of DNA synthesis, leading and lagging strand synthesis remains coupled throughout synthesis (10).

Two-dimensional neutral/neutral gel (2-D gel) electrophoresis has been extensively used to describe the conformational changes that occur in replication intermediates during the initiation and elongation steps of DNA replication (12). This method was derived by analyzing circular DNA on agarose gels and demonstrated that different shapes of a DNA molecule influences its electrophoretic mobility. Supercoiled 
and nicked circular DNA have mobilities that differ from linear molecules of the same mass. Branch molecules also run irregularly in agarose gels and this is influenced by the agarose concentration and the strength of the electric field (46). Based on these properties, Bell and Byers developed the 2D agarose gel method to separate linear molecules from branched intermediates (47). The first dimension gel is run under conditions that minimize the effect of molecular shape and separates molecules according to their mass. The second dimension gel is run under conditions that emphasize the effect of shape and separates the molecules accordingly $(46,48)$.

The first step in analyzing replication intermediates in 2D gels involves enriching the samples with replication intermediates by synchronizing the cells in G1 phase and harvesting the DNA during S-phase. The DNA molecules isolated are delicate branched molecules and precautions must be taken in order to preserves the integrity of the DNA at the fork. As described in Fig. 3.2, the genomic DNA is digested with restriction enzymes to create fragments specific to the chromosomal regions of interest. These fragments are run in a low percentage first dimension gel. The portion of the first dimension gel containing the restriction fragments of interest is cut, rotated $90^{\circ}$ and embedded in a higher percentage agarose second dimension gel. Electrophoresis is carried out in the presence of ethidium bromide to aid in separating the shapes of the replication intermediates. Following electrophoresis, the gel is subjected to Southern blotting and the membrane is hybridized with a ${ }^{32} \mathrm{P}$ labeled probe in order to visualize the replication intermediates at origins or surrounding chromosomal regions of interest (46). Fig. 3.3 diagrams the shapes of restriction fragments derived from replicating DNA. The $1 n$ spot located on the linear molecule line represents non-replicating molecules. Replication 


\section{Chromosome III}

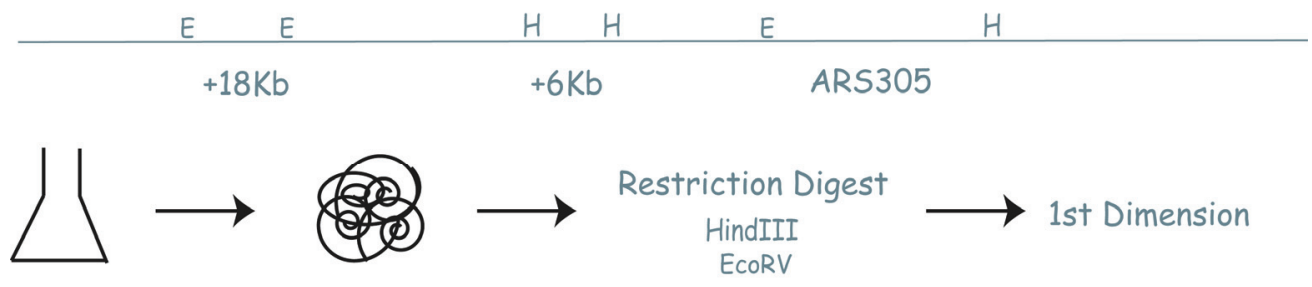

1st Dimension

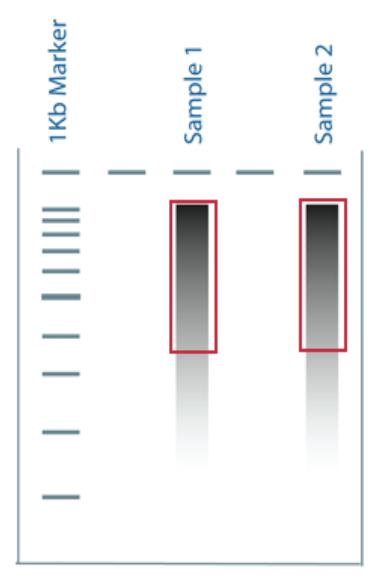

2nd Dimension

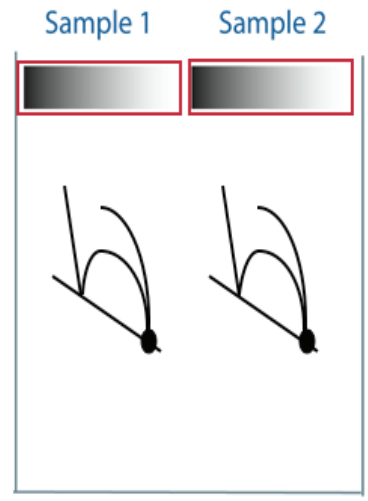

Fig. 3.2 Replication intermediate isolation and viualization by 2-D gel electrophoresis

Cells are synchronized in early G1 and released into S-phase. Genomic DNA is extracted from replication intermediates, restriction digested with HindIII and EcoRV and separated by size in the first dimension. Fragments of $3.5 \mathrm{~Kb}$ and larger are excised from the first dimension, rotated $90^{\circ}$, and separated in the second dimension by shape. Second dimension gels are blotted and probed for regions of interest on chromosome III. 


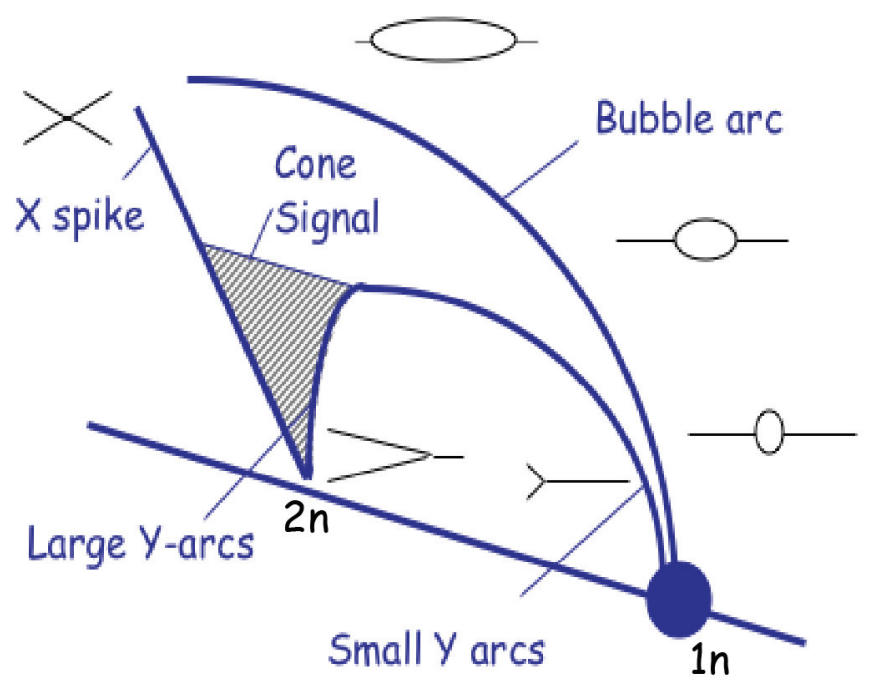

Fig. 3.3 Shapes of replication intermediates

Non-replicating molecules are represented by a $1 n$ spot located on the linear molecule line. Replication that is initiated within a restriction site results in a series of bubble shaped molecules representing initiation of bi-direction replication forks. A restriction fragment lying between an origin and the terminus results in a series of Y shaped molecules formed as a single replication fork moves through the restriction fragment. A $2 n$ spike or X-spike represents the shape of recombination intermediates. 
initiated within a restriction site results in a series of bubble shaped molecules representing initiation of bi-direction replication forks. A restriction fragment lying between an origin and the terminus results in a series of $Y$ shaped molecules formed as a single replication fork moves through the restriction fragment. A $2 n$ spike or X-spike represents the shape of recombination intermediates.

The isolation of the $c d c 45-10$ hypomorphic allele that conferred hypersensitivity to the CPT mimetic, $\mathrm{Top}_{1 \mathrm{~T}} \mathrm{~T}^{722} \mathrm{~A}$, supported a role for $\mathrm{Cdc} 45$ in protecting cells against Top1-DNA damage. Because Cdc45 is essential for the initiation and elongation steps of DNA replication, assessing origin firing and replication fork progression in $c d c 45-10$ cells provided a unique opportunity to assess whether $\operatorname{Cdc} 45 \mathrm{G}^{510} \mathrm{R}$ was defective in either of these two fundamental steps. Indeed, using 2-D agarose gel analysis, we report that $\mathrm{Cdc} 45 \mathrm{G}^{510} \mathrm{R}$ caused a decrease and a delay in origin firing at ARS305 when $c d c 45-10$ cells were shifted from $26^{\circ} \mathrm{C}$ to $36^{\circ} \mathrm{C}$ after release from $\alpha$-factor arrest, with no apparent alterations in replication fork progression. These results contrasted with the fragility of the replication forks that was observed when $c d c 45-10$ cells were shifted to the nonpermissive temperature prior to cell cycle arrest in G1-phase. Under these conditions, the licensing of origins at $36^{\circ} \mathrm{C}$ impaired the stability of the replication forks in S-phase. Thus, Cdc45 function is required to ensure the timely firing of an early replication origin and for the appropriate assembly of the replication machinery necessary to support processive replication. 


\subsection{EXPERIMENTAL PROCEDURES}

\subsubsection{Chemicals and yeast strains}

The mating pheromone $\alpha$-factor, purchased from US Biological, was stored at $-20^{\circ} \mathrm{C}$ at $1 \mathrm{mg} / \mathrm{ml}$ in methanol and used at a final $5 \mu \mathrm{g} / \mathrm{ml}$ or $10 \mu \mathrm{g} / \mathrm{ml}$.

S. cerevisiae strains, cultured using standard conditions, were CSY6 (MATa, ura3-52, his3 4200, leu2 41 , TRP1) and CLY16 (MATa, ura3-52, his3 4200 , leu2 $\Delta 1$, TRP1, TOP1, cdc45-10).

\subsubsection{Analysis of cell cycle progression and 2-D gel electrophoresis of replication intermediates}

Asynchronous cultures of isogenic $C D C 45$ and $c d c 45-10$ cells, exponentially growing at $26^{\circ} \mathrm{C}$, were diluted to an $\mathrm{OD}=0.3$, then treated with $5 \mu \mathrm{g} / \mathrm{ml} \alpha$-factor to induce cell cycle arrest in G1 phase. After 60 minutes the cells were shifted to $36^{\circ} \mathrm{C}$ and an additional $2.5 \mu \mathrm{g} / \mathrm{ml} \alpha$-factor was added, when greater than $95 \%$ of the cells exhibited a schmoo phenotype indicative of $\alpha$-factor arrest, the cells were released into S-phase by filtration and resuspended in media pre-warmed to $36^{\circ} \mathrm{C}$. Alternatively, cells cultured at $36^{\circ} \mathrm{C}$, were arrested with $10 \mu \mathrm{g} / \mathrm{ml}$ a-factor for 60 minutes, and treated with an additional $5 \mu \mathrm{g} / \mathrm{ml} \alpha$-factor for 60 minutes. As above, cells were then released into S-phase in media pre-warmed to $36^{\circ} \mathrm{C}$. At the times indicated, aliquots of the cells were collected by centrifugation for western blot analysis (see below) or fixed with 100\% ethanol and processed for FACs analysis as described (49). 
Replication intermediates were also purified at $0 \mathrm{~min}, 10 \mathrm{~min}, 20 \mathrm{~min}, 40 \mathrm{~min}, 60$ min, or 80 min following release of cells from $\alpha$-factor into YPD as described (12). To analyze $A R S 305, A R S 305+6 \mathrm{~Kb}, A R S 305+18 \mathrm{~Kb}$ or $A R S 305+29 \mathrm{~Kb}$ replication intermediates, purified DNA, restricted with Eco RV and Hind III, was resolved by 2-D gel electrophoresis, transferred to nylon membranes, successively hybridized with ${ }^{32} \mathrm{P}-$ labeled probes spanning $A R S 305, A R S 305+6 \mathrm{~Kb}, A R S 305+18 \mathrm{~Kb}$ or $A R S 305+29 \mathrm{~Kb}$ and visualized by PhosphorImage analysis. The probes were first PCR amplified from genomic DNA (primer pairs available upon request), then $\alpha-{ }^{32} \mathrm{P}-\mathrm{dATP}$ labeled using a Megaprime DNA Labeling kit from Amersham.

\subsubsection{Western blot analysis}

To assess $\mathrm{Cdc} 45$ and $\mathrm{Cdc} 45 \mathrm{G}^{510} \mathrm{R}$ protein levels, $\mathrm{NaOH} / \mathrm{TCA}$ extracts were prepared from cells following release from $\alpha$-factor as described (30). Cdc45 proteins were detected by immunoblotting with a rabbit polyclonal Cdc 45 antibody, followed by an HRP-conjugated donkey anti-rabbit antibody and chemiluminescence (Pierce). Immunostaining with tubulin antibodies served as loading controls.

\subsection{RESULTS}

Cdc45 is required for the initiation and elongation phases of DNA replication. We previously reported that $c d c 45-10$ mutant cells were hypersensitive to Top1-induced DNA damage. These cells also exhibited a transient accumulation of Okazaki-sized DNA fragments upon shift to the non-permissive temperature that suggested a defect in processive DNA replication. While these findings suggested that alterations in 
$\mathrm{Cdc} 45 \mathrm{G}^{510} \mathrm{R}$ function impaired the elongation of phase of DNA replication, they failed to define the exact nature of this defect. To more precisely address this question, we used 2D agarose gel electrophoresis to investigate the efficiency of origin firing and replication fork progression in $c d c 45-10$ cells. To discriminate between defects in origin licensing in G1-phase and processive DNA replication in S-phase, two experimental approaches were taken.

As diagrammed in Fig. 3.4A, to address Cdc45 function in the elongation phase of DNA replication, the cells were $\alpha$-factor arrested in G1 phase of the cell cycle at the permissive temperature of $26^{\circ} \mathrm{C}$, then released into S-phase at $36^{\circ} \mathrm{C}$. Under these conditions, $\mathrm{Cdc} 45 \mathrm{G}^{510} \mathrm{R}$ function in origin licensing would occur at the permissive temperature, while DNA replication would be initiated at the non-permissive temperature for $\mathrm{Cdc} 45 \mathrm{G}^{510} \mathrm{R}$. This contrasts with the experimental design diagrammed in Fig. 3.4B, where the mutant and wild-type cells are shifted to $36^{\circ} \mathrm{C}$ prior to $\alpha$-factor arrest in G1phase. In this case, both origin licensing and replication occur at the non-permissive temperature for $\mathrm{Cdc} 45 \mathrm{G}^{510} \mathrm{R}$. A comparison of these data would then allow us to define the consequences of defects in Cdc45 function in both phases of the cell cycle. At the permissive temperature of $26^{\circ} \mathrm{C}, c d c 45-10$ cells exhibit a subtle slow growth phenotype in the absence of exogenous DNA damage, which corresponds to a slight delay in S-phase transit relative to isogenic wild-type cells cultured under the same conditions (data not shown and the FACs profiles shown in Fig. 3.5). However, a survey of several $A R S$ s, including $A R S 305$ and $A R S 607$, failed to reveal any obvious defect in origin firing (data not shown). However, this was not the case when $c d c 45-10$ cells were either shifted to $36^{\circ} \mathrm{C}$ prior to S-phase transit, or cultured at $36^{\circ} \mathrm{C}$. 


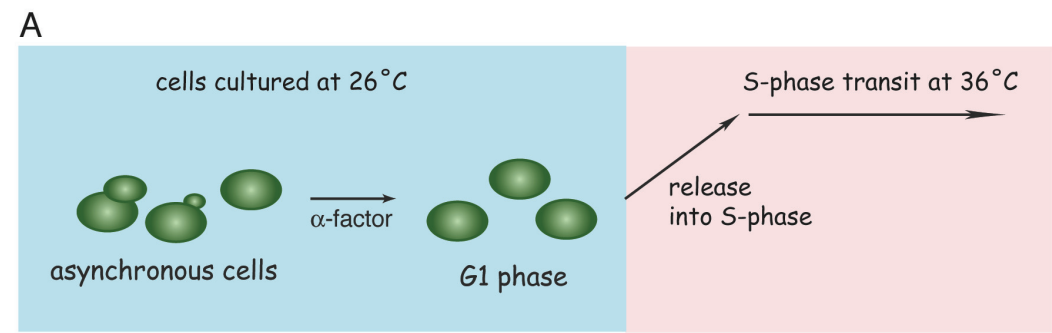

B

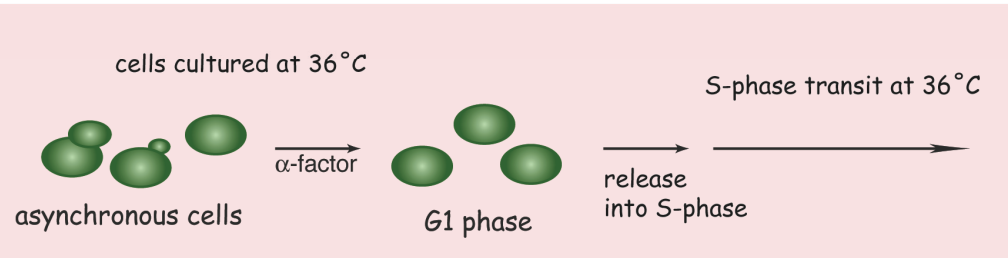

Fig. 3.4 Experimental approaches for defining defects in origin licensing in G1phase and processive DNA replication in S-phase

(A) $C D C 45$ and $c d c 45-10$ cells were cultured at $26^{\circ} \mathrm{C}$, synchronized in late G1-phase using $\alpha$-factor and released into S-phase at $36^{\circ} \mathrm{C}$.

(B) $C D C 45$ and $c d c 45-10$ cells were cultured at $36^{\circ} \mathrm{C}$, synchronized in late G1-phase using $\alpha$-factor and released into S-phase at $36^{\circ} \mathrm{C}$. 


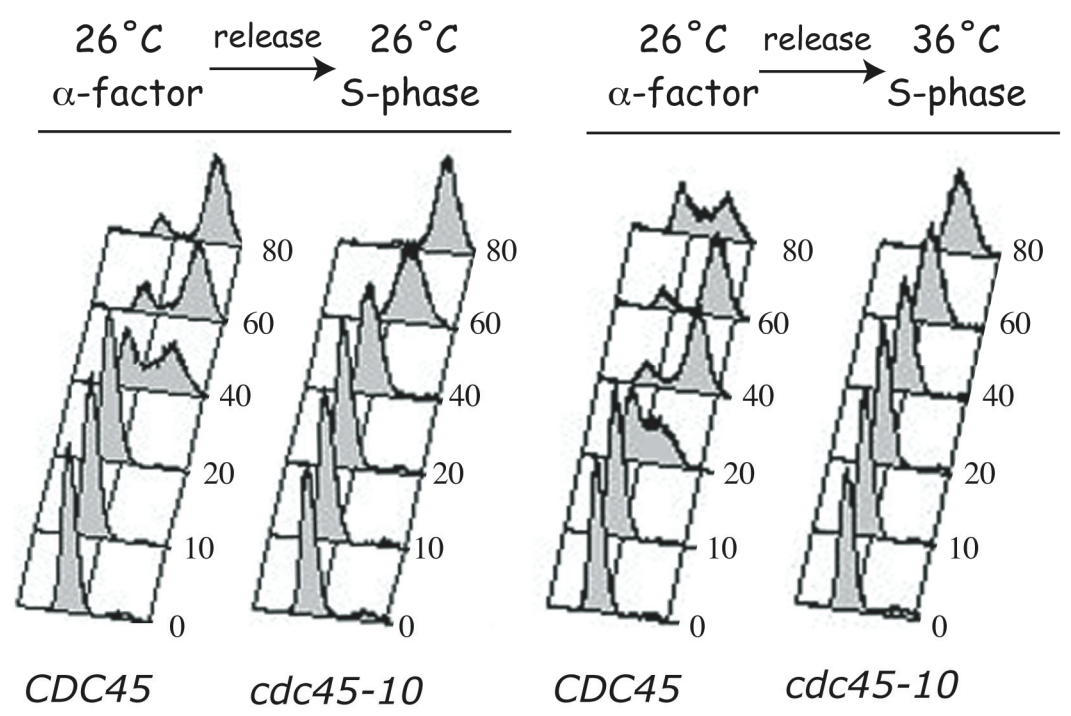

Fig. 3.5 CDC45 and $c d c 45-10$ S-phase transit at $26^{\circ} \mathrm{C}$ and $36^{\circ} \mathrm{C}$

At $26^{\circ} \mathrm{C}, c d c 45-10$ cells exhibit a subtle slow growth phenotype in the absence of exogenous DNA damage compared to $C D C 45$, however, when $c d c 45-10$ cells were shifted to $36^{\circ} \mathrm{C}$, the slow S-phase transit was exacerbated. 
In the first case, i.e., following synchronization in late $\mathrm{G} 1$ at $26^{\circ} \mathrm{C}, C D C 45$ and cdc45-10 cells were shifted to $36^{\circ} \mathrm{C}$ upon release into S-phase. Aliquots of cells were collected at time $0,10,20$ and 40 minutes following $\alpha$-factor release. The replication intermediates were extracted, digested with restriction enzymes specific for the regions of interest on chromosome III and separated in an agarose gel on the basis of size. The portion of the first dimension gel containing restriction fragments of 3.5 kilobases $(\mathrm{Kb})$ and larger were excised, rotated $90^{\circ}$ and the replication intermediates were then separated in the second dimension on the basis of shape. The DNA was then transferred to a nylon membrane and successively hybridized with ${ }^{32} \mathrm{P}$-labeled probes specific for regions spanning the left arm of chromosome III. The temporal pattern of $A R S$ firing and replication fork progression have been extensively characterized for chromosome III. In wild-type cells, bi-directional DNA replication initiates at ARS305 early in S-phase. Towards the left telomeric end of chromosome III, the remaining ARS elements, $A R S 301-304$, are cryptic and rarely fire. Thus, the timing of origin firing and the progression of a lone replication fork that uniquely originates at $A R S 305$ can be assessed as the cells synchronously transit S-phase.

As shown in Fig. 3.6, following release into S-phase, $C D C 45$ cells exhibited prominent firing of $A R S 305$ by 10 minutes, as evidenced by the appearance of a bubble arc (arrow). In the FACs profiles of these cells, shown in Fig. 3.5, the cells accumulated a 2n DNA content by 40 minutes. This time frame also coincided with a second, less intense round of DNA replication at ARS305 (Fig. 3.6), as the cells lose synchrony. These data contrast with those obtained with $c d c 45-10$ cells. As seen in Fig. 3.6, there was a delay in the timing of ARS305 firing, as well as the extent of origin firing. A bubble arc 

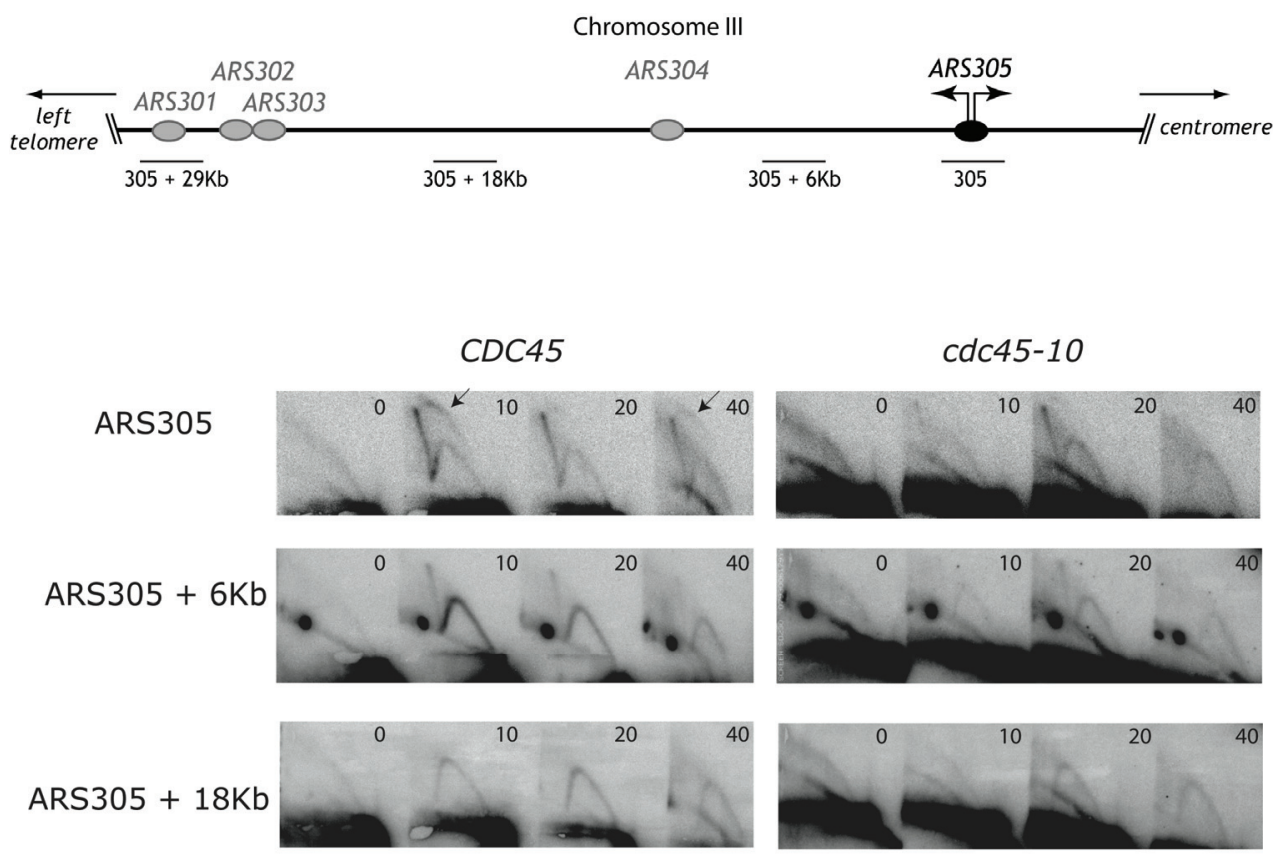

Fig. 3.6 Alterations in Cdc45 function delays and decreases early origin firing but does not affect replication fork progression

$C D C 45$ and $c d c 45-10$ cells were grown at $26^{\circ} \mathrm{C}$, synchronized in late $\mathrm{G} 1$ with $\alpha$-factor and released into S-phase a $36^{\circ} \mathrm{C}$. Replication intermediates were visualized using 2-D gel electrophoresis, blotted and probed for $A R S 305, A R S 305+6 \mathrm{~Kb}$ and $A R S 305+18 \mathrm{~Kb}$. $c d c 45-10$ cells exhibit a delay and decrease in origin firing at $A R S 305$ compared to $C D C 45$ cells. However, successive stripping and re-probing of the blots for regions $6 \mathrm{~Kb}$ and $18 \mathrm{~Kb}$ away from $A R S 305$ revealed that replication fork progression in $c d c 45-10$ cells was similar to that observed in CDC45 cells. 
was not detected until 20 minutes following release into S-phase and the signal was consistently weaker than that observed with $C D C 45$ cells. However, when the blots were stripped of the $A R S 305$ probe and re-probed for sequences $6 \mathrm{~Kb}$ or $18 \mathrm{~Kb}$ towards the left telomeric end of the chromosome, the replication forks appeared to progress with the same kinetics as those detected in $C D C 45$ cells. This decrease in the timing and efficiency of $A R S 305$ firing coincided with a more pronounced decrease in S-phase transit at $36^{\circ} \mathrm{C}$, as seen in the FACs profiles of Fig. 3.5. These data suggest that the alterations in $\mathrm{Cdc} 45 \mathrm{G}^{510} \mathrm{R}$ function in S-phase are restricted to the initiation of DNA replication. However, this $c d c 45-10$ phenotype could not be attributed to the selective thermolability of the $\mathrm{Cdc} 45 \mathrm{G}^{510} \mathrm{R}$ protein in S-phase upon shift to $36^{\circ} \mathrm{C}$. Indeed as seen in Fig. 3.7, there was actually an increase in steady state levels of $C d c 45 \mathrm{G}^{510} \mathrm{R}$ protein, relative to wild-type Cdc45 protein, when cells were released into S-phase. Whether the mutant protein exhibits alterations in chromatin association, and how this might impact Cdc45 protein turnover has yet to be addressed. Nevertheless, the replication defects in $c d c 45-10$ cells are not a consequence of $C d c 45 \mathrm{G}^{510} \mathrm{R}$ down regulation at the nonpermissive temperature.

We next considered the consequences of licensing ARS305 at the non-permissive temperature, as diagrammed in Fig. 3.4B. In these experiments, $C D C 45$ and $c d c 45-10$ cells were cultured at $36^{\circ} \mathrm{C}$, then synchronized in late $\mathrm{G} 1$ phase with $\alpha$-factor and released into S-phase at $36^{\circ} \mathrm{C}$. Aliquots of cells were collected at $0,10,20,40,60$, and 80 minutes after $\alpha$-factor release and the replication intermediates were resolved as above. As shown in Fig. 3.8, the temporal pattern of ARS305 firing in CDC45 cells was similar to that observed in Fig. 3.6. A prominent bubble arc was detected by 10 minutes 


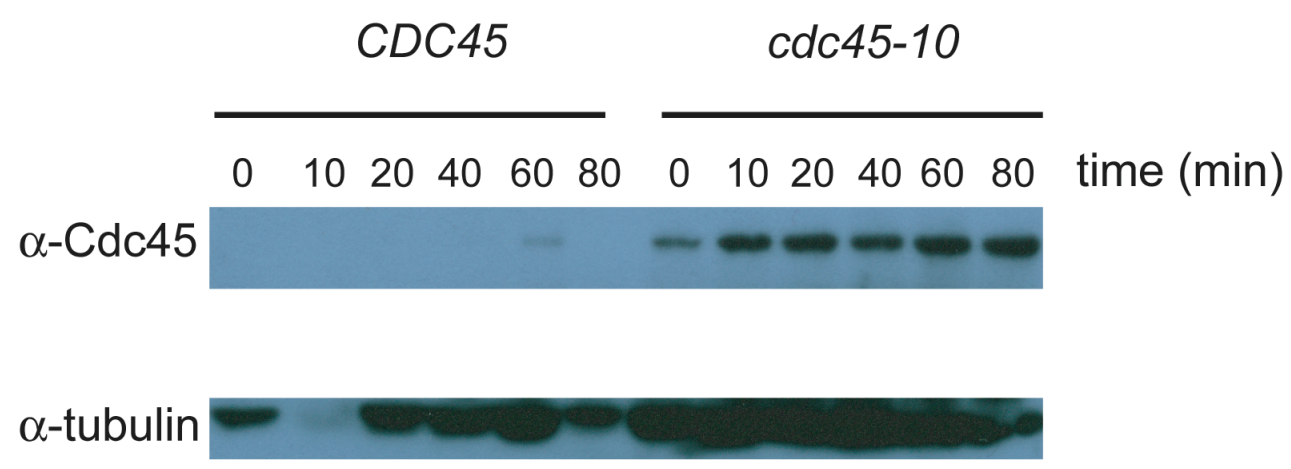

Fig. 3.7 cdc45-10 cells exhibit increased protein levels when origins are licensed at $26^{\circ} \mathrm{C}$ and $\mathrm{S}$-phase transit occurs at $36^{\circ} \mathrm{C}$

$C D C 45$ and $c d c 45-10$ cells were cultured at $26^{\circ} \mathrm{C}, \alpha$-factor arrested and released into Sphase at $36^{\circ} \mathrm{C}$. Time points were collected; whole cell extracts were prepared and visualized on western blots using a $\mathrm{Cdc} 45$ antibody and a tubulin antibody as a control. $c d c 45-10$ cells exhibited an increase in protein level compared to CDC45 cells. 


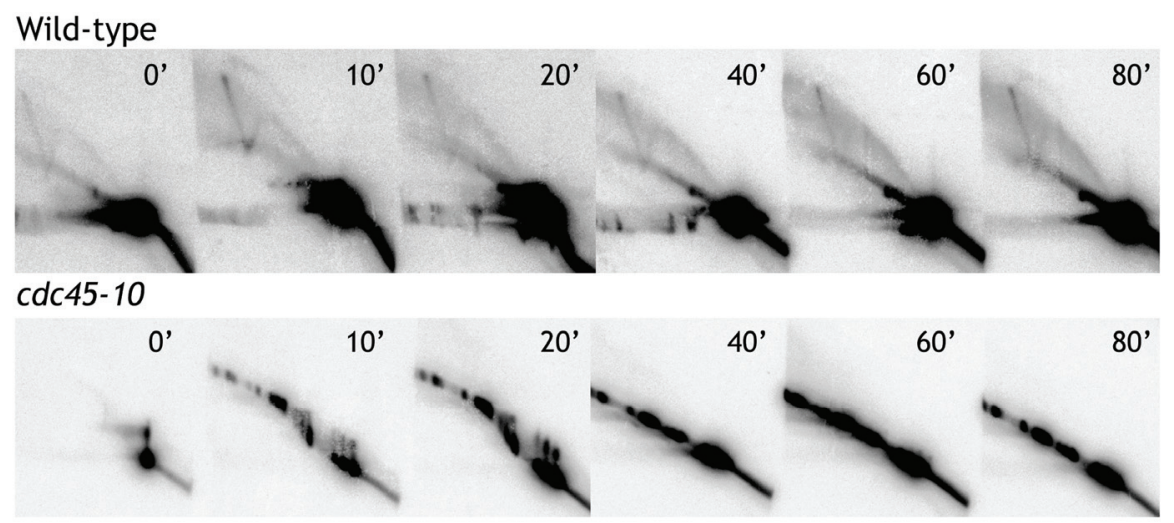

Fig 3.8 Licensing $A R S 305$ at $36^{\circ} \mathrm{C}$ alters replication fork stability in cdc45-10 cells $C D C 45$ and $c d c 45-10$ cells were grown at $36^{\circ} \mathrm{C}$, synchronized in late $\mathrm{G} 1$ with $\alpha$-factor and released into S-phase a $36^{\circ} \mathrm{C}$. Replication intermediates were visualized using 2-D gel electrophoresis, blotted and probed for $A R S 305$. The intermediates isolated from cdc45-10 cells were distributed along a linear diagonal with a DNA mass between 1n and 2n, implying initiation at $A R S 305$ however, the intermediates failed to retain differences in shape. 
following release from S-phase. In this case, a second round of replication was not evident at later times due to a rapid loss of cell cycle synchrony (data not shown). However, the results obtained with $c d c 45-10$ cells were rather remarkable. In contrast to the canonical distribution of replication intermediates along bubble and y-arcs, the intermediates isolated from $c d c 45-10$ cells cultured at $36^{\circ} \mathrm{C}$ were distributed along a linear diagonal with a DNA mass between $1 \mathrm{n}$ and $2 \mathrm{n}$. Thus, although DNA replication had initiated at $A R S 305$ to yield a greater than 1n DNA content, the intermediates failed to retain differences in shape. Replication fork stalling in vivo is typified by the accumulation of a discreet spot along the $\mathrm{Y}$-arc, while replication fork collapse in vivo has been described as an increase in cone and $\mathrm{X}$-spike signals, with a concomitant decrease in bubble and Y-arcs (50). Rather, the pattern obtained in Fig. 3.8 is consistent with replication fork collapse during the isolation of the intermediates. Indeed, this interpretation is consistent with the extended tails emanating from the spots in 0,10 and 20 ' samples. Hybridization of this blot with the ARS305 $+6 \mathrm{~Kb}$ probe revealed a similar, albeit weaker, pattern of spots with very faint $\mathrm{Y}$-arcs discernible in some samples (data not shown). The fragility of these replication intermediates is also mirrored in the FACs profiles, which demonstrate a board distribution of cells throughout S-phase (data not shown), as opposed to the tight distributions that mark the S-phase transit of $c d c 45-10$ cells in Fig. 3.5. However, as in $c d c 45-10$ cells shifted to $36^{\circ} \mathrm{C}$, $\mathrm{Cdc} 45 \mathrm{G}^{510} \mathrm{R}$ protein levels in cells cultured at $36^{\circ} \mathrm{C}$ were also elevated in S-phase, relative to wild-type Cdc 45 protein levels (Fig. 3.9). Taken together, these data indicate that licensing of origins in cdc45-10 cells at $36^{\circ} \mathrm{C}$ altered the assembly of stable replication forks in the subsequent S-phase, while the assembly of pre- $\mathrm{RC}$ complexes at $26^{\circ} \mathrm{C}$, followed by a shift to $36^{\circ} \mathrm{C}$ as 

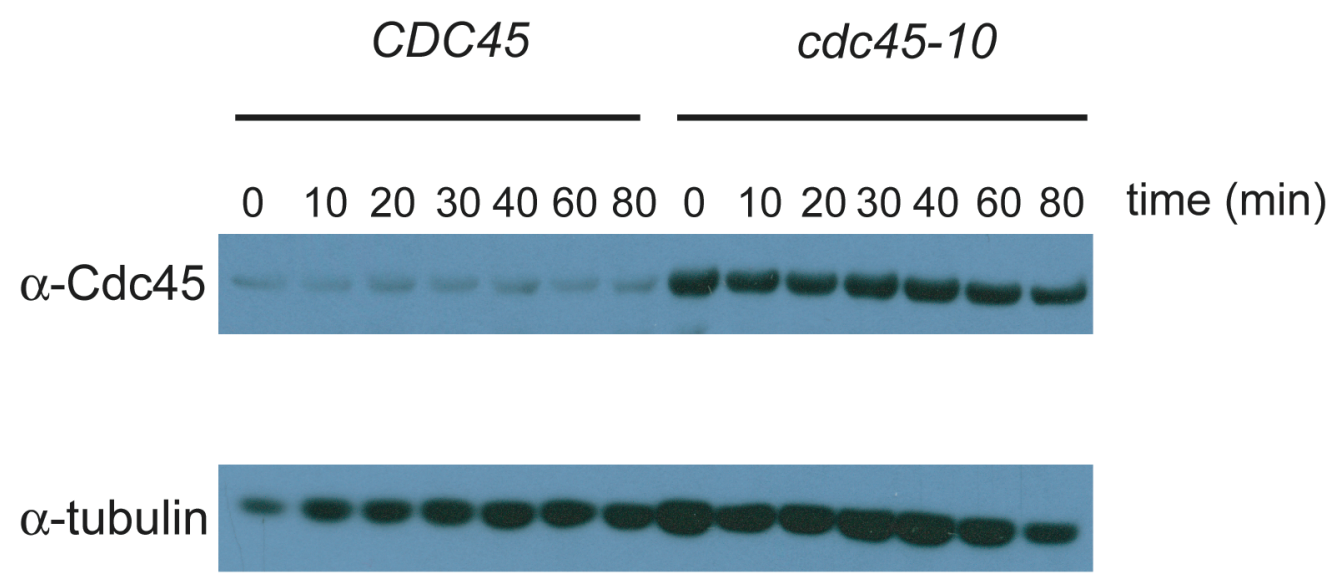

Fig. 3.9 cdc45-10 cells exhibit elevated protein levels when origin licensing and Sphase transit occurs at $36^{\circ} \mathrm{C}$

$C D C 45$ and $c d c 45-10$ cells were cultured at $36^{\circ} \mathrm{C}, \alpha$-factor arrested and released into Sphase at $36^{\circ} \mathrm{C}$. Time points were collected; whole cell extracts were prepared and visualized on western blots using a Cdc 45 antibody and a tubulin antibody as a control. $c d c 45-10$ cells exhibited an increase in protein level compared to CDC45 cells. 
$c d c 45-10$ cells entered S-phase, only affected the temporal pattern and efficiency of origin firing.

\subsection{DISCUSSION}

The $c d c 45-10$ hypomorphic mutant was isolated in a yeast genetic screen for conditional mutants exhibiting enhanced sensitivity to low levels of DNA damage induced by Top $1 \mathrm{~T}^{722} \mathrm{~A}$, a mutant enzyme that acts as a CPT mimetic. Cdc45 is an essential protein that functions in the formation of pre- $\mathrm{RC}$ complexes in late $\mathrm{G} 1$ phase, in the recruitment of replication machinery components to initiate DNA replication and as a processivity factor for the replicative Mcm2-7 helicase during the elongation phase of DNA replication. Cdc45 lacks any identifiable enzymatic activity and any similarity to known protein structural domains, other than a Cdc45-motif found in other members of this conserved protein family. Thus, Cdc45 appears to function as a scaffold for the assembly/recruitment of replication machineries.

Our previous characterization of $c d c 45-10$ cells defined a single $\mathrm{G}^{510} \mathrm{R}$ substitution in Cdc45 that conferred the synthetic lethal interactions of this mutant with defects in Dpb11 function, the Rad9 DNA checkpoint and the Rad52 homologous recombination pathway (data not shown) (22). Low resolution alkaline sucrose gradient analyses indicated a transient accumulation of Okazaki-sized DNA fragments in $c d c 45$ 10 cells upon shift to the non-permissive temperature, which was exacerbated in the double $c d c 45-10, d p b 11-10$ mutant. These data suggested a common defect in polymerase switching induced the synthetic lethality of the double mutant strain (22). However, our recent studies of dosage suppressors in Chapter 2 demonstrate that the alterations in 
$\mathrm{Cdc} 45 \mathrm{G}^{510} \mathrm{R}$ function, which enhance cell sensitivity to Top 1 poisons, are distinct from those that induce the synthetic lethality with $d p b 11-10$.

Indeed, our analysis of origin firing and fork progression in synchronized $c d c 45$ 10 and $C D C 45$ cells cultured under various conditions demonstrate distinct alterations in $\mathrm{Cdc} 45 \mathrm{G}^{510} \mathrm{R}$ function in the assembly of the replication machinery and the temporal regulation of origin firing. In G1-phase, when pre-RC assembly, i.e., licensing of a replication origin, occurs at the non-permissive temperature for $C d c 45 \mathrm{G}^{510} \mathrm{R}$, the replication forks assembled in the subsequent S-phase at $36^{\circ} \mathrm{C}$ were quite fragile. This phenotype was evident in the broad S-phase distribution of these cells (data not shown) and the collapse of the replication intermediates during purification (Fig. 3.8). The fragility of these intermediates precluded any assessment of the relative timing of $A R S 305$ firing or of the rate of replication fork progression. Nevertheless, the instability of these complexes contrasted with the stable replication intermediates isolated from cdc45-10 cells that were shifted to $36^{\circ} \mathrm{C}$ following release from $\alpha$-factor arrest. Thus, the assembly of replication forks at $36^{\circ} \mathrm{C}$ per se had no adverse effect on fork stability. This interpretation of the data is further supported by the relatively tight distribution of $c d c 45$ 10 cellular DNA content as cells transit S-phase at $36^{\circ} \mathrm{C}$ in Fig. 3.5. Rather, these results suggest that alterations in pre-RC assembly, due to specific defects in $C d c 45 \mathrm{G}^{510} \mathrm{R}$ function at $36^{\circ} \mathrm{C}$, impair the subsequent assembly of the replication machinery in Sphase. Cdc45 has been shown to physically interact with Mcm5; thus, it is tempting to speculate that alterations in $\mathrm{Cdc} 45 \mathrm{G}^{510} \mathrm{R}$ binding to Mcm5 could impact fork stability through alterations in helicase activity. Unfortunately, a rigorous assessment of Cdc $45 \mathrm{G}^{510} \mathrm{R}$ interactions with other components of the pre- $\mathrm{RC}$ will have to await the 
development of antibodies capable of immunoprecipitating $C d c 45 \mathrm{G}^{510} \mathrm{R}$, as described in Chapter 2. Nevertheless, such decreases in fork stability provide a mechanistic basis for the synthetic lethal interactions with $\mathrm{rad} 9 \Delta$ and $\mathrm{rad} 52 \Delta$ mutants, as a functional DNA damage checkpoint and homologous recombination, respectively, would enhance cell survival by affecting the repair of collapsed forks. The assembly of fragile forks would also enhance cell sensitivity to Top1 poisons, either as a consequence of direct collisions between the replication machinery and the stabilized Top1-DNA complexes or the local accumulation of positive supercoils in advance of the fork $(8,51,52)$.

The formation of pre-RC at the permissive temperature, followed by S-phase transit at the non-permissive temperature, revealed a role for $\mathrm{Cdc} 45$ in the timing and efficiency of $A R S 305$ firing. These findings suggest that the isolation of $A R S 1303$ as a weak dosage suppressor of $c d c 45-10$ cell sensitivity to $\mathrm{TopT}^{722} \mathrm{~A}$ (reported in Chapter 2), may reflect an increase in plasmid DNA stability, rather than a direct effect on Top $1 \mathrm{~T}^{722} \mathrm{~A}$-induced DNA damage. Whether $d p b 11-10$ cells also exhibit similar defects in origin firing has yet to be determined. Nevertheless, the ability of ARS1303 to dosage suppress $d p b 11-10$ and tah11-10 sensitivity to Top $1 \mathrm{~T}^{722} \mathrm{~A}$ does imply a common mechanism of suppression. However, the transient accumulation of Okazaki-sized DNA fragments observed in both $c d c 45-10$ and $d p b 11-10$ cells (22) upon shift of asynchronous cells to $36^{\circ} \mathrm{C}$, also suggests a common defect in fork stability. Indeed, as will be discussed in Chapter 4, such mutation-induced alterations in fork stability would not only enhance $c d c 45-10$ and $d p b 11-10$ cell sensitivity to Top1 poisons, such as CPT, but would also exacerbate the adverse effects that rapamycin inhibition of TORC1 has on S-phase progression. 


\section{CHAPTER 4: RAPAMYCIN-INDUCED ALTERATIONS IN S-PHASE TRANSIT}

\subsection{INTRODUCTION}

As described in Chapter 2, a yeast genetic screen was used to isolate conditional mutants that exhibit enhanced sensitivity to the self-poisoning Top $1 \mathrm{~T}^{722} \mathrm{~A}$ mutant. Several of these mutants, including hypomorphic alleles of $C D C 45$ and $D P B 11$, exhibit alterations in DNA replication, which exacerbate the S-phase-dependent toxicity of the Top1 poison, camptothecin. Surprisingly, many of these mutants were also hypersensitive to the macrocyclic lactone antibiotic rapamycin (RAP) (53). RAP, in complex with FKBP12, specifically targets TOR (target of rapamycin), a phosphatidylinositol 3-kinaserelated kinase family member that regulates cellular responses to a wide range of environmental stresses such as nutrient starvation, growth factor deprivation and hypoxia. These signals are transmitted by multi-protein complexes through a variety of downstream pathways to regulate cap-dependent mRNA translation, transcriptional stress responses, G1 to S-phase transition and cell survival (54-56). The dysregulation of AktTOR signaling has been associated with tumorigenesis, therefore, this pathway provides potential targets for cancer chemotherapy $(54,57)$. Currently RAP analogs are being developed in clinical oncology trials.

The TOR kinase was initially identified from a genetic screen in S. cerevisiae for mutants conferring resistance to RAP. In S. cerevisiae there are two closely related Tor1 and Tor2 kinases, while other eukaryotic genomes encode a single kinase, as exemplified by mammalian mTOR (56). As in mammalian cells, TOR signaling in yeast regulates cell 
growth through the function of distinct multi-protein complexes as seen in Fig. 4.1 (56,58-60). In yeast, Tor1 or Tor2 is a component of a RAP-sensitive TOR1 complex (TORC1) consisting of Kog1, Lst8 and Tco89. Mammalian TORC1 consists of mTOR, raptor (a Kog1 analog) and mLst8. Under favorable environmental conditions, TORC1 regulates the accumulation of cell mass by controlling the translation initiation of a limited subset of capped mRNAs, nutrient uptake and ribosome biogenesis. RAP treatment or depriving cells of nutrients or essential growth factors induces a starvation response characterized by decreased protein synthesis, macroautophagy and the induction of stress response transcription factors (56).

A second complex, TORC2, is RAP "insensitive" and is involved in regulating actin cytoskeletal organization during cell growth, endocytosis and calcineurin and sphingolipid signaling. Although in some cells, TORC2 is also inhibited as a consequence of long-term exposure to rapamycin (61). Yeast TORC2 consists of Tor2 in complex with other conserved proteins such as Avo3 (rictor in mammalian cells) $(56,62,63)$.

The PI3K-related kinase family members ATM, ATR, DNA-PK, yeast Mec1 and Tel1 have significant roles in repair and checkpoint responses to DNA damage (64). Although a direct role for TOR signaling in S-phase has yet to be defined, several observations suggest that TORC1 may function in response to DNA replication stress. For example, when $\mathrm{p} 53^{-/}$mouse embryo fibroblasts or cancer cells mutant for $\mathrm{p} 53$ are cultured under serum free conditions, RAP treatment induces apoptosis, which coincides with entry into S-phase $(65,66)$. Second, RAP inhibition of mTOR signaling has been shown to enhance the cytotoxic activity of the DNA damaging agent cisplatin $(67,68)$. 
TOR1 and TOR2 - targets of rapamycin in yeast

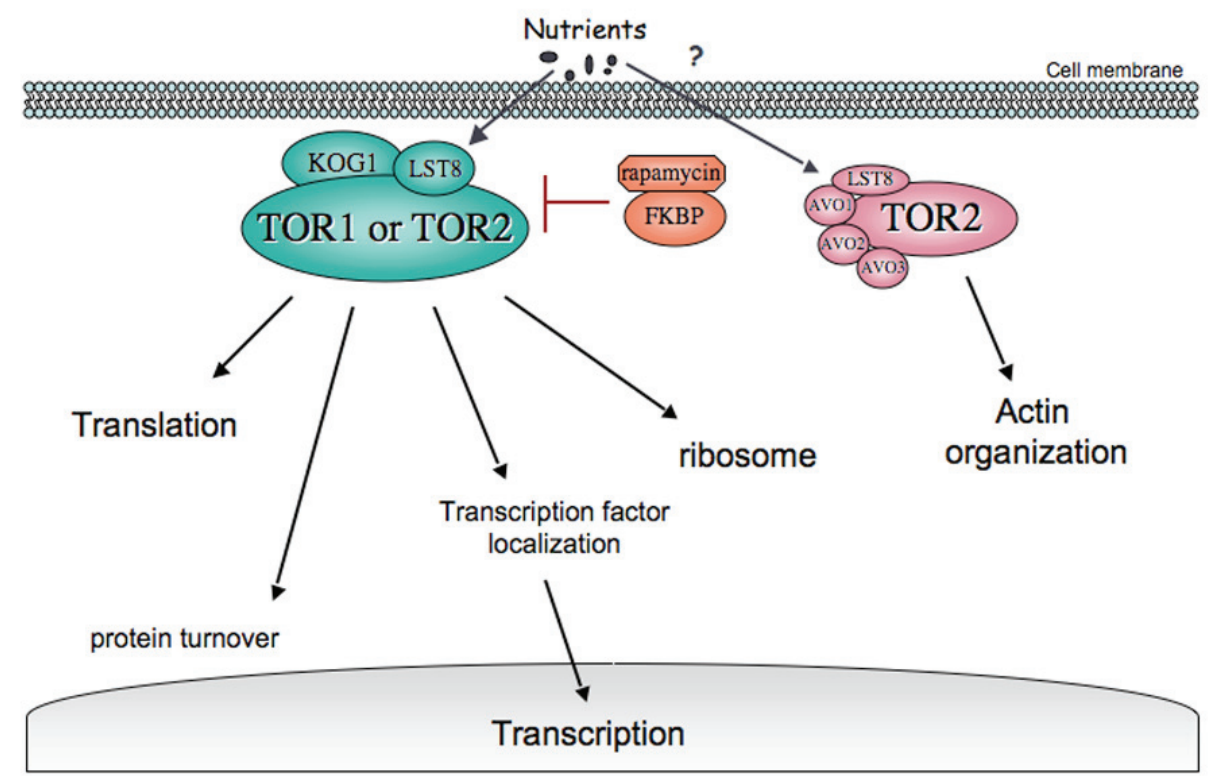

Fig. 4.1 The TOR pathway

The TOR pathway regulates cellular response to environmental stress such as nutrient starvation, growth factor deprivation and hypoxia. TOR1 or TOR2 can form a rapamycin sensitive TORC1 complex involved in regulating cap-dependent translation, transcriptional stress responses, cell cycle progression from G1 to S-phase and cell survival. TOR2 can for a rapamycin insensitive TORC2 complex involved in actin organization. 
Although, the underlying mechanisms affecting cell survival in S-phase remain unclear. A third line of evidence derived from our studies of the hypomorphic alleles of CDC45 and $D P B 11$ that are hypersensitive to Top $1 \mathrm{~T}^{722} \mathrm{~A}$-induced DNA damage and exhibit alterations in DNA replication $(22,30,34)$. These mutants are also hypersensitive to RAP implying that TOR signaling plays a role in S-phase.

In this study we report that rapamycin-sensitive TORC1 signaling functions to promote S-phase transit and maintain cell viability following Rad53 checkpoint activation by DNA damage or replicative stress. In response to MMS-induced DNA damage, TORC1 signaling was required to maintain the stability of stalled replication forks independent of the Rad53 checkpoint. In contrast, in response to hydroxyurea (HU) induced replication stress, TORC1 functioned to promote fork progression while cell viability and replication fork stability were maintained by the Rad53 checkpoint. Thus, TORC1 signaling appears to play distinct roles in S-phase in mediating cellular responses to DNA lesion versus the prolonged stress imposed on the replication machinery by $\mathrm{HU}$.

\subsection{EXPERIMENTAL PROCEDURES}

\subsubsection{Chemicals and yeast strains}

Hydroxyurea (HU) was purchased from U.S. Biological. RAP, obtained from the NCI drug repository, was dissolved in dimethyl sulfoxide, and stock solutions of $1 \mathrm{mg} / \mathrm{ml}$ were stored at $-20^{\circ} \mathrm{C}$. The mating pheromone $\alpha$-factor, from Diagnostic Chemicals Ltd, was stored at $-20^{\circ} \mathrm{C}$ at $1 \mathrm{mg} / \mathrm{ml}$ in methanol and used at a final concentration of $5 \mu \mathrm{g} / \mathrm{ml}$. MMS was purchased from Sigma. 
S. cerevisiae strains, cultured under standard conditions, were CSY6 (MATa,

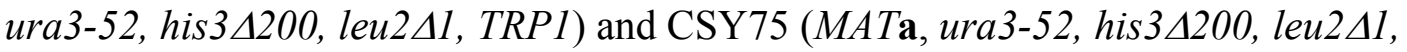
sml1 $:: H i s 3, \operatorname{rad} 53 \Delta:: T R P 1)$

\subsubsection{Cell cycle analysis and viability assays}

MATa cells, a-factor arrested in G1 phase of the cell cycle, were washed by filtration and released into medium alone, or medium supplemented with $200 \mathrm{ng} / \mathrm{ml} \mathrm{RAP \text {, }}$ 0.05\% MMS, $0.05 \%$ MMS plus $200 \mathrm{ng} / \mathrm{ml}$ RAP (MMS + RAP), $10 \mathrm{mg} / \mathrm{ml} \mathrm{HU}$, or 10 $\mathrm{mg} / \mathrm{ml} \mathrm{HU}$ plus $200 \mathrm{ng} / \mathrm{ml} \mathrm{RAP}(\mathrm{HU}+\mathrm{RAP})$. Isogenic strains prototrophic for tryptophan synthesis were used to avoid the complications of RAP-induced down regulation of the Tryptophan transporter. For cell viability assays, aliquots of the cells were washed by centrifugation at the times indicated, to remove the drugs, serially tenfold diluted and plated to determine clonogenic survival at $30^{\circ} \mathrm{C}$. Aliquots of the cells were also fixed with $70 \%$ ethanol and stored at $4^{\circ} \mathrm{C}$ for subsequent FACs analysis.

\subsubsection{2-D gel analysis of replication intermediates}

Replication intermediates were purified at the indicated times following release of the cells from $\alpha$-factor into YPD or YPD plus RAP, MMS, MMS+RAP, HU or HU + RAP as described (12). To analyze ARS305 replication intermediates, purified DNA, restricted with Eco RV and Hind III, were resolved by 2-D gel electrophoresis, transferred to nylon membranes, hybridized with a ${ }^{32} \mathrm{P}$-labeled probe spanning ARS305 and visualized by PhosphorImage analysis. To assess replication fork progression along the left arm of chromosome III, the same blots were successively stripped and re-probed 
with radiolabeled DNA derived from genomic sequences $6 \mathrm{~Kb}, 18 \mathrm{~Kb}$ or $29 \mathrm{~Kb}$ from ARS305.

\subsection{RESULTS}

\subsubsection{TOR signaling is a determinant of cell survival in response to DNA damage}

RAP inhibition of TOR signaling induces yeast cell cycle arrest in early G1 phase, which precedes the G1 block induced by the $\alpha$-factor mating pheromone (69). Therefore, as diagrammed in Fig. 4.2, we reasoned that TOR signaling in S-phase could be assessed by first arresting cells in late G1 phase with the mating pheromone $\alpha$-factor, then releasing cells into media containing RAP, in the presence or absence of the DNAdamaging agent MMS or the ribonucleotide reductase inhibitor HU.

$\mathrm{We}$, and others, have reported that when cells are released into media containing RAP a subpopulation of $\alpha$-factor arrested cells failed to transit S-phase (data not shown, $(53,69)$. However, our studies demonstrated that the kinetics of S-phase transit for those cells that entered S-phase mirrored those of the untreated control cells with RAP-treated cells accumulating in the next G1 phase. When cells were released into media containing MMS, S-phase transit was decreased due to the activation of the Rad53 checkpoint. This effect on S-phase transit has been well documented. However, our results demonstrate that RAP treatment further delayed the slow S-phase transit induced by MMS (data not shown). As shown in Fig. 4.3, under the same conditions, RAP treatment alone was growth inhibitory not cytotoxic. In contrast, the cytotoxicity of MMS was enhanced by co-treatment with RAP (compare MMS with MMS+RAP in Fig. 4.3). Thus, the further 

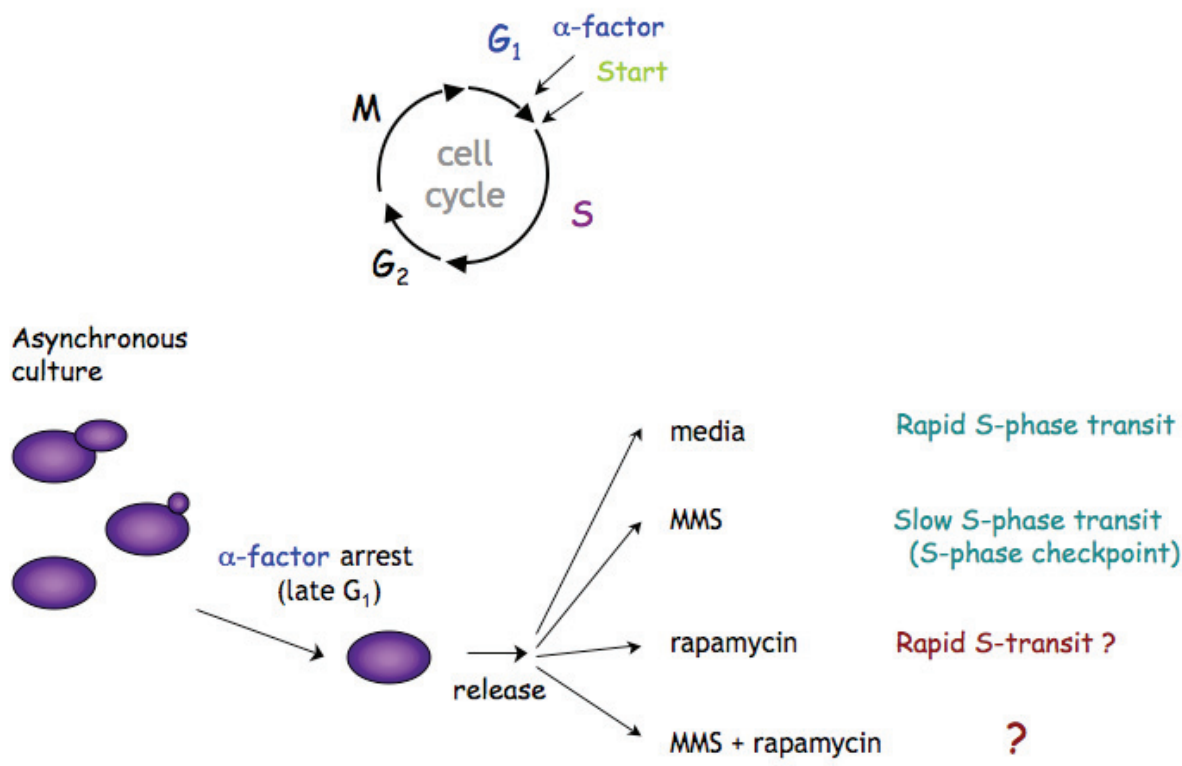

Fig. 4.2 Experimental design for assessing TOR signaling in S-phase

Asynchronous cultures were $\alpha$-factor arrested in late G1-phase. The cultures were released into S-phase into media as a control, MMS, rapamycin and MMS + rapamycin to assess S-phase transit. 


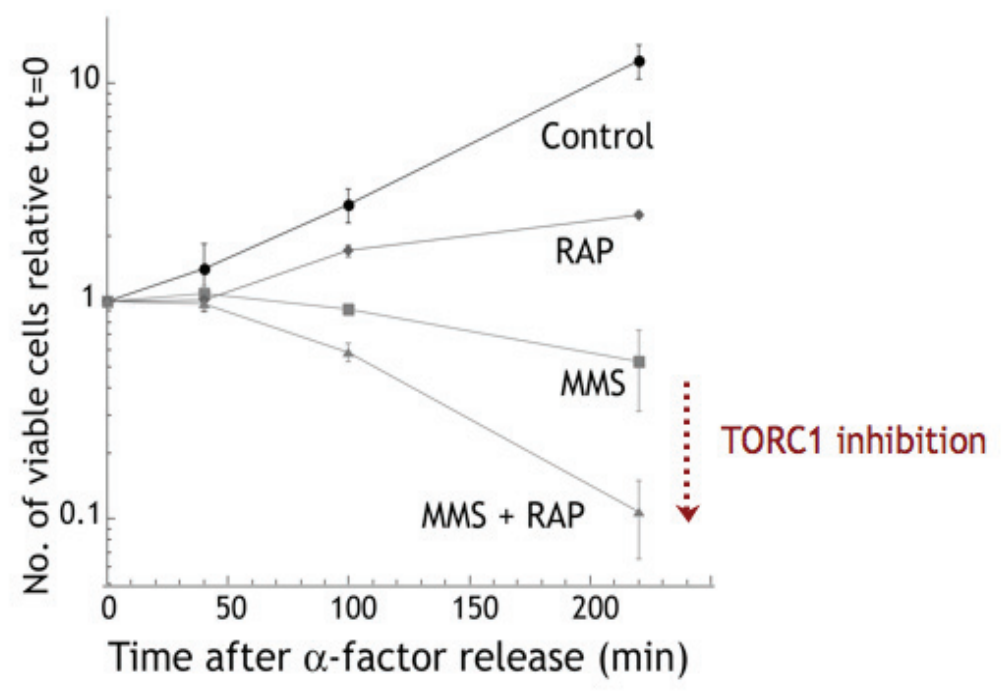

Fig. 4.3 Rapamycin inhibition of TOR signaling decreases cell viability in response to MMS treatment

Arrested cells were released into media with no drug, RAP, MMS or MMS + RAP. The cells were serially diluted at the times indicated and the number of viable cells forming colonies on YPD plates following incubation at $30^{\circ} \mathrm{C}$ was plotted relative to time $=0$.

Error bars indicate standard deviations $(n=3)$. 
delay in S-phase transit induced by MMS+RAP over that observed with MMS alone was reflected in a proportional decrease in colony number over time.

We recently reported that TORC1 acts as a survival pathway in response to genotoxic stress, in part, by maintaining the elevated expression of the ribonucleotide reductase subunits Rnr1 and Rnr3 induced by DNA damage activation of the Rad53 Sphase checkpoint (53). Our findings supported a model whereby TORC1 acts as a survival pathway in response to DNA damage by maintaining the deoxynucleoside triphosphate pools necessary for error-prone translesion DNA polymerases. In fact as diagrammed in Fig. 4.4, TOR-dependent cell survival in response to DNA damaging agents coincides with increased mutation rates. Thus, one consequence of TORC1 signaling in the face of persistent DNA damage may be the acquisition of mutations that confer drug resistance. However, the pronounced delay in S-phase transit induced by MMS+RAP also led us to consider the effects that inhibiting TORC1 signaling might have on the stability of the replication forks.

\subsubsection{Replication fork stability is diminished by MMS + RAP}

To assess origin firing and fork stability in cells treated with MMS +/- RAP, replication intermediates resolved in 2-D gels, were probed with sequences corresponding to the early replication origin $A R S 305$ or flanking DNA $(6 \mathrm{~Kb}, 18 \mathrm{~Kb}$ or $29 \mathrm{~Kb}$ towards the left telomere of chromosome III), where ARS301-304 are normally

dormant. In these gels, a bubble arc reflects bidirectional origin firing and $\mathrm{Y}$ arcs result from the asymmetric movement of replication forks through the restriction fragment being probed. X-spikes accompany origin firing and decrease in intensity as forks 


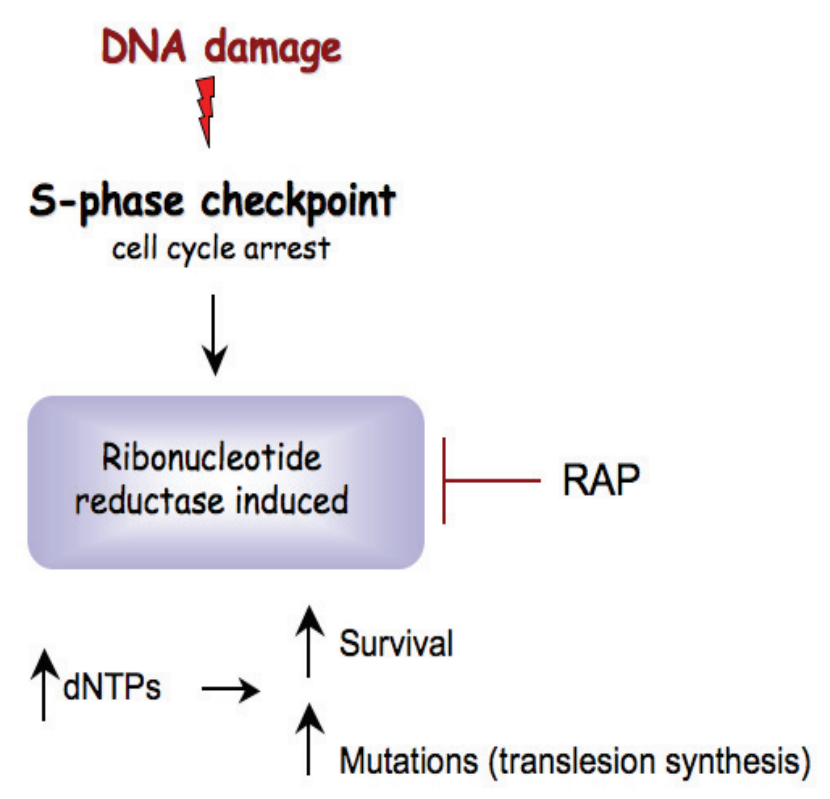

Fig. 4.4 TORC1 acts as a survival pathway in response to DNA damage by maintaining the dNTP pools

When the S-phase checkpoint is activated by DNA damage, ribonucleotide reductase (RNR) is induced to maintain dNTP pools to for translesion of DNA synthesis and survival. RAP inhibition of TORC1 inhibits the induction of RNR subunits thereby decreasing levels of dNTP pools. 
migrate (12).

As shown in Fig. 4.5, after release into S-phase, firing of $A R S 305$ was unaffected by rapamycin, as evidenced by a robust bubble arc at 10 minutes. Untreated cells continued to cycle: the bubble arc apparent after release from $\alpha$-factor, was not detected at 60 minutes and reappeared at 180 minutes as cells entered subsequent cell cycles. The decrease in replication intermediates after 60 minutes of rapamycin treatment coincided with the accumulation of cells in G1 phase. With MMS, the accumulation of a strong Y arc and X-spike indicates slow fork progression at 30 minutes. The decrease in intermediates at 60 minutes coincided with fork progression and the accumulation of cells with a 2n DNA content. A slightly less intense pattern of replication intermediates was obtained with MMS + RAP at 30 minutes. However, the decrease in replication intermediates at 60 and 180 minutes, relative to MMS alone, did not correspond with increased DNA content. A persistent cell cycle arrest in early S-phase due to Rad53 checkpoint activation would yield stable replication intermediates over the time course of these experiments. Rather these data suggest a decrease in fork stability.

To directly assess these issues, we next assessed replication fork migration towards the left telomere of chromosome III in isogenic strains wild-type for the Rad53 checkpoint or deleted for RAD53 (rad53A). As shown in Fig. 4.6, similar blots of replication intermediates obtained from cells released from $\alpha$-factor into MMS alone or MMS + RAP were successively re-probed with sequences $18 \mathrm{~Kb}$ and $29 \mathrm{~Kb}$ downstream. Replication intermediates isolated from MMS-treated rad53 $\Delta$ cells demonstrated a more rapid progression of replication forks (relative to wild-type cells) with a strong Y arc detectable at $+29 \mathrm{~Kb}$ by 60 minutes and little evidence of fork collapse. The dormant 


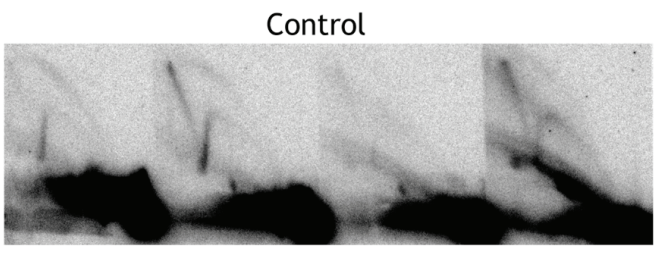

RAP

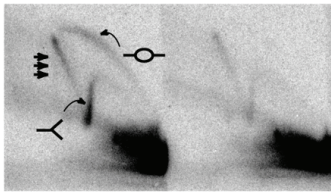

10

30
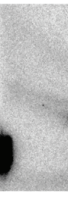

60

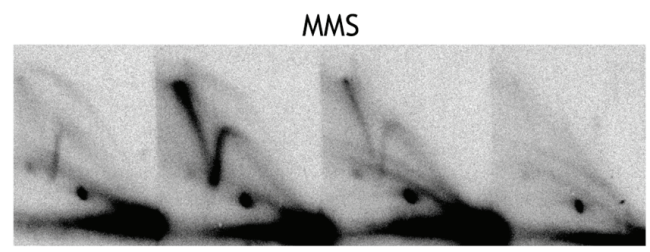

$M M S+R A P$

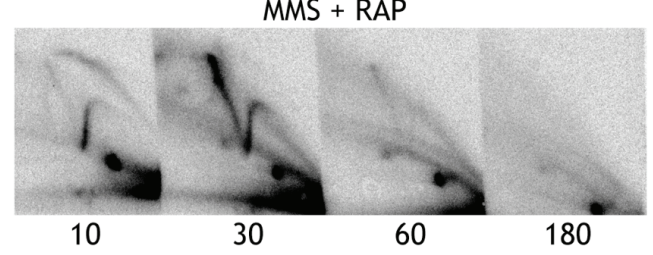

Fig. 4.5 MMS+RAP treatment diminishes replication fork stability At the times indicated following $\alpha$-factor release into YPD, MMS, RAP, or MMS+RAP, replication intermediates were resolved in 2-D gels. The distribution of bubble arcs, $Y$ arcs and X-spikes, which indicate origin firing, passive DNA replication and slow fork progression, respectively, was determined in southern blots with an ARS305 probe. 


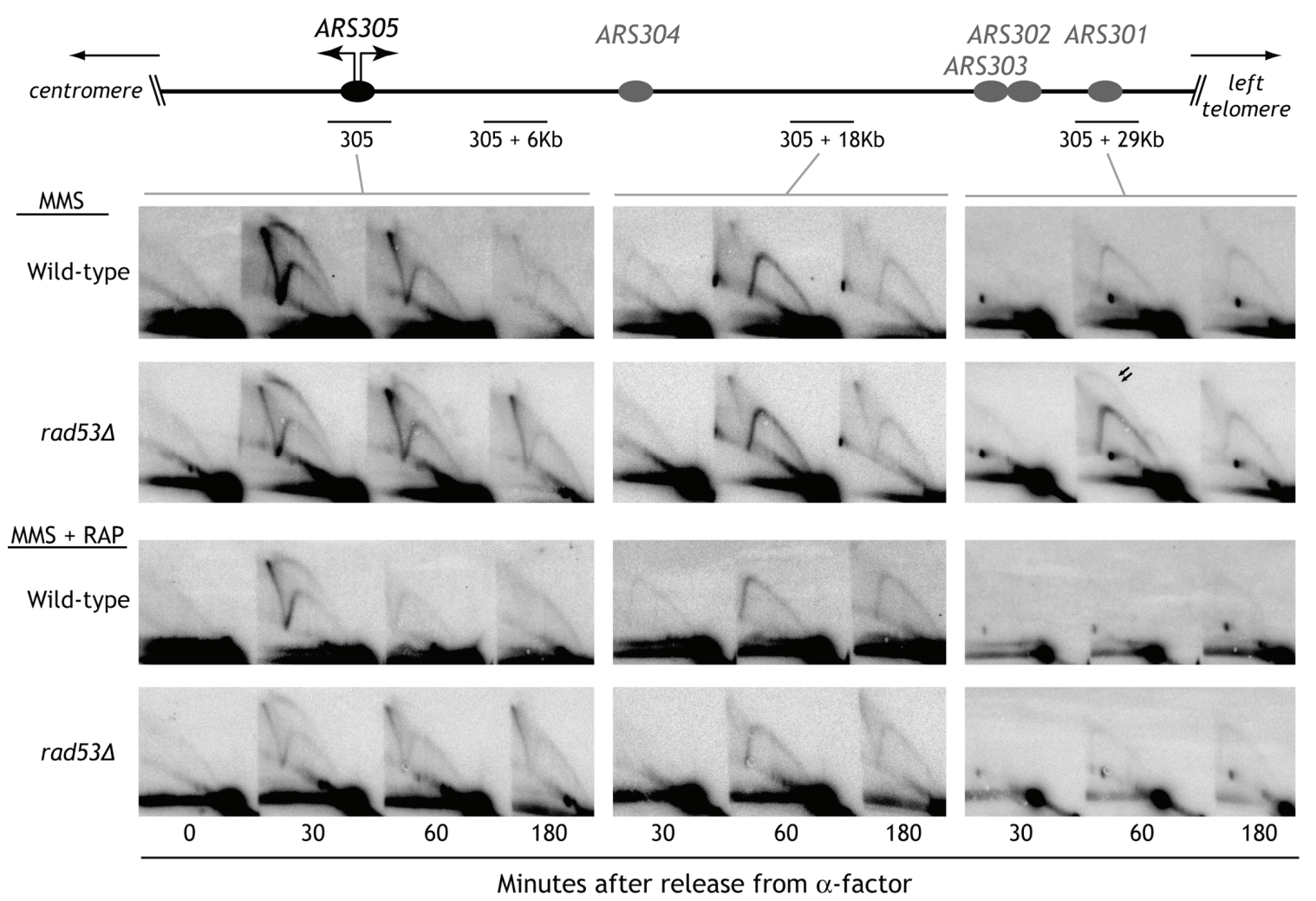

Fig. 4.6 Decreased fork stability induced by MMS+RAP treatment is Rad53independent

Replication intermediates from wild-type and rad534 cells, released from $\alpha$-factor into MMS or MMS+RAP, were resolved in 2-D gels. The blots were successively hybridized with probes derived from $A R S 305$ and sequences $6 \mathrm{~Kb}, 18 \mathrm{~Kb}$ and $29 \mathrm{~Kb}$ to the left of $A R S 305$ on chromosome III (the reverse orientation is diagrammed). Dormant ARS301, 302,303 and 304 are in grey.

of ARS305. In MMS-treated wild-type cells, replication intermediates evident at ARS305 at 30 minutes, shifted to a strong $\mathrm{Y}$ arc at $+18 \mathrm{~Kb}$ by 60 minutes and had dissipated by 180 minutes, indicating continued fork progression. Only weak $Y$ arcs were detected at $+29 \mathrm{~Kb}$. In contrast, the uniform decrease in Y arc signal along chromosome III seen in MMS+RAP treated cells (Fig. 4.6) and concomitant delay in S-phase transit (data not shown) indicated a decrease in fork stability. 
ARS301 at $+29 \mathrm{~Kb}$ also fired in MMS treated rad53 $\Delta$ strains, as previously reported (12). In contrast, the pattern of fork progression in rad53 $\Delta$ cells treated with MMS+RAP resembled that obtained with wild-type cells. Thus, the decreased fork stability induced by MMS + RAP appeared to be Rad53-independent. We next asked if TORC1 only maintains fork stability in response to DNA damage or also functions in response to replicative stress, which does not involve translesion DNA synthesis. To address this question, we also isolated DNA replication intermediates from wild-type and rad53 4 cells treated with $\mathrm{HU}+$ or- RAP.

\subsubsection{TORC signaling promotes fork progression in response to $\mathrm{HU}$-induced replication checkpoint activation}

As diagrammed in Fig. 4.2, the same experimental approach was also used to assess the consequences of inhibiting TORC1 signaling in the presence of $\mathrm{HU}$. HU is a potent inhibitor of ribonucleotide reductase. Although $\mathrm{HU}$ treatment activates the Rad53checkpoint, this is a consequence of depleted dNTP pools inducing a slowing of replication fork progression, which in turn triggers the checkpoint. Allosteric feedback activation of ribonucleotide reductase holoenzyme activity ensures the production of sufficient dNTP levels to maintain cell viability and yeast cells can withstand prolonged exposure to HU without adverse affects on clonogenic survival. Since HU treatment does not produce frank DNA lesions, we asked if RAP inhibition of TORC1 signaling would adversely impact cell survival in the face of persistent replicative stress.

As shown in Fig. 4.7, checkpoint activation by HU slowed S-phase transit; replication forks did progress, albeit at a reduced rate. And, as observed with MMS, 
A

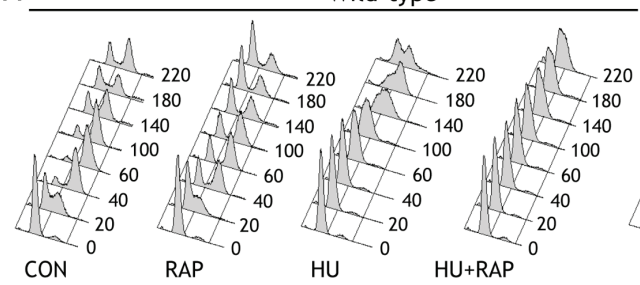

Wild-type
B

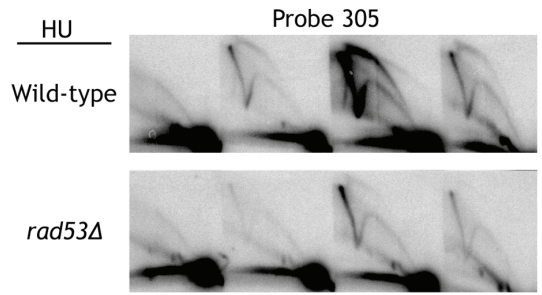

$\frac{H U+R A P}{\text { Wild-type }}$

e

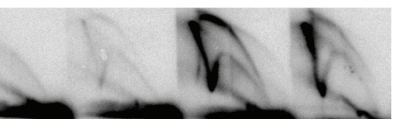

$\operatorname{rad53\Delta }$

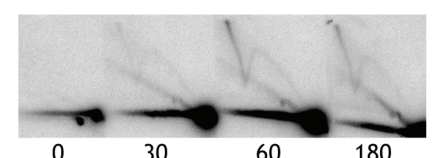

30

60

30
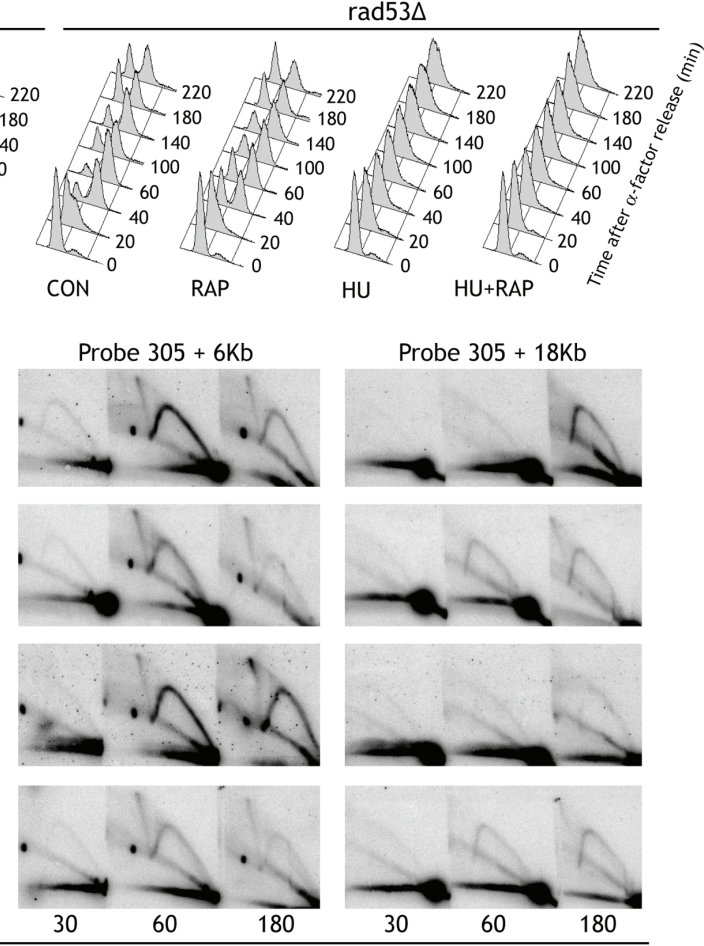

Fig. 4.7 TORC1 signaling promotes replication fork progression and maintains the viability of cells exposed to $\mathrm{HU}$

Replication intermediates from wild-type and rad53 $\Delta$ cells, treated with HU or HU + RAP were resolved in 2-D gels and successively probed with sequences derived from $A R S 305,305+6 \mathrm{~Kb}$ and $305+18 \mathrm{~Kb}$. 
TORC1 inhibition further diminished the S-phase transit of cells treated with HU. Yet, in stark contrast to MMS + RAP, the delay in cell cycle induced by HU + RAP resulted from a more pronounced decrease in the fork progression, without detectable alterations in fork stability. In HU treated wild-type cells, the ARS305 bubble arc accumulated at 60 minutes, independent of rapamycin. The slow progression of the $\mathrm{Y}$ arc induced by $\mathrm{HU}$ (from $+6 \mathrm{~Kb}$ at 60 minutes to $+18 \mathrm{~Kb}$ at 180 minutes), was further delayed in the presence of $\mathrm{HU}+\mathrm{RAP}$ (a strong $\mathrm{Y}$ arc persists at $+6 \mathrm{~Kb}$ at 180 minutes). These results contrasted with HU treatment of rad53 $\Delta$ cells, which induced replication fork collapse, independent of TORC1 signaling. Thus, unlike the situation with the DNA damage induced by MMS treatment, in HU treated cells the inhibition of TORC1 signaling suppressed fork progression, while Rad53 functioned to maintain fork stability.

However, when drug exposure was extended to 24 hours, cells treated with $\mathrm{HU}+$ RAP exhibited a persistent arrest in early S-phase, accompanied by a $\sim 30$-fold drop in cell viability (data not shown). In contrast, cells exposed to HU for 5-9 hours exhibited a late S/G2 phase DNA content, and by 24 hours most cells were in G1 phase with little or no loss of viability (data not shown). These findings suggest that TORC1 signaling is not only required to promote replication fork progression, but also functions to maintain cell viability in the presence of persistent replicative stress. Indeed, as shown in Fig. 4.8, HU treatment dramatically slows the progression of the replication forks that initiate at $A R S 305$, such that a robust $\mathrm{Y}$-arc is only detected at residues $18 \mathrm{~Kb}$ downstream from ARS305 after 3 hours following $\alpha$-factor release. A weaker, yet persistent $\mathrm{Y}$-arc is detected at 3-5 hours at $+29 \mathrm{~Kb}$. A weak bubble arc is also seen at 5 hours, indicative of a small percentage of cells entering the next cell cycle. These data are consistent with the 

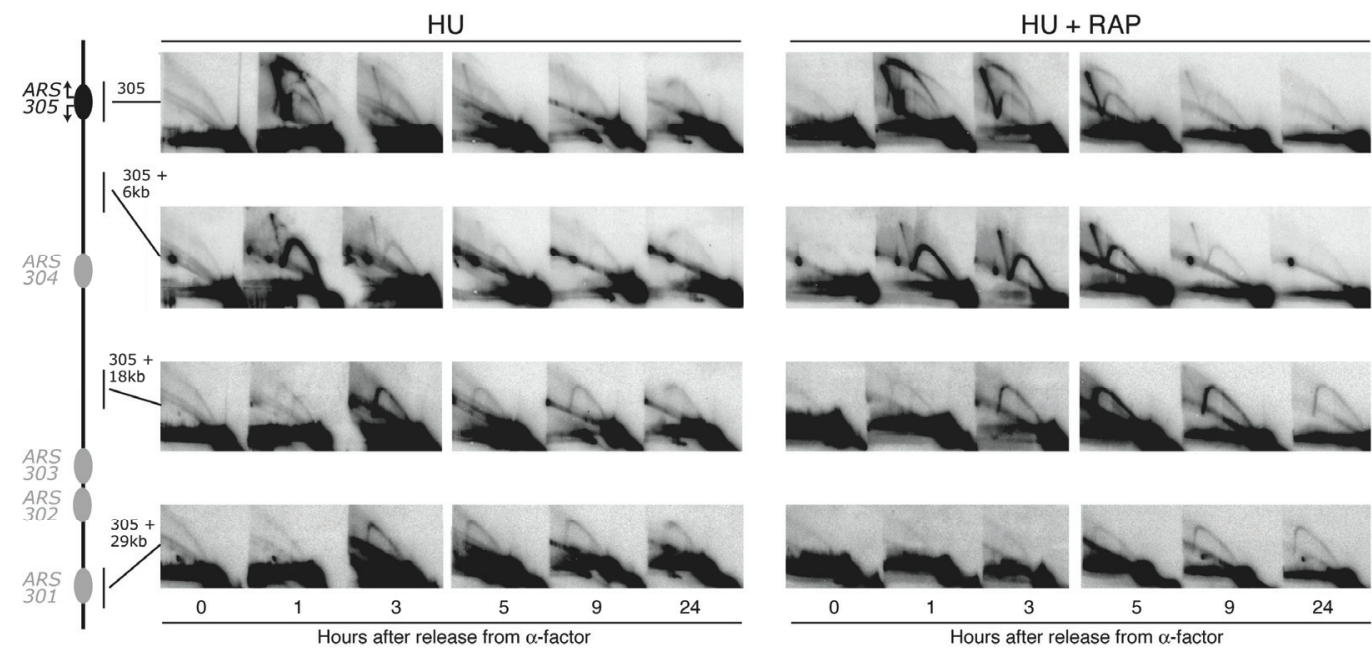

Fig. 4.8 TORC1 signaling is required for fork progression during persistent replicative stress

Replication intermediates were isolated from cell released into media containing HU and $\mathrm{HU}+\mathrm{RAP}$, visualized using 2-D gel electrophoresis, blotted and probe for ARS305, $A R S 305+6 \mathrm{~Kb}, A R S 305+18 \mathrm{~Kb}$ and $A R S 305+29 \mathrm{~Kb}$. Replication fork progression from $A R S 305$ is dramatically slowed when cell are released into HU, in contrast, cells released into $\mathrm{HU}+\mathrm{RAP}$ exhibit a persistent delay in fork progression. 
FACs profiles obtained under the same conditions (data not shown). In contrast, a persistent delay in fork progression is obtained from HU+RAP treated cells. A robust bubble arc persists from 1 through 5 hours, followed by appearance of a robust Y-arc at more distal $(+6 \mathrm{~Kb}$ and $+18 \mathrm{~Kb})$ sites. However, consistent with the FACs profiles, a similar pattern of robust $\mathrm{Y}$-arcs are not detected at $+29 \mathrm{~Kb}$. Taken together, these data suggest that TORC1 signaling is required for fork progression in the face of persistent replicative stress, but not to maintain fork stability. Nevertheless, this prolonged retardation of fork progression will ultimately impair cell viability.

\subsection{DISCUSSION}

Our findings revealed that rapamycin-sensitive TORC1 signaling functions to promote S-phase transit and maintain cell viability following Rad53 checkpoint activation by DNA damage or replicative stress. In response to MMS-induced DNA damage, TORC1 appears to exhibit Rad53 checkpoint dependent and independent functions. First, TORC1 signaling is required to sustain the DNA damage checkpointmediated induction of ribonucleotide subunits Rnr1 and Rnr3, thereby ensuring sufficient ribonucleotide reductase activity to generate the high levels of dNTPs necessary for translesion DNA synthesis to bypass MMS-induced DNA lesions. The regulation of translesion synthesis of DNA adducts by this mechanism could also explain the increased sensitivity of mammalian cells to cisplatin that is induced by rapamycin (68). Second, TORC1 signaling was also required to maintain replication fork stability, independent of the Rad53 checkpoint. Whether this phenotype results from a RAP-induced decrease in the translation of replication fork components has yet to be assessed. Nevertheless, these 
findings support a model for the enhanced RAP sensitivity of $c d c 45-10$ cells. The fragility of forks assembled in $c d c 45-10$ cells at the non-permissive temperature, which suffices to slow S-phase transit and requires the S-phase checkpoint to maintain cell viability, would be exacerbated by RAP-induced fork collapse. Similar considerations would also hold for $d p b 11-10$ cells. Indeed, the enhanced sensitivity of $c d c 45-10$ and dpb11-10 cells to RAP was only observed at the non-permissive temperature. Whether the dosage suppressors defined in Chapter 2, or the SUMO site mutation in Cdc45 also impacts the RAP sensitivity of $c d c 45-10$ cells has yet to be determined.

The effects of RAP inhibition on TORC1 signaling in cells exposed to MMSinduced DNA damage contrasted with that of cells exposed to HU. When cells are exposed to replicative stress, due to HU-induced depletion of dNTPs, fork stability was dependent on Rad53, not TORC1 signaling. In the face of prolonged exposure to HU, the forks are very stable; however, they fail to progress when TORC1 signaling is inhibited by RAP and the cells will eventually die. These data suggest that in response to DNA damage, RAP treatment impairs the activity of some factor or factors whose activity is required to maintain fork stability. However, in $\mathrm{HU}$ treated cells, this activity is either not required or is not affected by RAP and fork stability is maintained by Rad53.

In response to MMS or HU treatment, RAP does induce the down regulation of Rnr1 and Rnr3 (data not shown) (53). In the case of MMS-induced DNA damage, the resultant decrease in dNTP levels effectively suppresses translesion DNA synthesis such that the mutagenic activity of MMS is repressed and cell viability is further compromised (53). HU does not induce mutagenic DNA lesions, so the consequences of Rnr1/3 down regulation are quite distinct. HU itself inhibits ribonucleotide reductase to partially 
deplete intracellular levels of dNTPs. However, the enzyme is also subject to allosteric regulation such that a modest increase in activity provides sufficient dNTP levels to maintain cell viability, although fork progression is severely hampered (as seen in Fig. 4.8). However, our findings suggest that the additional down regulation of Rnr1 and Rnr3 by RAP inhibition of TORC1 further reduces ribonucleotide reductase levels, thereby effecting a much more severe depletion of dNTPs. In essence, the replication machinery becomes starved for dNTPs, the building blocks of DNA, and the fork stalling is more pronounced. In this case, Rad53 then plays a critical role in maintaining fork stability. In the face of prolonged replication stress, the cells will eventually die. Thus, TORC1 signaling also functions as a survival factor in response to DNA damaging agents as well as prolonged replication stress. 


\section{CHAPTER 5: DISCUSSION}

Eukaryotic DNA topoisomerase I (Top1) acts as a swivel to remove positive and negative supercoils that accumulate during cellular processes such as DNA replication, recombination and transcription through a mechanism of transient DNA strand cleavage and religation $(1,2)$. Top1 is a monomeric enzyme that forms a protein clamp around duplex DNA. The active site (Tyr727 in yeast) acts as a nucleophile to cleave the phosphodiester backbone of a single DNA strand, forming a covalent 3' phospho-tyrosyl linkage with the DNA. The 5' end of the DNA rotates within this covalent Top1-DNA complex about the nonscissile strand to relax the positive or negative supercoils. The $5^{\prime} \mathrm{OH}$ of the cleaved strand acts as a nucleophile in a second transesterification reaction to resolve the Top-DNA intermediate and religate the DNA $(1,2)$.

Top1 is the sole cellular target of the anticancer agent camptothecin (CPT). CPT targets Top 1 and intercalates between the ends of the cleaved strand, interacting with both the DNA and the enzyme, to prevent the religation step of the catalytic cycle thereby extending the life of the covalently linked Top1-DNA intermediate $(70,71)$. These stabilized drug-enzyme-DNA intermediates are formed in all stages of the cell cycle; however the cytotoxic activity of CPT is S-phase dependent. There are two suggested mechanisms to explain this S-phase toxicity. First, biochemical and genetic data provide evidence that advancing replication forks collide with the stabilized CPT-Top1-DNA complexes to induce irreversible DNA lesions that trigger checkpoint activation and cell death (6). Second, recent single molecule studies using human Top1 and a CPT analog topotecan, suggests a second mechanism where drug binding of Top1-DNA complexes 
induce the accumulation of positive supercoils in front of advancing replication forks that could in turn block fork progression resulting in fork collapse and lethal DNA lesions that induce cell death (8). Despite extensive study, remarkably little is known of the molecular interactions involved in converting the drug-enzyme-DNA complexes into DNA lesions that trigger checkpoint activation or the downstream pathways required for the resolution and repair of these lesions.

The genetically tractable budding yeast, $S$. cerevisiae, has been extensively used to study cellular processes such as DNA replication and the mechanism of cancer therapeutics (29) as most basic cellular processes, cell cycle machinery and mechanism of cell sensitivity and resistance to CPT are highly conserved from yeast to human.

Using $S$. cerevisiae as a model system, a genetic screen was designed to isolate conditional temperature sensitive mutants that exhibit enhanced sensitivity to the CPT mimetic, Top $1 \mathrm{~T}^{722} \mathrm{~A}$. This self-poisoning enzyme exhibits a decrease in the rate of DNA religation. Yeast cells can tolerate low-level expression of this enzyme making it a valuable tool for identifying gene products and pathways that mediate cellular responses to CPT, while avoiding the complication of drug uptake and efflux. From this genetic screen, ten recessive tah mutants were identified. These mutants were unable to survive the damage induced by Top $1 \mathrm{~T}^{722} \mathrm{~A}$ at $36^{\circ} \mathrm{C}$ due to the loss or decrease of $T A H$ gene product function. The tah mutants function in a variety of cellular pathways. One $T A H$ gene identified, $U B C 9$, encodes the sole E2 conjugating enzyme in the SUMOylation pathway. Three of the $T A H$ genes are essential for DNA replication. $C D C 45$ encodes a DNA replication initiation factor that is essential for the initiation and elongation steps of DNA replication. DPB11 encodes a subunit of the DNA polymerase II epsilon $(\varepsilon)$ 
complex that is essential for the loading of DNA polymerases to initiate DNA synthesis and is required for the S-phase checkpoint. TAH11 encodes a DNA replication licensing factor required for pre-replicative complex formation (5).

The tah mutant $c d c 45-10$ has a single amino acid substitution $\left(\mathrm{G}^{510} \mathrm{R}\right)$. These cells are hypersensitive to Top $1 \mathrm{~T}^{722} \mathrm{~A}$ expression at $36^{\circ} \mathrm{C}$ and transiently accumulate in early S-phase when shifted to $36^{\circ} \mathrm{C}$ due to a defect in Okazaki fragment maturation. $c d c 45-10$ cells also exhibit a slow growth phenotype when $R A D 9$ is deleted suggesting that the damage accumulating in these cells is sensed by the Rad9 DNA damage checkpoint. $c d c 45-10$ exhibits a synthetic lethal interaction with another tah mutant, dpb11-10, which coincides with a persistent accumulation of Okazaki sized DNA fragments. Despite extensive study, the function Cdc45 during the initiation and elongation steps of DNA replication has yet to be defined. Our results imply that Cdc45 functions normally to protect cells against Top1-DNA damage. Therefore, further characterization of the replication defects in $c d c 45-10$ cells would provide insights into the molecular interactions required to protect cells against Top-induced DNA damage.

\subsection{CDC45 HAS TWO DISTINCT FUNCTIONS}

Isolation of $c d c 45-10$ as a hypomorphic allele exhibiting enhanced sensitivity to Top $1 \mathrm{~T}^{722} \mathrm{~A}$ suggests that $\mathrm{Cdc} 45$ normally functions to protect cells against Top1-induced DNA damage. Increased gene dosage of this mutant allele restored cellular resistance to low-level expression of Top $1 \mathrm{~T}^{722} \mathrm{~A}$ at $36^{\circ} \mathrm{C}$, however, failed to suppress the synthetic lethality of $c d c 45-10, d p b 11-10$ cells. These results suggested that the essential function of Cdc45 needed to protect cells from Top1 poisons is distinct from the functional 
interactions that are essential to maintain cell viability and Okazaki fragment maturation. The alterations observed in $c d c 45-10$ could not be attributed to thermolability of the protein as steady state protein levels of $\mathrm{Cdc} 45 \mathrm{G}^{510} \mathrm{R}$ in asynchronus cultured mirrored those of Cdc45. In addition, the results obtained in the $c d c 45-10$ high copy suppressor screen also suggested two distinct functions of Cdc45. The dosage suppressors isolated complemented $c d c 45-10$ cell sensitivity to Top $1 \mathrm{~T}^{722} \mathrm{~A}$ but failed to restore cell viability to the $c d c 45-10, d p b 11-10$ double mutant strain at $36^{\circ} \mathrm{C}$. These two distinct functions of Cdc45 is further supported by the results obtained from our attempts to epitope tag Cdc45. Incorporating an $\mathrm{HA}$ tag at the $\mathrm{C}$-terminus of $\mathrm{Cdc} 45$ resulted in a protein that could maintain cell viability in plasmid shuffle assays, however, failed to complement the synthetic lethality of the $c d c 45-10, d p b 11-10$ double mutant strain. In contrast, incorporating a C-terminal HA tag on $c d c 45-10$ resulted in a protein that could not maintain cell viability suggesting that the $\mathrm{C}$-terminus of $\mathrm{Cdc} 45$ functionally interacts with the residues spanning $\mathrm{Gly}^{510}$ such that modifying the $\mathrm{C}$-terminus results in a lethal protein. With the exception of a bipartite nuclear localization signal, the amino acid sequence of Cdc45 does not predict similarities with any known domains. Therefore, having the X-ray structure of $\mathrm{Cdc} 45$ would provide a means of visualizing the functional interaction between the $\mathrm{C}$-terminus of the protein and region spanning the $\mathrm{Gly}^{510}$.

\subsection{DOSAGE SUPPRESSORS OF $c d c 45-10$ SUGGEST DISTINCT DEFECTS}

Increased gene dosage of $c d c 45-10$ suppressed the hypersensitivity of the cells to Top $1 \mathrm{~T}^{722} \mathrm{~A}$ at $36^{\circ} \mathrm{C}$, but not the synthetic lethality of $c d c 45-10, d p b 11-10$ cells. To define pathways specific for cellular resistance to Top1 poisons, we used a yeast genetic screen 
to identify extragenic dosage suppressors of $c d c 45-10$ sensitivity to $\mathrm{Top}^{1} \mathrm{~T}^{722} \mathrm{~A}$. The characterization of the two dosage suppressors isolated suggested distinct defects in $\mathrm{Cdc} 45 \mathrm{G}^{510} \mathrm{R}$. The first suppressor, $A R S 1303$, is an origin of replication located on chromosome XIII. Isolation of this suppressor suggests a defect in origin licensing or firing in $c d c 45-10$ cells. This dosage suppressor also complemented the tah phenotype of dpb11-10 and tah11-10, which are also essential during DNA replication. To date, very little information is available for $A R S 1303$, therefore, determining if this ARS sequence normally fires during S-phase and the temporal pattern of this firing would provide valuable information to further characterize this dosage suppressor. Furthermore, determining if other ARS sequences such as ARS305 or ARS309 could dosage suppress $c d c 45-10, d p b 11-10$ or tah11-10 would determine if $A R S 1303$ is a unique ARS sequence with distinct dosage suppressor function or if simply increasing the number of origins on a plasmid increases the likelihood of at least one origin firing per cell and therefore contributes to the stability of the plasmid in the cell.

The second dosage suppressor, SIZ1, encodes a gene product that functions in the SUMOylation pathway as an E3 ligase. This suppressor restored cell viability to $c d c 45$ 10 and $u b c 9-10$ in the presence of Top $1 \mathrm{~T}^{722} \mathrm{~A}$ at $36^{\circ} \mathrm{C}$ suggesting that SUMO modification of target proteins is required to protect cells from Top1 poisons. The amino acid sequence of Cdc45 revealed one consensus SUMO site, however, mutating the consensus SUMO site in Cdc45 did not alter cell sensitivity to $\mathrm{CPT}$ or $\mathrm{HU}$ at $36^{\circ} \mathrm{C}$, but mutating this same site in $c d c 45-10$ enhanced the temperature sensitivity and CPT and HU sensitivity at $36^{\circ} \mathrm{C}$. Moreover, $\mathrm{Cdc} 45^{\mathrm{SUMO}}$ did not restore $c d c 45-10$, $d p b 11-10$ cell viability. Altogether, these results suggest that mutating this site has no effect on the drug 
sensitivity of $\mathrm{Cdc} 45$, but does alter the essential function of $\mathrm{Cdc} 45$ needed for the interaction with Dpb11. Therefore, determining if Cdc45 is a target for SUMO modification and if this modification is altered in $\mathrm{Cdc} 45^{\mathrm{SUMO}}$ or $c d c 45-10$ may provide insight into the defects that alter the essential function of these proteins. Furthermore, since Cdc45 is a scaffolding protein that interacts with many different components of the replication machinery, immunoprecipitation assays can be utilized to determine defects in $\mathrm{Cdc} 45^{\mathrm{SUMO}}$ and $c d c 45-10$ binding to known interacting proteins such as Dpb11 or Mcm5.

\subsection{CDC45 FUNCTION IS REQUIRED FOR TIMELY ORIGIN FIRING AND APPROPRIATE ASSEMBLY OF REPLICATION MACHINERY}

Cdc45 is essential for initiation and elongation during DNA replication, therefore assessing origin firing and replication fork progression in $c d c 45-10$ cells identified the alterations evident in these cells. We utilized two distinct experimental approaches to address defects occurring in the licensing step (G1) or the initiation and elongation steps (S-phase). The first approach was to synchronize cultures in late G1 at the permissive temperature release the cells into S-phase at the non-permissive temperature. This would permit licensing to occur at the permissive temperature, while replication would occur at the non-permissive temperature. Under these conditions $c d c 45-10$ cells exhibited a decrease and delay in origin firing at ARS305, however, replication forks progressed with kinetics similar to wild-type suggesting that $C d c 45 G^{510} \mathrm{R}$ cells were defective in the initiation step only. This $c d c 45-10$ phenotype was not the result of a thermolabile

Cdc $45 \mathrm{G}^{510} \mathrm{R}$ protein as we observed an increase in $\mathrm{Cdc} 45 \mathrm{G}^{510} \mathrm{R}$ steady state protein levels compared to wild-type when cells were released into S-phase at $36^{\circ} \mathrm{C}$. These results 
imply that the replication defects in $c d c 45-10$ cells is not the consequence of $\operatorname{Cdc} 45 \mathrm{G}^{510} \mathrm{R}$ down regulation when cells are shifted to $36^{\circ} \mathrm{C}$.

The second approach was to culture $c d c 45-10$ at $36^{\circ} \mathrm{C}$ prior to $\mathrm{G} 1$ arrest where licensing and replication would be carried out at the non-permissive temperature. Under these conditions replication forks appeared to be distributed along a linear diagonal with a DNA mass between $1 \mathrm{n}$ and $2 \mathrm{n}$ implying that DNA replication had initiated at $A R S 305$, however, the intermediates isolated were fragile and collapsed upon purification. As in the previous experiment, the protein levels of $\mathrm{Cdc} 45 \mathrm{G}^{510} \mathrm{R}$ in the cells cultured at $36^{\circ} \mathrm{C}$ were also elevated in S-phase compared to Cdc45. Altogether these results indicate that origin licensing in $c d c 45-10$ cells at $36^{\circ} \mathrm{C}$ altered the assembly of stable replication forks in subsequent S-phase such that they collapse upon purification, while the assembly of pre-RC complexes at $26^{\circ} \mathrm{C}$, followed by S-phase progression at $36^{\circ} \mathrm{C}$, only affected the temporal pattern and efficiency of origin firing in $c d c 45-10$ cells.

Cdc45 has been shown to be a scaffolding protein that interacts with components of the replication machinery including Dpb11, Mcm5 and the GINS complex. Therefore, determining if $\mathrm{Cdc} 45 \mathrm{G}^{510} \mathrm{R}$ is defective in binding to any of the known interacting proteins may provide an explanation for the alterations observed in replication fork stability. The development of an antibody capable of immunoprecipitating $\operatorname{Cdc} 45 \mathrm{G}^{510} \mathrm{R}$ will provide the answers to these questions.

\subsection{RAPAMYCIN-INDUCED ALERATIONS IN S-PHASE TRANSIT}

A yeast genetic screen was designed to isolate conditional mutants exhibiting enhanced sensitivity to the self-poisoning Top $1 \mathrm{~T}^{722} \mathrm{~A}$ (5). Surprisingly, several of these 
mutants were also hypersensitive to the macrocyclic lactone antibiotic rapamycin (RAP), including CDC45 and DPB11 (53). RAP, in complex with FKBP12, specifically targets TOR (target of rapamycin), a phosphatidylinositol 3-kinase-related kinase family member that regulates cellular responses to a wide range of environmental stresses such as nutrient starvation, growth factor deprivation and hypoxia. These signals are transmitted by multi-protein complexes through a variety of downstream pathways to regulate capdependent mRNA translation, transcriptional stress responses, G1 to S-phase transition and cell survival $(55,57,58)$. Several reports including our report that $C D C 45$ and $D P B 11$ are sensitive to RAP, implies a role for TOR signaling in S-phase, as these hypomorphic alleles are essential for the initiation and elongation steps during DNA replication $(65,66)$.

In yeast cells, RAP inhibition of TOR signaling induces cell cycle arrest in early G1. This arrest precedes the G1 block induced by $\alpha$-factor (69) providing a means for assessing TOR signaling in S-phase. When cells were released into media containing RAP, a subpopulation of $\alpha$-factor arrested cells did not transit S-phase, however, the kinetics of S-phase transit for those cells that did enter S-phase were similar those of the untreated control cells with RAP-treated cells accumulating in the next G1 phase. When cells were released into media containing MMS, S-phase transit was slowed due to the activation of the Rad53 checkpoint. In contrast, when cells were treated with MMS + RAP a further delay in the slow S-phase transit was observed. RAP treatment alone is growth inhibitory not cytotoxic. However, MMS treatment is cytotoxic and this cytotoxicity is enhanced when cells are co-treated with RAP + MMS which is evident by a proportional decrease in colony number that we observed over time. 
We previously reported that TORC1 signaling is required to maintain the elevated expression of the ribonucleotide reductase subunits, Rnr1 and Rnr3, to maintain dNTP pools for tranlesion synthesis and survival in response to genotoxic stress (53). The results observed in the MMS+RAP treated cells suggested a role for TORC signaling in stabilizing replication forks in cells exposed to DNA damage. Using 2-D gel analysis we assessed origin firing and fork stability in cells treated with MMS +/- RAP. RAP treatment did not affect origin firing at $A R S 305$ and cells moved through S-phase with a subpopulation accumulating in the subsequent G1 phase. MMS treated cells exhibited slow fork progression, however, these cells did accumulate a 2n DNA content. A slightly less intense pattern of replication intermediates was obtained with MMS + RAP treatment suggesting a decrease in replication fork stability. To determine if these results were dependent on the Rad53 checkpoint pathway, the same experiments were conducted in cells lacking Rad53 (rad534). Replication intermediates isolated from MMS-treated rad53 4 cells demonstrated a more rapid progression of replication forks compared to wild-type with little evidence of fork collapse. The cryptic origin ARS301 fired in these cells as previously reported (12). When rad53 4 were treated with MMS + RAP the pattern of fork progression observed was similar to that of wild-type suggesting the decrease in fork stability induced by MMS + RAP appeared to be Rad53-independent.

To determine if TORC1 also functions in response to replicative stress, replication intermediates were isolated from wild-type and $\mathrm{rad} 53 \Delta$ cells treated with HU +/- RAP. HU treatment results in inhibition of ribonucleotide reductase causing a depletion of dNTP pools and activating the $\operatorname{Rad} 53$ checkpoint to inducing a decrease in replication fork progression. Sufficient dNTP levels are produced to maintain cell viability due to 
allosteric feedback activation of ribonucleotide reductase holoenzyme activity. This allows cells to withstand prolonged exposure to HU without adverse affects on cell viability. HU treated cells exhibited a slowed S-phase transit due to checkpoint activation, however, the replication forks did progress. Similar to MMS treatment, cells treated with HU + RAP exhibited a further delay in S-phase transit. In contrast to MMS + RAP, the HU + RAP treated cells exhibited a more pronounced decrease in the fork progression, without affecting fork stability. HU treatment of rad53 $\Delta$ cells resulted in replication fork collapse and this was independent of TORC1 signaling. Therefore in HU treated cells the inhibition of TORC1 signaling suppressed fork progression, while Rad53 functioned to maintain fork stability. When cells were exposed to replicative stress for an extended period of time (HU at 24 hours), no decrease in cell viability was observed. In contrast, when cells were treated with HU + RAP for 24 hours an arrest in early S-phase with a decrease in cell viability was observed. Together these findings suggest that TORC1 signaling is required to promote replication fork progression and also functions to maintain cell viability in the presence of persistent replicative stress.

In this study, we suggest two independent functions of TORC1 signaling in Sphase. First, TORC1 signaling functions to promote S-phase transit and maintain cell viability following Rad53 checkpoint activation by DNA damage or replicative stress. Second, TORC1 signaling is also required to maintain replication fork stability, independent of the Rad53 checkpoint. One consequence of RAP inhibition of TORC1 signaling is a decrease in protein translation, therefore analyzing mRNA and protein levels of the replication fork components in cells treated with RAP will provide evidence as to the exact defects observed as a result of RAP treatment. 
Our studies suggest a model for the enhanced RAP sensitivity of $c d c 45-10$ and dpb11-10 cells. This enhanced sensitivity to RAP occurred at the non-permissive temperature only, which corresponds to the observation of fragile replication forks in $c d c 45-10$ cells at $36^{\circ} \mathrm{C}$. Therefore, determining if treatment of these cells with RAP exacerbates this phenotype by inducing fork collapse would determine if our model is correct. In addition, determining if the suppressors isolated in the $c d c 45-10$ high copy suppressor screen, or the $\mathrm{Cdc} 45^{\mathrm{SUMO}}$ or $\mathrm{Cdc} 45^{\mathrm{SUMO}}, \mathrm{G}^{510} \mathrm{R}$ mutants alter $c d c 45-10$ sensitivity to RAP will further characterize the defects observed in these cells. 


\section{LIST OF REFERENCES}

1. Champoux, J. J. (2001) Annu Rev Biochem 70, 369-413

2. Wang, J. C. (2002) Nat Rev Mol Cell Biol 3(6), 430-440

3. Forterre, P., Gribaldo, S., Gadelle, D., and Serre, M. C. (2007) Biochimie 89(4), 427-446

4. $\quad$ Pommier, Y. (2006) Nat Rev Cancer 6(10), 789-802

5. Fiorani, P., and Bjornsti, M. A. (2000) Ann N Y Acad Sci 922, 65-75

6. Reid, R. J., Benedetti, P., and Bjornsti, M. A. (1998) Biochim Biophys Acta 1400(1-3), 289-300

7. Li, T. K., and Liu, L. F. (2001) Annu Rev Pharmacol Toxicol 41, 53-77

8. Koster, D. A., Palle, K., Bot, E. S., Bjornsti, M. A., and Dekker, N. H. (2007) Nature 448(7150), 213-217

9. Toone, W. M., Aerne, B. L., Morgan, B. A., and Johnston, L. H. (1997) Annu Rev Microbiol 51, 125-149

10. Tabancay, A. P., Jr., and Forsburg, S. L. (2006) Curr Top Dev Biol 76, 129-184

11. Kelly, T. J., and Brown, G. W. (2000) Annu Rev Biochem 69, 829-880

12. Lopes, M., Cotta-Ramusino, C., Liberi, G., and Foiani, M. (2003) Mol Cell 12(6), 1499-1510

13. Cvetic, C. A., and Walter, J. C. (2006) Mol Cell 21(2), 143-144

14. Nishitani, H., and Lygerou, Z. (2002) Genes Cells 7(6), 523-534

15. Takayama, Y., Kamimura, Y., Okawa, M., Muramatsu, S., Sugino, A., and Araki, H. (2003) Genes Dev 17(9), 1153-1165

16. Sawyer, S. L., Cheng, I. H., Chai, W., and Tye, B. K. (2004) J Mol Biol 340(2), 195-202

17. Moir, D., Stewart, S. E., Osmond, B. C., and Botstein, D. (1982) Genetics 100(4), 547-563 
18. Zou, L., Mitchell, J., and Stillman, B. (1997) Mol Cell Biol 17(2), 553-563

19. Hopwood, B., and Dalton, S. (1996) Proc Natl Acad Sci U S A 93(22), 1230912314

20. Robbins, J., Dilworth, S. M., Laskey, R. A., and Dingwall, C. (1991) Cell 64(3), 615-623

21. Hardy, C. F. (1997) Gene 187(2), 239-246

22. Reid, R. J., Fiorani, P., Sugawara, M., and Bjornsti, M. A. (1999) Proc Natl Acad Sci U S A 96(20), 11440-11445

23. Owens, J. C., Detweiler, C. S., and Li, J. J. (1997) Proc Natl Acad Sci U S A 94(23), 12521-12526

24. Zou, L., and Stillman, B. (1998) Science 280(5363), 593-596

25. Zou, L., and Stillman, B. (2000) Mol Cell Biol 20(9), 3086-3096

26. Kanemaki, M., and Labib, K. (2006) Embo J 25(8), 1753-1763

27. Seki, T., Akita, M., Kamimura, Y., Muramatsu, S., Araki, H., and Sugino, A. (2006) J Biol Chem 281(30), 21422-21432

28. Saha, P., Thome, K. C., Yamaguchi, R., Hou, Z., Weremowicz, S., and Dutta, A. (1998) J Biol Chem 273(29), 18205-18209

29. Bjornsti, M. A. (2002) Cancer Cell 2(4), 267-273

30. Jacquiau, H. R., van Waardenburg, R. C., Reid, R. J., Woo, M. H., Guo, H., Johnson, E. S., and Bjornsti, M. A. (2005) J Biol Chem 280(25), 23566-23575

31. Goldstein, A. L., Pan, X., and McCusker, J. H. (1999) Yeast 15(6), 507-511

32. van Waardenburg, R. C., Duda, D. M., Lancaster, C. S., Schulman, B. A., and Bjornsti, M. A. (2006) Mol Cell Biol 26(13), 4958-4969

33. Reid, R. J., Kauh, E. A., and Bjornsti, M. A. (1997) J Biol Chem 272(18), 1209112099

34. Fiorani, P., Reid, R. J., Schepis, A., Jacquiau, H. R., Guo, H., Thimmaiah, P., Benedetti, P., and Bjornsti, M. A. (2004) J Biol Chem 279(20), 21271-21281

35. Sikorski, R. S., and Hieter, P. (1989) Genetics 122(1), 19-27 
36. Longtine, M. S., McKenzie, A., 3rd, Demarini, D. J., Shah, N. G., Wach, A., Brachat, A., Philippsen, P., and Pringle, J. R. (1998) Yeast 14(10), 953-961

37. Kamimura, Y., Tak, Y. S., Sugino, A., and Araki, H. (2001) Embo J 20(8), 20972107

38. Aparicio, O. M., Weinstein, D. M., and Bell, S. P. (1997) Cell 91(1), 59-69

39. Harlow, E. (1988) Cold Spring Harbor Laboratory

40. Hay, R. T. (2005) Mol Cell 18(1), 1-12

41. Hoege, C., Pfander, B., Moldovan, G. L., Pyrowolakis, G., and Jentsch, S. (2002) Nature 419(6903), 135-141

42. Pfander, B., Moldovan, G. L., Sacher, M., Hoege, C., and Jentsch, S. (2005) Nature 436(7049), 428-433

43. Hennessy, K. M., Lee, A., Chen, E., and Botstein, D. (1991) Genes Dev 5(6), 958969

44. Hartwell, L. H., Culotti, J., and Reid, B. (1970) Proc Natl Acad Sci U S A 66(2), $352-359$

45. Kamimura, Y., Masumoto, H., Sugino, A., and Araki, H. (1998) Mol Cell Biol 18(10), 6102-6109

46. Friedman, K. L., and Brewer, B. J. (1995) Methods Enzymol 262, 613-627

47. Bell, L., (1983) Analytical Biochemistry 130, 527-535

48. Brewer, B. J., (1987) Cell 51, 463-471

49. Haase, S. B., and Lew, D. J. (1997) Methods Enzymol 283, 322-332

50. Lopes, M., Cotta-Ramusino, C., Pellicioli, A., Liberi, G., Plevani, P., MuziFalconi, M., Newlon, C. S., and Foiani, M. (2001) Nature 412(6846), 557-561

51. Madden, K. R., Stewart, L., and Champoux, J. J. (1995) Embo J 14(21), 53995409

52. Camilloni, G., Di Martino, E., Di Mauro, E., and Caserta, M. (1989) Proc Natl Acad Sci U S A 86(9), 3080-3084

53. Shen, C., Lancaster, C. S., Shi, B., Guo, H., Thimmaiah, P., and Bjornsti, M. A. (2007) Mol Cell Biol 27(20), 7007-7017 
54. Bjornsti, M. A., and Houghton, P. J. (2004) Nat Rev Cancer 4(5), 335-348

55. Hay, N., and Sonenberg, N. (2004) Genes Dev 18(16), 1926-1945

56. Wullschleger, S., Loewith, R., and Hall, M. N. (2006) Cell 124(3), 471-484

57. Bjornsti, M. A., and Houghton, P. J. (2004) Cancer Cell 5(6), 519-523

58. Wullschleger, S., Loewith, R., Oppliger, W., and Hall, M. N. (2005) J Biol Chem 280(35), 30697-30704

59. Sarbassov, D. D., Ali, S. M., and Sabatini, D. M. (2005) Curr Opin Cell Biol 17(6), 596-603

60. Loewith, R., Jacinto, E., Wullschleger, S., Lorberg, A., Crespo, J. L., Bonenfant, D., Oppliger, W., Jenoe, P., and Hall, M. N. (2002) Mol Cell 10(3), 457-468

61. Guertin, D. A., and Sabatini, D. M. (2007) Cancer Cell 12(1), 9-22

62. Tabuchi, M., Audhya, A., Parsons, A. B., Boone, C., and Emr, S. D. (2006) Mol Cell Biol 26(15), 5861-5875

63. Mulet, J. M., Martin, D. E., Loewith, R., and Hall, M. N. (2006) J Biol Chem 281(44), 33000-33007

64. Abraham, R. T. (2004) DNA Repair (Amst) 3(8-9), 883-887

65. Huang, S., Liu, L. N., Hosoi, H., Dilling, M. B., Shikata, T., and Houghton, P. J. (2001) Cancer Res 61(8), 3373-3381

66. Huang, S., Shu, L., Dilling, M. B., Easton, J., Harwood, F. C., Ichijo, H., and Houghton, P. J. (2003) Mol Cell 11(6), 1491-1501

67. Shi, Y., Frankel, A., Radvanyi, L. G., Penn, L. Z., Miller, R. G., and Mills, G. B. (1995) Cancer Res 55(9), 1982-1988

68. Beuvink, I., Boulay, A., Fumagalli, S., Zilbermann, F., Ruetz, S., O'Reilly, T., Natt, F., Hall, J., Lane, H. A., and Thomas, G. (2005) Cell 120(6), 747-759

69. Barbet, N. C., Schneider, U., Helliwell, S. B., Stansfield, I., Tuite, M. F., and Hall, M. N. (1996) Mol Biol Cell 7(1), 25-42

70. Liu, L. F., Desai, S. D., Li, T. K., Mao, Y., Sun, M., and Sim, S. P. (2000) Ann N Y Acad Sci 922, 1-10 
71. Staker, B. L., Hjerrild, K., Feese, M. D., Behnke, C. A., Burgin, A. B., Jr., and Stewart, L. (2002) Proc Natl Acad Sci U S A 99(24), 15387-15392 


\section{VITA}

Cynthia Sue Lancaster was born in West Memphis, AR on November 26, 1977. She graduated from Marion High School in May, 1996. In 2001 she received a Bachelor of Science from the Arkansas State University. She enrolled in Interdisciplinary program at the University of Tennessee in 2001. 